\title{
Extensão do ASiA para Simulação de Arquiteturas de Computadores
}

\author{
Sarita Mazzini Bruschi
}

São Carlos (SP)

1997 


\title{
Extensão do ASiA para Simulação de Arquiteturas de Computadores
}

\author{
Sarita Mazzini Bruschi
}

\author{
Orientadora \\ Profa. Dra. Regina Helena Carlucci Santana
}

Dissertação apresentada ao Instituto de Ciências Matemáticas de São Carlos, da Universidade de São Paulo, como parte dos requisitos para obtenção do título de Mestre na Área de Ciências de Computação e Matemática Computacional.

Área de Concentração:

Sistemas Distribuídos e Programação Concorrente

São Carlos (SP)

Setembro/1997 
Dedico este trabalho aos meus avós Luiz (in memorian) e Maria do Carmo (in memorian), Pilade (in memorian) e Izaura, ao meu pai, Antonio Guilherme e a minha mãe, Maria Cristina. 
"O progresso da sociedade não depende apenas da ciência material.

É preciso desenvolver o quanto antes a ciência do espirito"

Mokiti Okada 


\section{Agradecimentos}

À Deus, por acompanhar meus passos e pela permissão de concluir mais esta etapa.

À Prof ${ }^{a}$. Dra. Regina Helena C. Santana, pela orientação e pelo profissionalismo.

Ao Prof. Dr. Marcos José Santana, pela importante ajuda no desenvolvimento deste trabalho.

À Regina e ao Marcos, pela amizade, competência, dedicação e sobretudo pela sinceridade.

Ao Rogério (Dei Santi), pela amizade e companheirismo durante os anos de graduação e mestrado.

Às companheiras de república: Simone, Sofia, Ana Cláudia (e Felipe), Alexandra e Regina (e João Felipe), pelos bons momentos vividos.

Ao pessoal do grupo de Sistemas Distribuídos e Programação Concorrente: Célia, Flávio, Rita, Mário, Laís, Paulo Sérgio (Simone e Felipe), Márcio (Luiza), Boca, Renata, Roberta, Luciano, Silmara, Renato, Regiane, Ana Elisa, Adriana, Hélder, Kalinka, Omar, Aletéia e Cláudia, pela união, amizade e companheirismo.

Aos amigos: Gustavo (Batista e Rosalem) Ciro, Cláudia, Andréia, Shiro, Rogério (Mouro e Florian), Fábio, Robson, Júlio, Vítor, Patrícia, Edna, Marisa, Rudinei.

Ao pessoal da Biblioteca: Silvana, Rose (Casali e Zambon), Gislene, Maria, Sandra, Giselda e Mara, por sempre estarem dispostas a colaborar.

À Beth, Laura e Marília, da Secretaria, ao Jacques, do xerox, e a todos os funcionários do ICMSC, pela atenção dispensada durante o mestrado.

À todos aqueles que, direta ou indiretamente, contribuíram para a realização deste trabalho.

À Capes, pelo apoio financeiro.

E, especialmente, aos meus pais, Antonio Guilherme e Maria Cristina, às minhas irmãs, Simone e Sofia, ao meu irmão João Guilherme e a minha avó Izaura, por sempre estarem por perto em todos os momentos. 


\section{Resumo}

Esta dissertação de Mestrado apresenta uma extensão do ASiA (Ambiente de Simulação Automático), para simulação de arquiteturas de computadores, denominada Módulo Arquitetura. Este módulo possibilita que o usuário utilize arquiteturas já definidas (alterando ou não os seus parâmetros) ou desenvolva o modelo de uma nova arquitetura utilizando ferramentas específicas para simulação de arquitetura de computadores. Dois exemplos ilustram a utilização do Módulo Arquitetura, destacando as vantagens de sua aplicação tanto em ensino como em pesquisa.

Este trabalho apresenta ainda algumas alterações efetuadas no ASiA para torná-lo mais amigável e flexível. Uma revisão bibliográfica dos assuntos relacionados ao tema é também apresentada. 


\section{Abstract}

This MSc dissertation presents an extension of the ASiA (Ambiente de Simulação Automático) for computer architecture simulation, named Architecture Module. This module allows the use of previously defined architectures (with possible alteration of parameters) or new architecture models using specific tools for computer architecture simulation. Two examples show the utilization of the Architecture Module highlighting its advantages as both a teaching and a research tool.

This work also presents some improvements to the ASiA with the aim of becoming more friendly and flexible. A literature review of the subjects related to the general theme is also presented. 


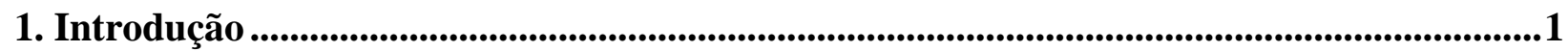

2. Arquitetura de Computadores ..................................................................................4

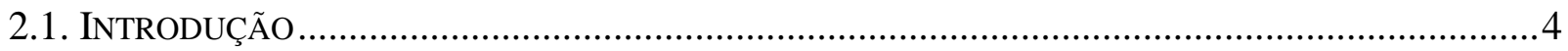

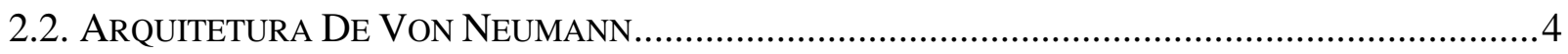

2.2.1. A Unidade Central de Processamento (UCP) ............................................................

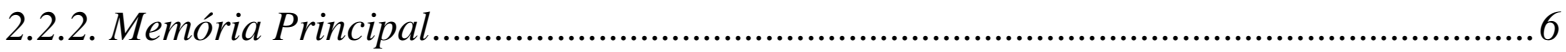

2.2.3. Dispositivos de Entrada e Saída (E/S)........................................................................

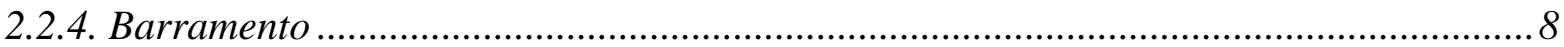

2.2.5. Processadores RISC ................................................................................... 8

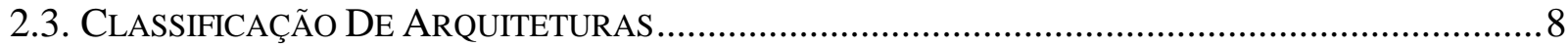

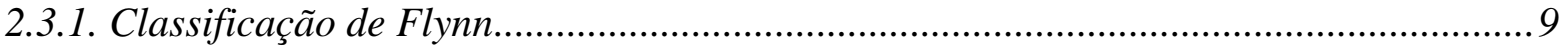

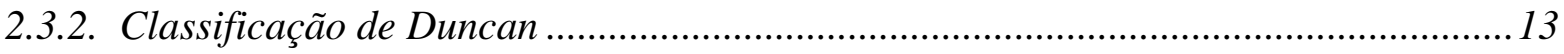

2.4. Conceitos BÁsicos De Processamento Paralelo ........................................................15

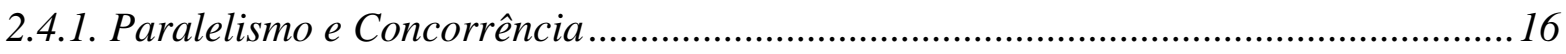

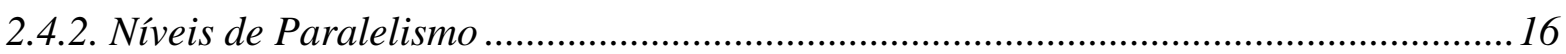

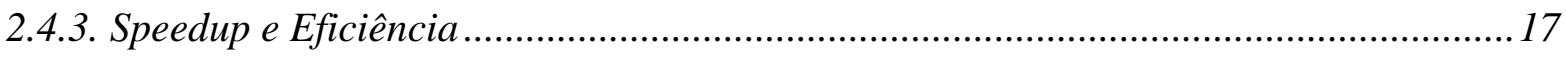

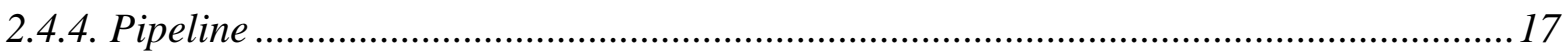

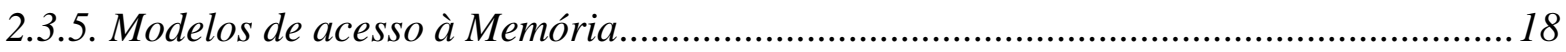

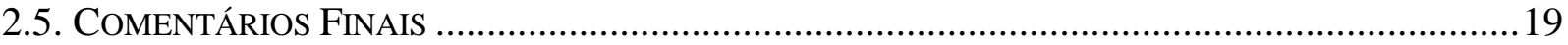

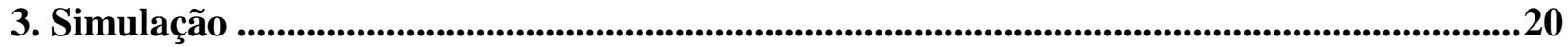

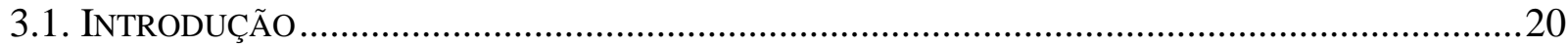

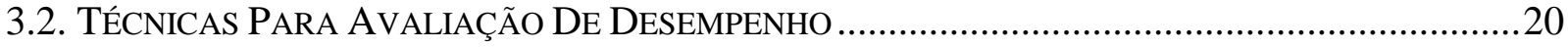

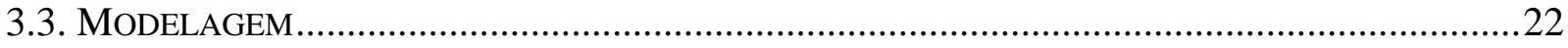

3.3.1. Redes de Filas e Modelos Baseados em Redes de Filas................................................23

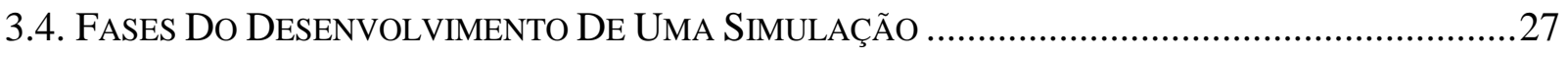

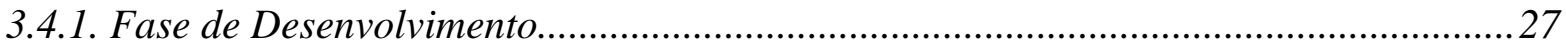

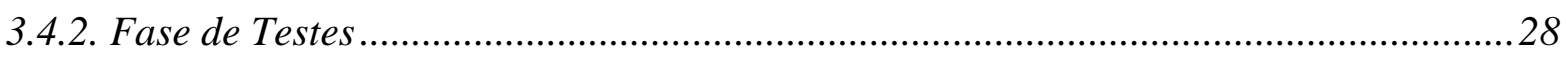

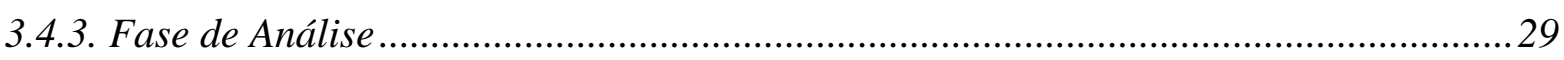

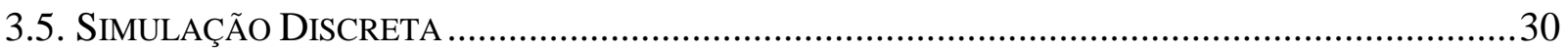

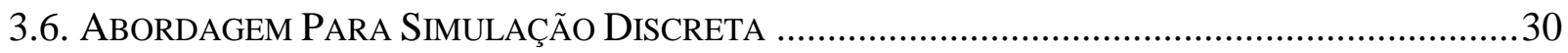

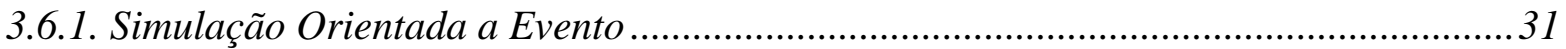

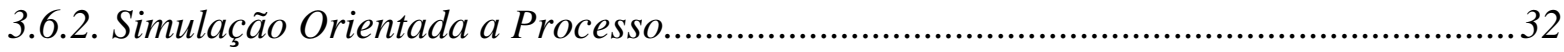

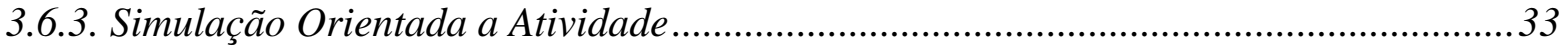

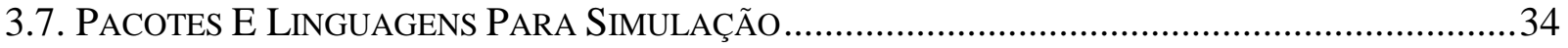

3.7.1. Linguagens de programação convencionais .................................................................... 34 


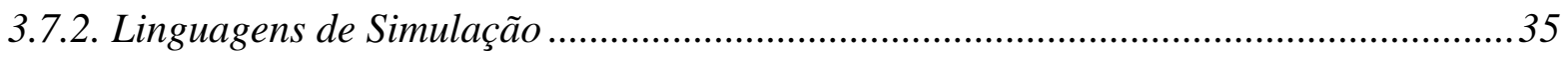

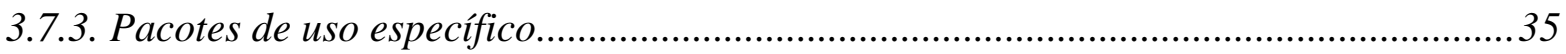

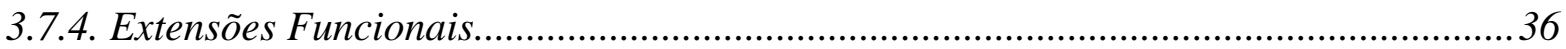

3.7.5. Escolha da Linguagem para Simulação ................................................................... 36

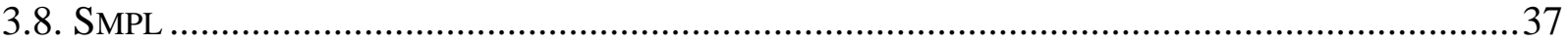

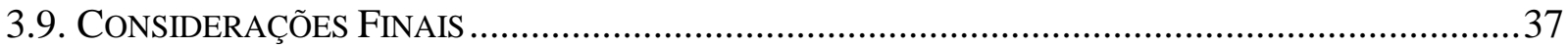

4. Ambientes De Simulação Automáticos ..............................................................................39

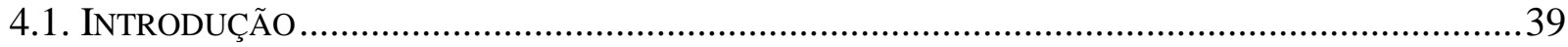

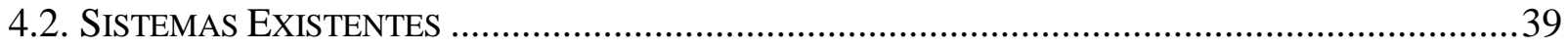

4.3. Asia - Ambiente De SimulaÇÃo Automático ...................................................... 41

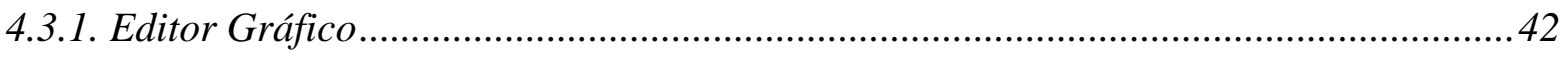

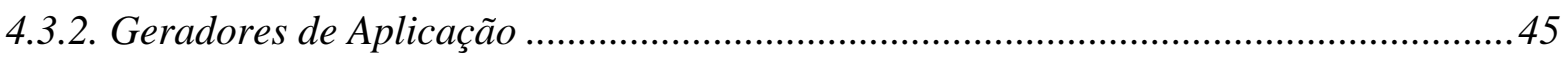

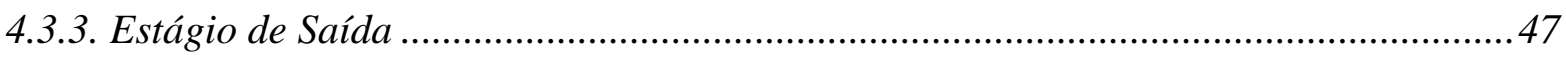

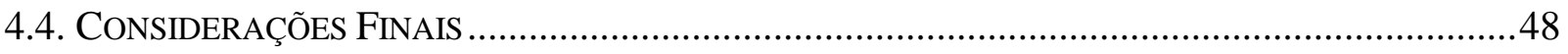

5. Modificações Introduzidas no Asia ...................................................................................49

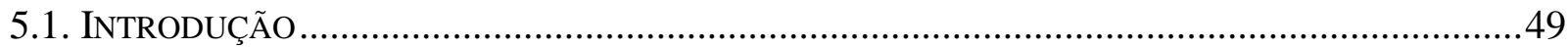

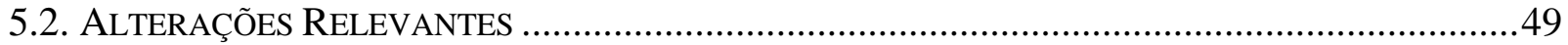

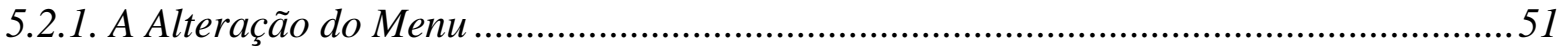

5.2.2. Alteração das Caixas de Diálogo ..............................................................................54

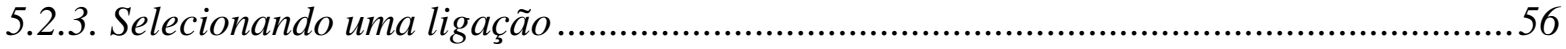

5.2.4. Parametrização das ramificações..........................................................................56

5.2.5. Exibição dos dados quando o Recurso/Modelo já foi parametrizado ............................56

5.2.6. Duplo pressionamento do botão esquerdo do mouse ...................................................57

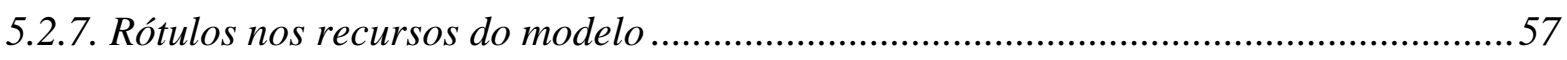

5.2.8. Modificações introduzidas com a inserção do Gerador de Aplicações.........................57

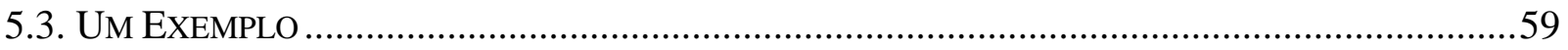

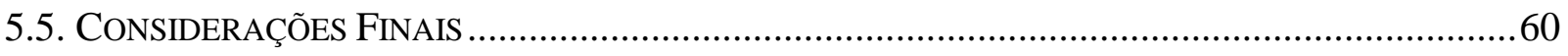

6. Extensão do Asia para Simulação de Arquiteturas de Computadores..................................62

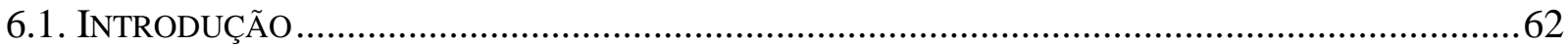

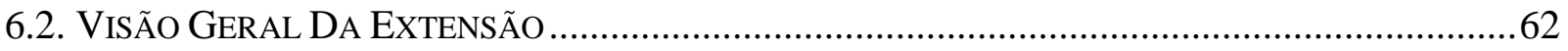

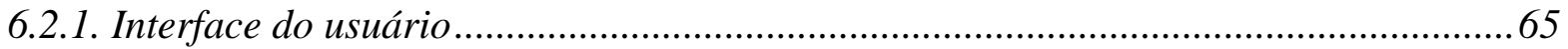

6.2.2. Manutenção do arquivo de parâmetros .......................................................................68

6.2.3. Consistência, Armazenamento e Manutenção .............................................................. 69

6.3. Utilizando Os Modelos De ARQuiteturas Já DEFINIDOS .........................................70

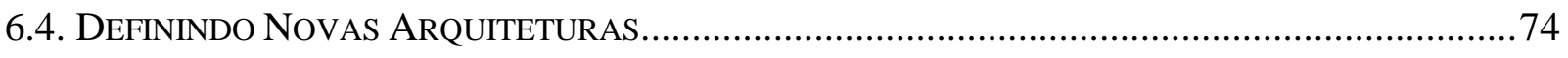

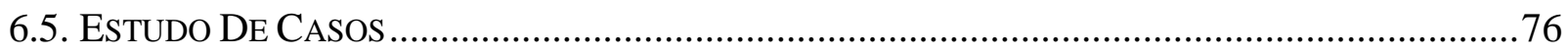

6.5.1. Alteração no Modelo da arquitetura de von Neumann .............................................76 
6.5.2. Alteração nos parâmetros da arquitetura de von Neumann com pipeline .................. 78

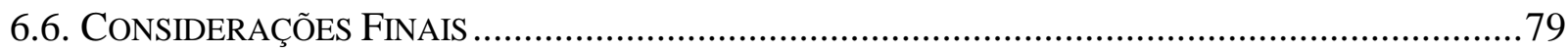

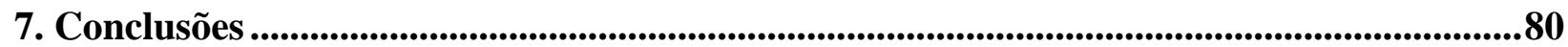

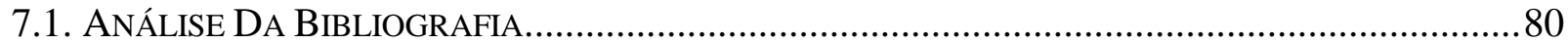

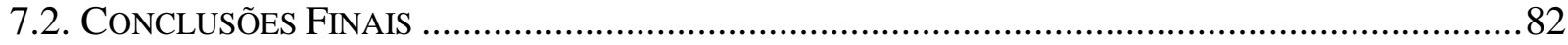

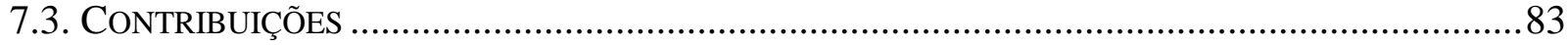

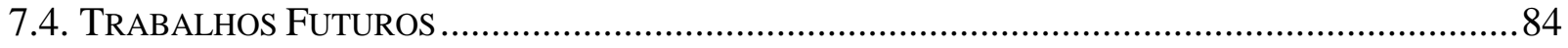

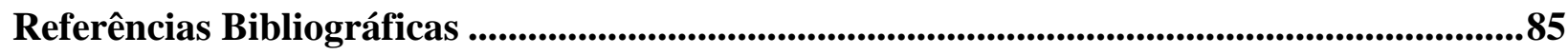


Figura 2.1: Unidades funcionais de um computador .......................................................5

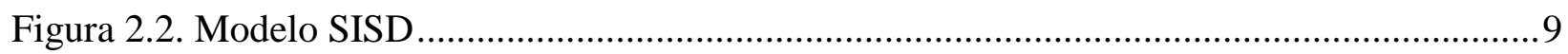

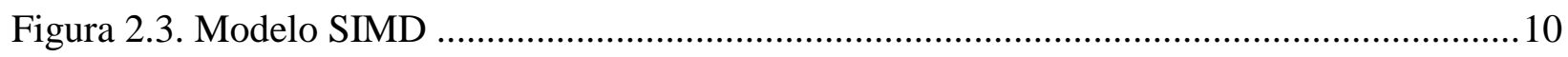

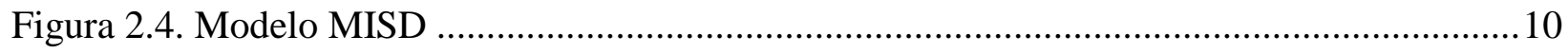

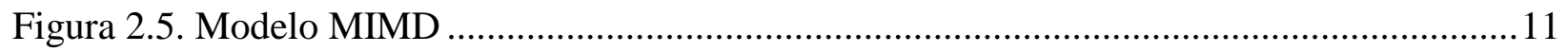

Figura 2.6. Processadores com memória compartilhada ........................................................... 11

Figura 2.7. Processadores com memória distribuída ............................................................. 12

Figura 2.8. Classificação de Duncan .................................................................................. 13

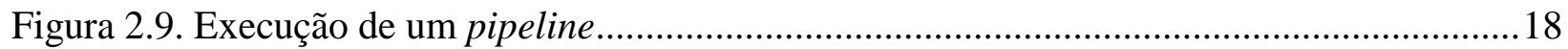

Figura 3.1. Técnicas para avaliação de desempenho ..........................................................2 21

Figura 3.2. Centro de Serviço: uma fila, um servidor .........................................................24

Figura 3.3. Centro de Serviço: uma fila, vários servidores.....................................................24

Figura 3.4. Centro de Serviço: várias filas, um servidor .......................................................25

Figura 3.5. Centro de Serviço: várias filas, vários servidores ................................................25

Figura 3.6. Processo de desenvolvimento de uma simulação...................................................27

Figura 3.7. Relação entre evento, atividade e processo ......................................................... 30

Figura 3.8. Código fonte de um modelo M/M/1 .................................................................. 38

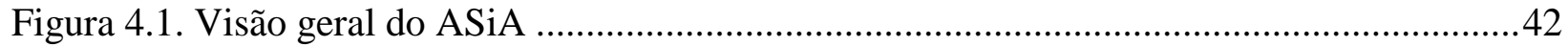

Figura 4.2. Visão Geral do Editor Gráfico do ASiA ….........................................................43

Figura 4.3. Tela principal do EdGraf ............................................................................44

Figura 4.4. Estrutura de um Gerador de Aplicações ...............................................................45

Figura 4.5. Fluxo de dados no Gerador de Aplicações ..........................................................47

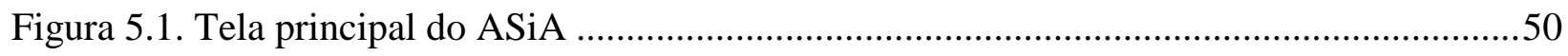

Figura 5.2. Estrutura do menu do EdGraf..........................................................................52

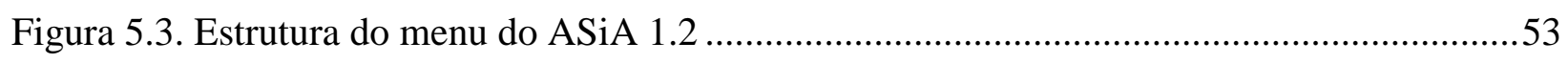

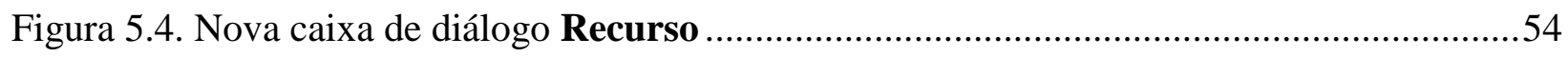

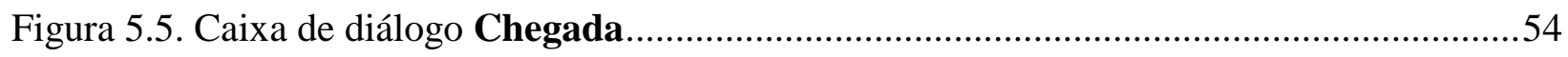

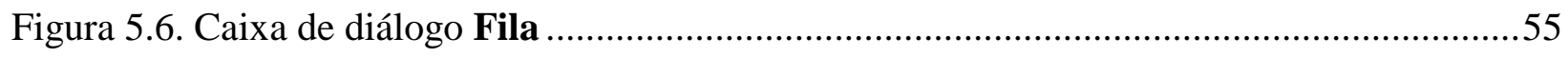

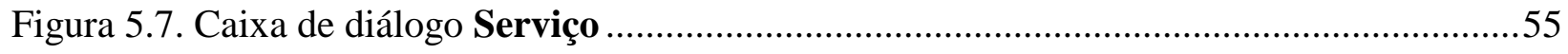

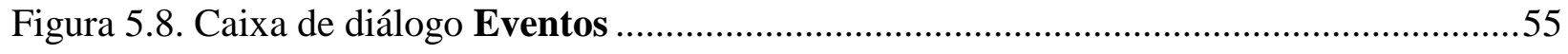

Figura 5.9. Exemplo de uma ligação e ramificação...............................................................56 


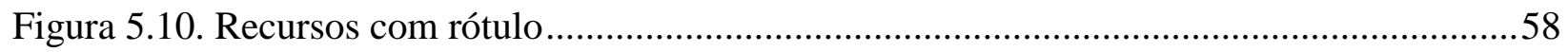

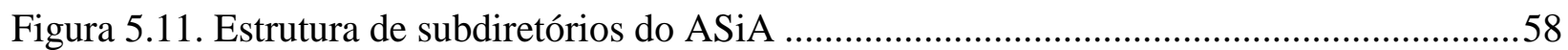

Figura 5.12. Tela do ASiA com um modelo já parametrizado .................................................59

Figura 5.13. Tela de parametrização do modelo......................................................................60

Figura 5.14. Tela de visualização do código gerado................................................................ 1

Figura 5.15. Relatório gerado com a execução do exemplo .....................................................61

Figura 6.1. Ativando o Módulo Arquitetura ........................................................................63

Figura 6.2. Visão geral da estrutura do Módulo Arquitetura ..................................................64

Figura 6.3. Tela de início do Módulo Arquitetura..............................................................65

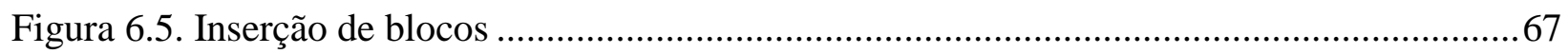

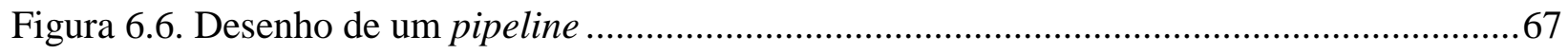

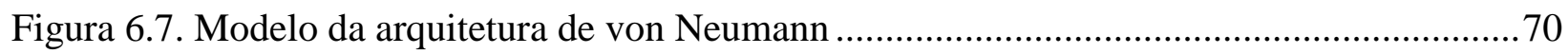

Figura 6.8. Modelo da arquitetura de von Neumann com pipeline ............................................70

Figura 6.9. Modelo da arquitetura MIMD com memória compartilhada. ..................................71

Figura 6.10. Modelo da arquitetura MIMD com memória distribuída ........................................71

Figura 6.11. Tela principal do ASiA com o Módulo Arquitetura ativo .....................................72

Figura 6.12. Código gerado a partir do modelo da arquitetura de von Neumann........................74

Figura 6.13. Relatório gerado a partir da simulação da arquitetura de von Neumann .................74

Figura 6.14. Tela para solicitar ao usuário modo de ligação de dois blocos ...............................75

Figura 6.15. Resultado da seleção da opção "Ligar um a um”" ...............................................75

Figura 6.16. Resultado da seleção da opção "Ligar todos com todos"........................................76

Figura 6.17. Alteração no modelo da arquitetura de von Neumann .........................................77

Figura 6.18. Relatório gerado com a alteração da arquitetura de von Neumann..........................77

Figura 6.19. Modelo de uma arquitetura de von Neumann com pipeline de instrução .................78

Figura 6.20. Relatório da arquitetura de von Neumann com pipeline ........................................78

Figura 6.21. Relatório gerado com a alteração da arquitetura de von Neumann com pipeline .....79 


\section{Índice de tabelas}

Tabela 1. Evolução dos processadores da linha Intel 80 x 86 ............................................6

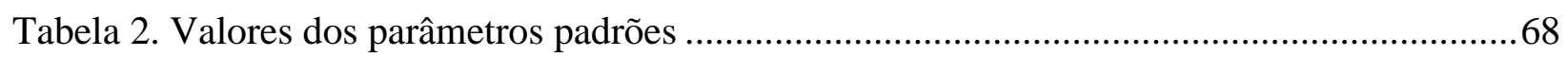




\section{Introdução}

As arquiteturas de computadores vêm apresentando uma grande evolução nos últimos anos. Diferentes direções têm sido consideradas. As arquiteturas seqüenciais de von Neumann são ainda as mais conhecidas e mais utilizadas e vêm adotando uma série de aperfeiçoamentos, que visam a obtenção de um melhor desempenho.

Alguns exemplos de abordagens utilizadas para enriquecer as arquiteturas de von Neumann são as diferentes formas de pipeline, as unidades funcionais, processador vetorial, etc.

No entanto, para certas aplicações, a arquitetura de von Neumann não satisfaz os requisitos de desempenho almejados, além de apresentar um custo muito elevado, quando supercomputadores com características avançadas são considerados. Uma opção para sobrepor esse problema é a utilização de arquiteturas paralelas. Nesse nível, tem-se a utilização de multiprocessadores ou multicomputadores, que permitem a realização de mais de uma instrução paralelamente.

Um dos problemas que surgiu com o constante avanço de arquiteturas é a forma de avaliar as novas abordagens que vêm sendo propostas. Isto é, como avaliar o funcionamento e principalmente o desempenho das arquiteturas propostas. Diversas técnicas vêm sendo propostas e baseiam-se em duas abordagens: as de técnicas de aferição, onde as informações requeridas por um estudo podem ser obtidas a partir do próprio sistema, e as técnicas de modelamento onde se constrói um modelo representativo do sistema.

As técnicas de aferição podem ser: coleta de dados, benchmarks ou construção de protótipos. São mais utilizadas quando o sistema já está implementado, ou em fase final de desenvolvimento. Já as técnicas de modelamento podem ser: modelagem analítica ou simulação. No modelagem analítica, a modelagem é feita em termos de equações que podem ser resolvidas analiticamente. Na simulação, a modelagem do sistema é desenvolvida e o modelo é transformado em um programa que representa o sistema real.

As técnicas de modelagem oferecem grande flexibilidade a baixo custo. A adoção de tais técnicas é atrativa tanto para o sistema existente como para verificação de projetos. A escolha entre a solução analítica e por simulação, depende, principalmente, do sistema a ser avaliado e do nível de detalhe a ser considerado. A solução analítica permite a obtenção de resultados mais precisos. No entanto, à medida que aumenta a complexidade do modelo aumenta também o grau de dificuldade da resolução analítica. Além disso, quando o sistema sofre alguma alteração, é necessário refazer todas as equações e resolvê-las novamente. Na simulação, qualquer alteração no sistema é refletida com maior facilidade no programa de simulação. Uma desvantagem para utilização de simulação é o tempo excessivo de processamento para algumas aplicações 
Para o caso de arquiteturas de computadores, a simulação é especialmente atrativa, principalmente nos casos em que diversas arquiteturas ou diferentes mecanismos para melhorar o seu desempenho são considerados. A modificação das características da arquitetura podem ser refletidas no programa de simulação e seu impacto no desempenho da arquitetura verificado sem requerer um grande esforço.

Um problema na simulação de uma arquitetura é que o usuário deve ter conhecimento tanto de arquitetura de computadores quanto de simulação. Os conhecimentos necessários para o desenvolvimento de uma simulação confiável envolvem conceitos de estatística, probabilidades, etc. Mesmo nos casos em que ferramentas apropriadas para simulação são utilizadas, a implementação de um modelo de simulação pode ser uma tarefa árdua para usuários com pouco experiência. Essa dificuldade limita de forma expressiva a utilização de simulação para a aprendizagem de arquiteturas de computadores.

Para facilitar esta tarefa, pode-se utilizar ferramentas específicas para o desenvolvimento de simulações. Tais ferramentas visam oferecer ao usuário de simulação, uma série de recursos (tais como: editor gráfico, gerador automático de código, etc) que facilitem seu trabalho. Neste sentido, vem sendo desenvolvido, pelo Grupo de Sistemas Distribuídos e Programação Concorrente do ICMSC-USP, o ASiA (Ambiente de Simulação Automático) [SPO94, SPO94a] com o objetivo de automatizar o processo de construção do programa de simulação.

Neste ambiente, um editor gráfico, utilizando-se dos dados fornecidos pelo usuário, gera uma tabela que especifica o modelo a ser simulado e os parâmetros necessários para a simulação. Com base nesta tabela e no pacote de simulação adotado, o gerador de aplicações produz um programa de simulação.

O objetivo desta dissertação de mestrado é o desenvolvimento de uma extensão do ASiA para simulação de Arquitetura de Computadores, denominada Módulo Arquitetura.

O Módulo Arquitetura oferece ao usuário ferramentas específicas para a simulação de arquiteturas de computadores. Dispositivos como disco, processador, entrada, saída, já estão disponíveis com uma parametrização padrão, que podem ser alteradas pelo usuário. Tem-se ainda no Módulo Arquitetura, modelos já definidos para simulação da arquitetura de von Neumann, arquitetura de von Neumann com pipeline, arquitetura MIMD com memória compartilhada e arquitetura MIMD com memória distribuída. Alguns exemplos foram desenvolvidos para ilustrar a utilização do Módulo Arquitetura.

Esta dissertação apresenta uma revisão bibliográfica contendo os tópicos relacionados com o desenvolvimento do trabalho (capítulos 2, 3 e 4) e as fases envolvidas no desenvolvimento do Módulo Arquitetura (capítulos 5 e 6). Uma breve descrição dos tópicos de cada capítulo é apresentado a seguir.

No capítulo 2 faz-se uma revisão bibliográfica sobre arquiteturas de computadores, destacando-se a arquitetura de von Neumann e as arquiteturas paralelas. Neste capítulo são revisados ainda os principais conceitos de processamento paralelo. 
No capítulo 3 são apresentados os métodos disponíveis para análise de desempenho. A técnica de solução de modelos por simulação é discutida em detalhes. Dentre os tópicos revisados salienta-se a modelagem de sistemas, redes de filas e modelos baseados em redes de filas.

O capítulo 4 discute diversos tipos de ferramentas disponíveis para simulação dando ênfase para os ambientes de simulação. O ASiA (Ambiente de Simulação Automático), ambiente utilizado neste trabalho, é discutido em detalhes.

O capítulo 5 mostra as alterações que foram necessárias no ASiA para que este pudesse suportar a simulação de arquitetura de computadores. No capítulo 6 é apresentado detalhes referentes a implementação da extensão desenvolvida, seu modo de utilização e exemplos.

Finalmente, no capítulo 7 são apresentadas a análise da bibliografia, as conclusões e contribuições obtidas, além de sugestões para trabalhos futuros. 


\section{Arquitetura de Computadores}

\subsection{INTRODUÇÃO}

Várias arquiteturas de computadores estão disponíveis na atualidade, para as mais diversas aplicações. A mais utilizada é a arquitetura idealizada por von Neumann. Desde a sua criação até hoje muita coisa mudou: os processadores tornaram-se mais rápidos, a capacidade de memória aumentou, as redes transmitem uma grande quantidade de dados em curto espaço de tempo, etc. Todo esse progresso é acompanhado por uma diminuição gradual de custo, o que torna a tecnologia computacional mais acessível e aumenta o leque de aplicações que podem ser computacionalmente resolvidas de maneira eficiente [TUR93].

No entanto, está se tornando cada vez mais difícil obter um bom desempenho do modelo de von Neumann. Aplicações que necessitam de uma grande potência computacional, como por exemplo previsão do tempo, simulação de aerodinâmica e sensoriamento remoto, buscam suas soluções em computadores de alto desempenho. Contudo, obter alto desempenho não depende somente do uso dos dispositivos de hardware mais rápidos e mais seguros. Depende também de uma melhoria na arquitetura dos computadores e nas técnicas de processamento [HWA84].

Este capítulo traz uma revisão da arquitetura de von Neumann, as classificações das arquiteturas paralelas e finalmente alguns conceitos básicos de processamento paralelo.

\subsection{ARQUITETURA DE VON NEUMANN}

Todos os componentes de um computador são agrupados basicamente em 3 subsistemas básicos: Unidade central de processamento (UCP), memória principal e dispositivos de entrada e saída $(E / S)$. Esses componentes podem ser observados na Figura 2.1.

\subsubsection{A Unidade Central de Processamento (UCP)}

A UCP, ou simplesmente processador, tem como função principal unificar todo o sistema controlando as funções realizadas por cada unidade funcional, ou seja, é o "cérebro" do computador. A UCP é também responsável pela execução de todos os programas do sistema, que obrigatoriamente deverão estar armazenados na memória [MAC92]. 


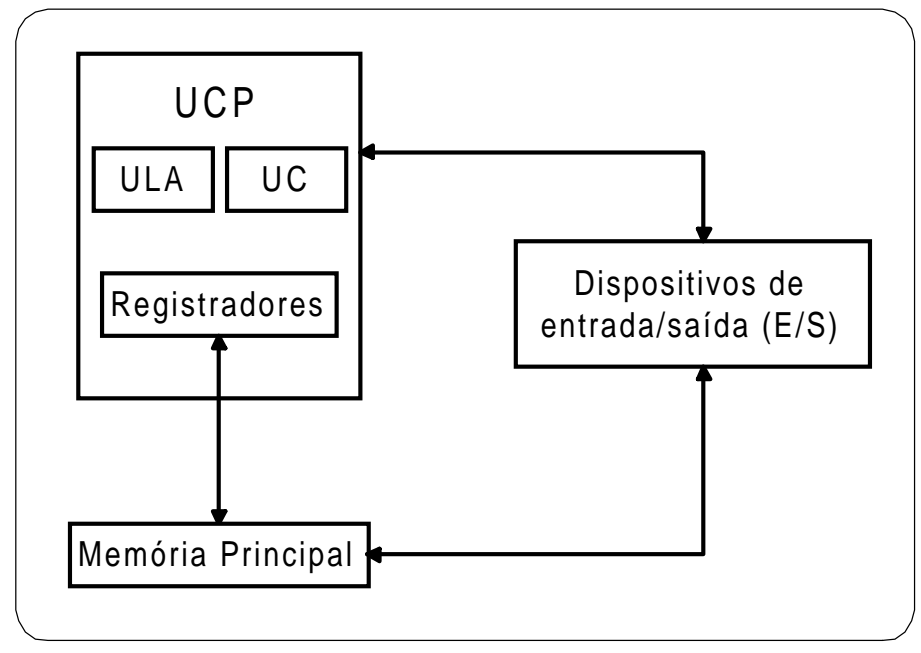

Figura 2.1: Unidades funcionais de um computador

A UCP é composta de várias partes distintas. A UC (Unidade de Controle) coordena a execução das instruções através da emissão de pulsos elétricos. A ULA (Unidade Lógica e Aritmética) realiza operações aritméticas (por exemplo, adição e subtração) e operações booleanas (AND, OR) necessárias para realizar as instruções.

A UCP contém também pequenas memórias de alta velocidade usadas para armazenamento temporário de informações. Estas memórias consistem de um número de registradores, cada um com uma determinada função. O registrador mais importante é o PC (Program Counter) ou CI (Contador de Instruções), o qual aponta a próxima instrução a ser executada. O nome "contador" é enganoso uma vez que esse registrador não funciona como um contador, mas o termo é universalmente usado. Outro registrador importante é o IR (Instruction Register) ou RI (Registrador de Instrução), o qual armazena a instrução que está sendo executada. A maioria dos computadores têm muitos outros registradores [TAN84].

A especificação da velocidade de processamento de uma UCP é determinada pelo número de instruções que o processador executa por unidade de tempo, normalmente o segundo. Como exemplo tem-se o MIPS (milhões de instruções por segundo) e o MFLOPS/GFLOPS (milhões/bilhões de instruções de ponto flutuante por segundo).

Dentro da UCP existe ainda uma memória interna de alta velocidade. Ela funciona como um cache interno e acelera a movimentação dos dados. Esse cache é muito rápido (e também caro) pois trabalha na velocidade do processador.

Um número bastante elevado de processadores vem se tornando disponível ao longo dos últimos anos. Dentre os processadores que se destacam nos computadores pessoais ( $P C$ Personal Computer), os processadores Intel da linha 80 x 86 são os que se tornaram mais populares. A Tabela 1. [FEI93, RAN94, INT97] ilustra a evolução desses processadores, com sua data de lançamento, velocidade de clock inicial, quantidade de instruções por segundo, número de transistores e o tamanho do barramento interno. 


\begin{tabular}{|c|c|c|c|c|c|}
\hline Processador & $\begin{array}{c}\text { Data de } \\
\text { lançamento }\end{array}$ & clock & $\begin{array}{c}\text { Instruções/ } \\
\text { segundo }\end{array}$ & $\begin{array}{l}\text { número de } \\
\text { transistores }\end{array}$ & $\begin{array}{c}\text { barramento } \\
\text { interno }\end{array}$ \\
\hline 4004 & 1971 & & & & \\
\hline 8080 & 1974 & $2 \mathrm{MHz}$ & 0.64 MIPS & 6.000 & 8 bits \\
\hline 8086 & 1978 & $4.77 \mathrm{MHz}$ & 0.33 MIPS & 29.000 & 16 bits \\
\hline 80286 & 1982 & $8 \mathrm{MHz}$ & 1.2 MIPS & 134.000 & 16 bits \\
\hline 80386DX & 1985 & $\begin{array}{l}16 \mathrm{MHz} / \\
20 \mathrm{MHz} / \\
25 \mathrm{MHz} / \\
33 \mathrm{MHz} / \\
40 \mathrm{MHz}\end{array}$ & 5 a 6 MIPS & 275.000 & 32 bits \\
\hline 80386SX & 1988 & $25 \mathrm{MHz}$ & & & $\begin{array}{l}32 \text { bits } 16 \\
\text { bits externo }\end{array}$ \\
\hline $\begin{array}{l}\text { 80486DX (com } \\
\text { coprocessador) }\end{array}$ & 1989 & $\begin{array}{c}25 \mathrm{MHz} / \\
33 \mathrm{MHz} / \\
50 \mathrm{MHz}\end{array}$ & 20 MIPS & 1.2 milhões & 32 bits \\
\hline $\begin{array}{l}80486 \mathrm{SX} \text { (sem } \\
\text { coprocessador) }\end{array}$ & 1991 & $20 \mathrm{MHz}$ & 16.5 MIPS & 1.185 milhões & 32 bits \\
\hline Pentium & 1993 & $\begin{array}{l}60 \mathrm{MHz} / \\
66 \mathrm{MHz} / \\
90 \mathrm{MHz} / \\
100 \mathrm{MHz}\end{array}$ & 112 MIPS & 3,1 milhões & 64 bits \\
\hline Pentium Pró & 1995 & $\begin{array}{c}150 \mathrm{MHz} / \\
166 \mathrm{MHz} / \\
180 \mathrm{MHz} / \\
200 \mathrm{MHz}\end{array}$ & & 5,5 milhões & $\begin{array}{c}64 \text { bits }+64 \\
\text { bits para } \\
\text { cache L2 }\end{array}$ \\
\hline Pentium II & 1997 & $\begin{array}{c}233 \mathrm{MHz} / \\
266 \mathrm{MHz} / \\
300 \mathrm{MHz}\end{array}$ & & 7,5 milhões & $\begin{array}{c}64 \text { System Bus } \\
+ \\
64 \text { Cache Bus }\end{array}$ \\
\hline
\end{tabular}

Tabela 1. Evolução dos processadores da linha Intel 80 x 86

\subsubsection{MEMÓRIA PRINCIPAL}

A memória é a parte do computador onde os programas e/ou dados são armazenados. É na memória que o processador lê ou escreve informações. $\mathrm{O}$ armazenamento pode ser feito de duas maneiras: 
- Armazenamento secundário

- Armazenamento primário ou memória principal

Quando uma informação está na memória secundária ela deve ser primeiramente transferida para a memória principal para ser processada.

A memória principal consiste de um número de células onde cada uma pode armazenar um "pedaço de informação". Cada célula possui um número, chamado endereço, através do qual elas podem ser referenciadas. Se a memória tem $n$ células, terá endereços de 0 a $n-1$.

A UCP comunica-se com a memória principal usando 2 registradores: o Memory Address Register (MAR) e o Memory Buffer Register (MBR). Quando a UCP necessita ler uma célula da memória, seja instrução ou dados, ela coloca o endereço da célula desejada no MAR e envia um sinal de leitura para a memória. A memória inicia a operação e após um ciclo ela coloca a célula desejada no MBR, de onde a UCP pode retirar. Para escrever uma célula na memória, a UCP coloca o endereço de onde a célula será armazenada no MAR e a célula a ser armazenada no MBR, envia um sinal de escrita para a memória e esta realiza a operação [TAN84].

A memória principal pode ser classificada em função de sua volatilidade, que é a capacidade da memória preservar o seu conteúdo mesmo sem uma fonte de alimentação. As memórias denominadas voláteis se caracterizam por permitir tanto a operação de escrita quanto a de leitura. Como exemplo, tem-se a memória RAM (Random Access Memory). As memórias denominadas não voláteis, se caracterizam por permitir somente a leitura dos dados, não permitindo a escrita. Como exemplo, tem-se as memórias ROM e EPROM.

\subsubsection{Dispositivos de EnTRAda E SAÍDA (E/S)}

A utilização de computadores para a solução de problemas inclui três etapas básicas:

- entrada do programa e dados

- execução

- saída dos resultados

A entrada e saída de dados é efetuada nos computadores através de dispositivos de entrada e saída (E/S). É necessário ressaltar que nem toda entrada é fornecida por pessoas assim como nem toda saída é destinada a pessoas.

Alguns dispositivos de E/S podem transmitir uma grande quantidade de dados em um curto espaço de tempo. Se a UCP tem que processar cada caracter separadamente, muito tempo de UCP é desperdiçado. Para impedir que a UCP fique "amarrada" por muito tempo em E/S, muitos computadores de médio e grande porte têm um ou mais processadores especializados e de baixo custo dedicados a tarefa de E/S. Devido a E/S ser realizada por esses processadores, a UCP fica disponível para outros processamentos. Os processadores de E/S trabalham em paralelo com a UCP, ou seja, enquanto a UCP está processando, esses processadores se dedicam a operações de $\mathrm{E} / \mathrm{S}$. 


\subsubsection{BARRAMENTO}

A UCP, a memória principal e os dispositivos de E/S são interligados através de linhas de comunicação denominadas barramento. Um barramento, também chamado de via, é um conjunto de fios paralelos (linhas de transmissão), onde trafegam informações como dados, endereços e sinais de controle.

Os barramentos podem ser classificados como unidirecionais (transmissão em um só sentido) ou bidirecionais (transmissão em ambos os sentidos). Na ligação UCP e memória principal três barramentos são necessários para que a comunicação seja realizada. $\mathrm{O}$ barramento de dados, do tipo bidirecional, transmite informações entre a memória principal e a UCP. O barramento de endereços, do tipo unidirecional, é utilizado pela UCP para especificar o endereço da célula de memória que será acessada. Finalmente, o barramento de controle, do tipo unidirecional, é por onde a UCP envia os pulsos de controle relativos às operações de leitura e escrita.

\subsubsection{PROCESSADORES RISC}

Os processadores que seguem a tecnologia RISC (Reduced Instruction Set Computer) possuem, como o próprio nome diz, um conjunto reduzido de instruções, o que os tornam menores, com menor custo e muito mais rápidos.

As instruções RISC são simples e normalmente são do mesmo comprimento. Elas não manipulam muitos modos de endereçamento como as instruções dos processadores CISC (Complex Instruction Set Computer), e acessam a memória usando instruções dedicadas. Os processadores RISC são baseados em pipeline (ver 2.4.4). As instruções RISC são próprias para trabalhar em pipeline devido ao fato de serem aproximadamente do mesmo tamanho [BAS93].

Como alguns exemplos de máquinas que utilizam os processadores RISC tem-se: Power PC (união entre Apple, Motorola e IBM), as estações Sun (Sun Microsystems) e o DECchip 21064 (Digital Equipment Corporation). A Sun Microsystems foi a pioneira na tecnologia RISC e é, até hoje, a maior fornecedora, mesmo não oferecendo o melhor equipamento [THO93, RAN94, THO94].

\subsection{CLASSIFICAÇÃO DE ARQUITETURAS}

Existem diversas propostas diferentes para classificação de arquiteturas de computadores, no entanto, devido à sua constante evolução nenhuma classificação consegue abranger todas as arquiteturas existentes.

A classificação de Flynn [FLY72] é a mais conhecida e utilizada embora seja antiga e não consiga englobar todos os tipos de arquiteturas existentes atualmente. A classificação de Flynn baseia-se na unicidade e multiplicidade do fluxo de instruções e dados. Duncan [DUN90] propôs uma classificação mais recente e abrange a maior parte das arquiteturas, porém é menos conhecida. Estas duas classificações são apresentadas a seguir. 


\subsubsection{ClassificaÇÃo de FLYNN}

A classificação de Flynn divide os computadores em quatro categorias conforme a presença de um ou vários fluxos de instruções e dados. Um fluxo de instruções é uma seqüência de instruções executadas em um único processador. Um fluxo de dados é uma sequiência de dados de entrada, de resultados parciais ou intermediários utilizado pelo fluxo de instruções [FLY72, HWA84, NAV89, DUN90, ALM94].

As 4 categorias são:

SISD Single Instruction Stream, Single Data Stream

Um fluxo de instruções, um fluxo de dados

SIMD Single Instruction Stream, Multiple Data Stream

Um fluxo de instruções, vários fluxos de dados

MISD Multiple Instruction Stream, Single Data Stream

Vários fluxos de instruções, um fluxo de dados

MIMD Multiple Instruction Stream, Multiple Data Stream

Vários fluxo de instruções, vários fluxos de dados

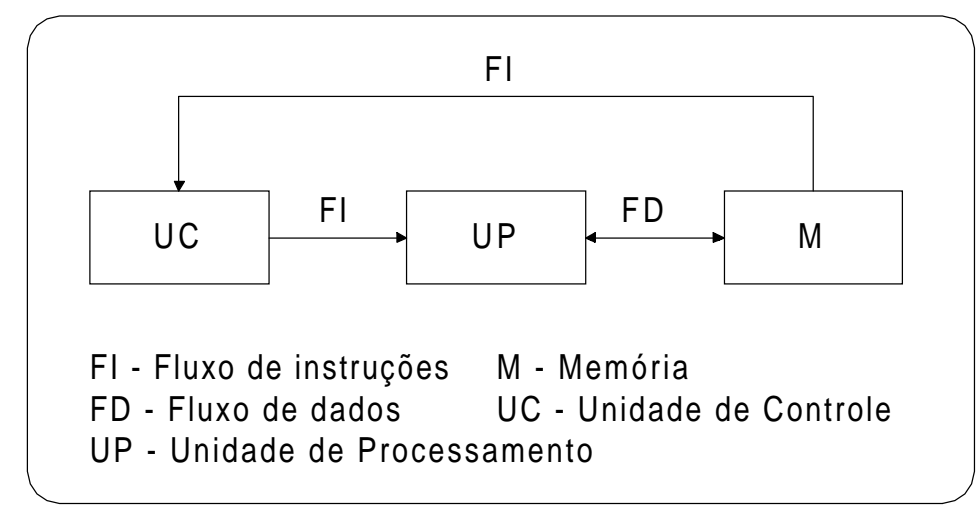

Figura 2.2. Modelo SISD

A categoria SISD representa os computadores convencionais (seriais), baseados no modelo de von Neumann, como pode ser observado na Figura 2.2. As instruções são executadas serialmente porém seus estágios (busca da instrução, decodificação, busca do operando e execução) podem ser sobrepostos (pipeline). Um computador SISD pode conter mais que uma unidade funcional, porém com um único processador sob o controle de uma unidade de controle.

A categoria SIMD corresponde aos processadores matriciais, paralelos e associativos. Existe uma única unidade de controle que envia um único fluxo de instrução para os vários processadores. Esses processadores recebem a mesma instrução mas atuam sob diferentes fluxos de dados. Uma representação desta categoria pode ser observada na Figura 2.3.

A categoria MISD corresponde às máquinas com vários processadores, onde cada um recebe instruções distintas de suas unidades de controle. Estas instruções são executadas sobre o 


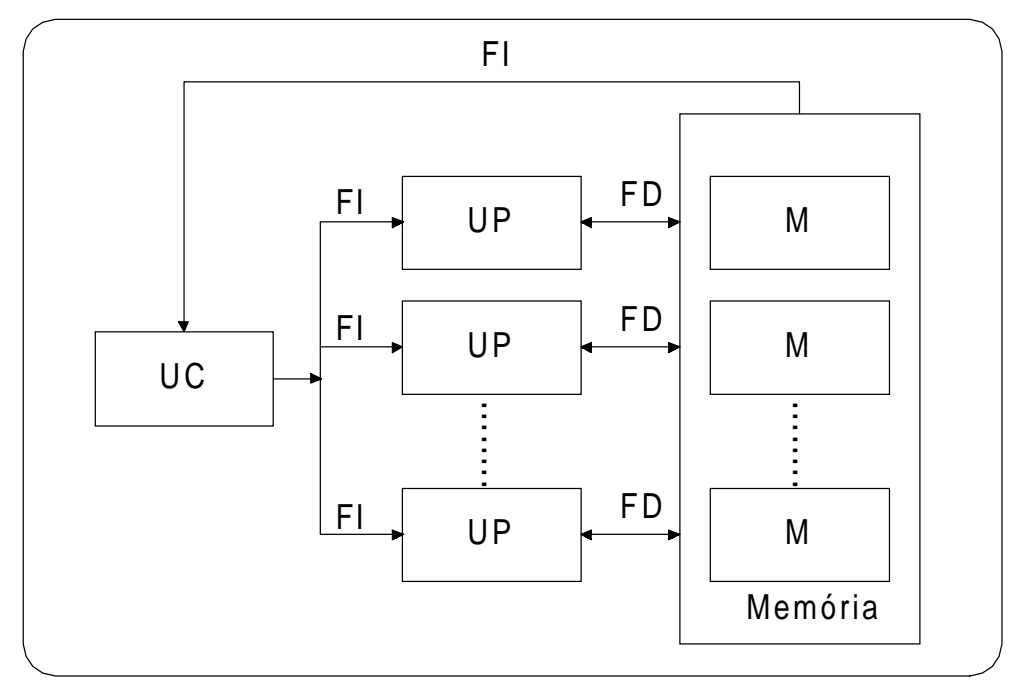

Figura 2.3. Modelo SIMD

mesmo conjunto de dados. No entanto, não há na literatura disponível nenhuma máquina representante desta categoria. Alguns autores chegam até a excluí-la da classificação por considerá-la sem validade [NAV89]. Outros já consideram o pipeline como representante desta categoria [ALM94]. Uma representação desta categoria pode ser observada na Figura 2.4.

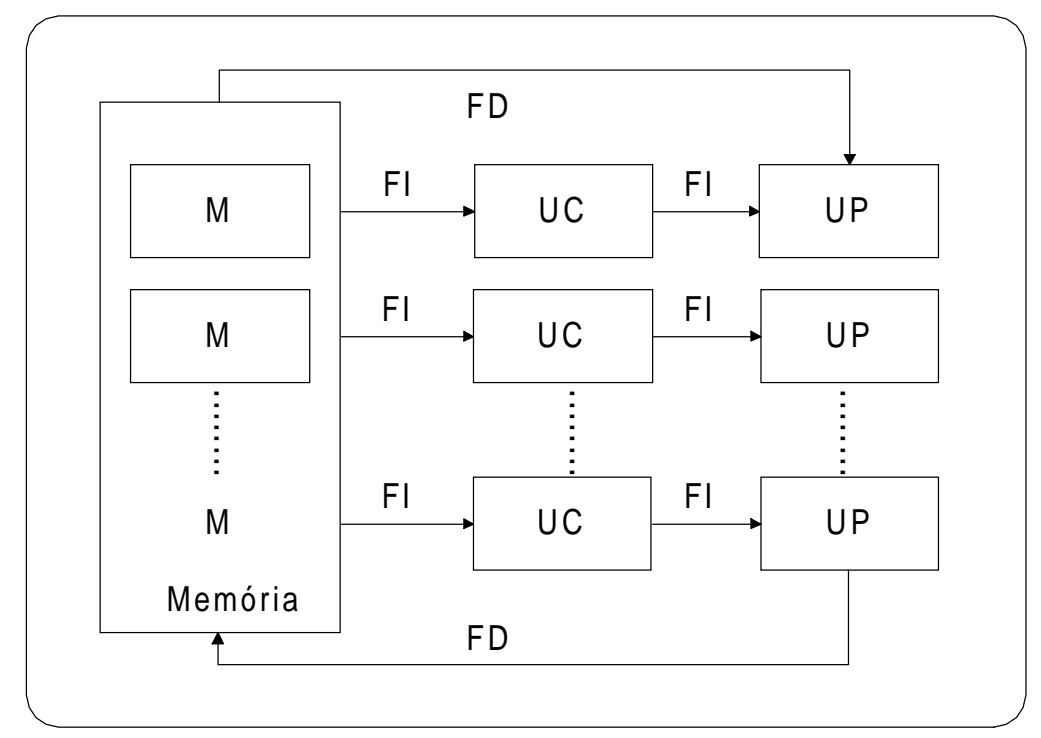

Figura 2.4. Modelo MISD

A categoria MIMD consiste de vários processadores, cada um, controlado por uma unidade de controle. Os processadores recebem instruções diferentes e operam sob fluxos de dados diferentes. O modelo desta categoria pode ser observada na Figura 2.5.

As máquinas MIMD podem ser fracamente acopladas ou fortemente acopladas, dependendo do grau de interação existentes entre os processadores [NAV89]. 


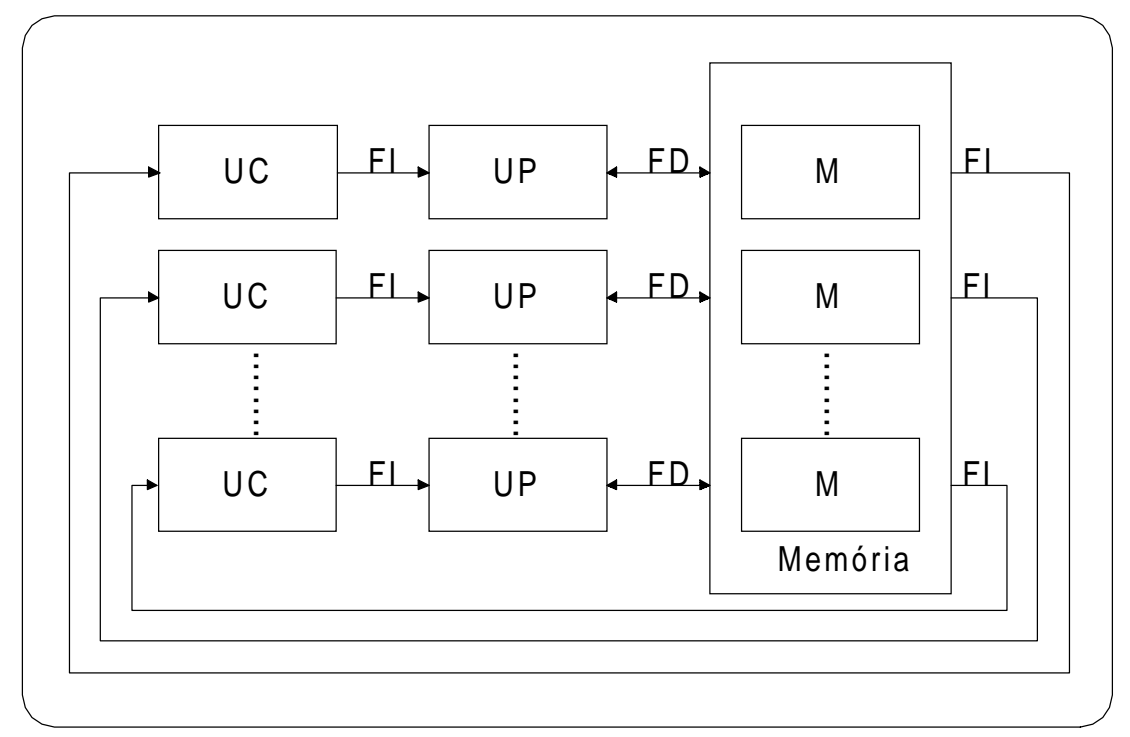

Figura 2.5. Modelo MIMD

As arquiteturas MIMD e SIMD podem ser classificadas quanto a organização de memória em:

- memória compartilhada: que definem espaço de endereçamento único para todos os processadores;

- memória distribuída: cada processador tem um espaço de endereçamento independente.

\section{Arquiteturas com Memória Compartilhada}

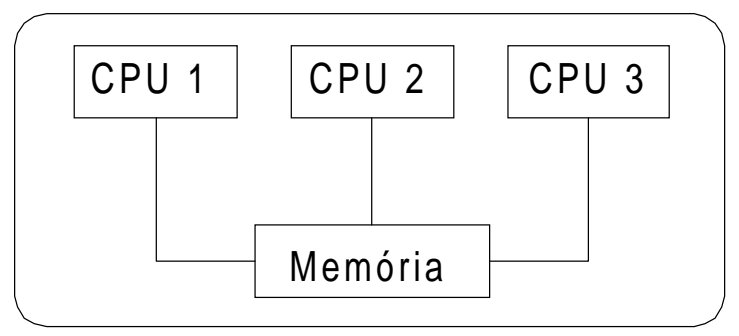

Figura 2.6. Processadores com memória compartilhada

Neste tipo de arquitetura tem-se múltiplos processadores operando independentemente mas compartilhando o mesmo espaço de endereçamento, ou seja, um único bloco de memória, como pode ser observado na Figura 2.6. Somente um processador pode acessar a memória por vez. Por isso deve haver por parte do programador um controle de acesso para manter os dados consistentes. Não deve ser permitido que enquanto um processador esteja lendo um dado, um outro processador escreva na mesma localização. Isto é feito utilizando mecanismos como semáforos e monitores.

Duas vantagens da memória compartilhada podem ser citadas: 
- a velocidade para a troca de dados entre as tarefas é igual a velocidade de acesso à memória, ou seja, rápido;

- simplicidade, o que permite uma utilização eficiente.

As desvantagens são:

- a memória pode se tornar o gargalo do sistema;

- o aumento do número de processadores implica em perda de desempenho se a bandwidth não for suficiente;

- o usuário é responsável pela sincronização.

Máquinas que utilizam memória compartilhada são também denominadas multiprocessadores.

\section{Arquitetura com Memória Distribuída}

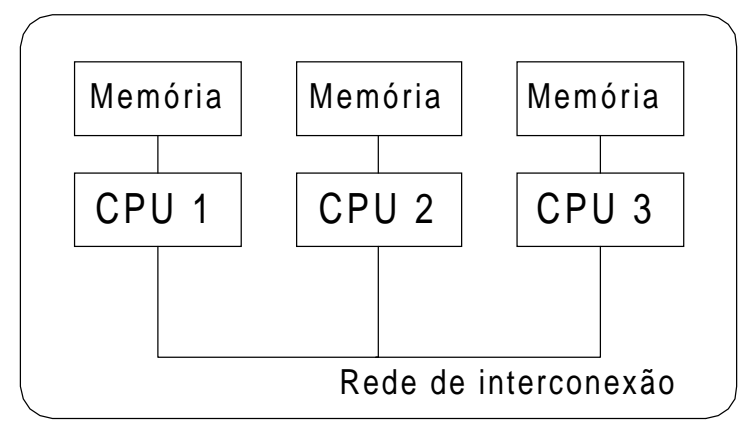

Figura 2.7. Processadores com memória distribuída

Neste tipo de arquitetura tem-se múltiplos processadores independentes mas cada um possui uma memória própria (local) que é diretamente acessível somente pelo processador, como pode ser observado na Figura 2.7. Os dados podem ser compartilhados através de uma rede de comunicação utilizando troca de mensagens.

Nesse modo de acesso, o programador deve também se preocupar com a sincronização, que é obtida através da passagem de mensagem. A troca de mensagens torna o sincronismo automático.

Como vantagens tem-se:

- A memória aumenta proporcionalmente com o aumento do número de processadores;

- Cada processador pode acessar rapidamente sua própria memória, sem interferências.

Como desvantagem:

- O usuário é responsável por enviar e receber dados entre os processos alocados em elementos de processamento (processador e memória) distintos, o que implica em controle de fluxo, controle sobre mensagens perdidas e "bufferização". 
Máquinas que utilizam memória distribuída são também denominadas multicomputadores.

\subsubsection{ClassificaÇão de DUNCAN}

Duncan [DUN90] propôs uma classificação de arquiteturas paralelas mais moderna e abrangente. Esta nova classificação satisfaz as seguintes considerações:

- Exclui arquiteturas que possuem mecanismos de paralelismo de baixo nível, os quais são características comuns nos computadores atuais. Um exemplo desses mecanismos é a utilização de pipeline.

- Mantém os elementos da classificação de Flynn devido à sua grande utilização.

- Inclui arquiteturas que foram criadas após a classificação de Flynn e que não se encaixam nela.

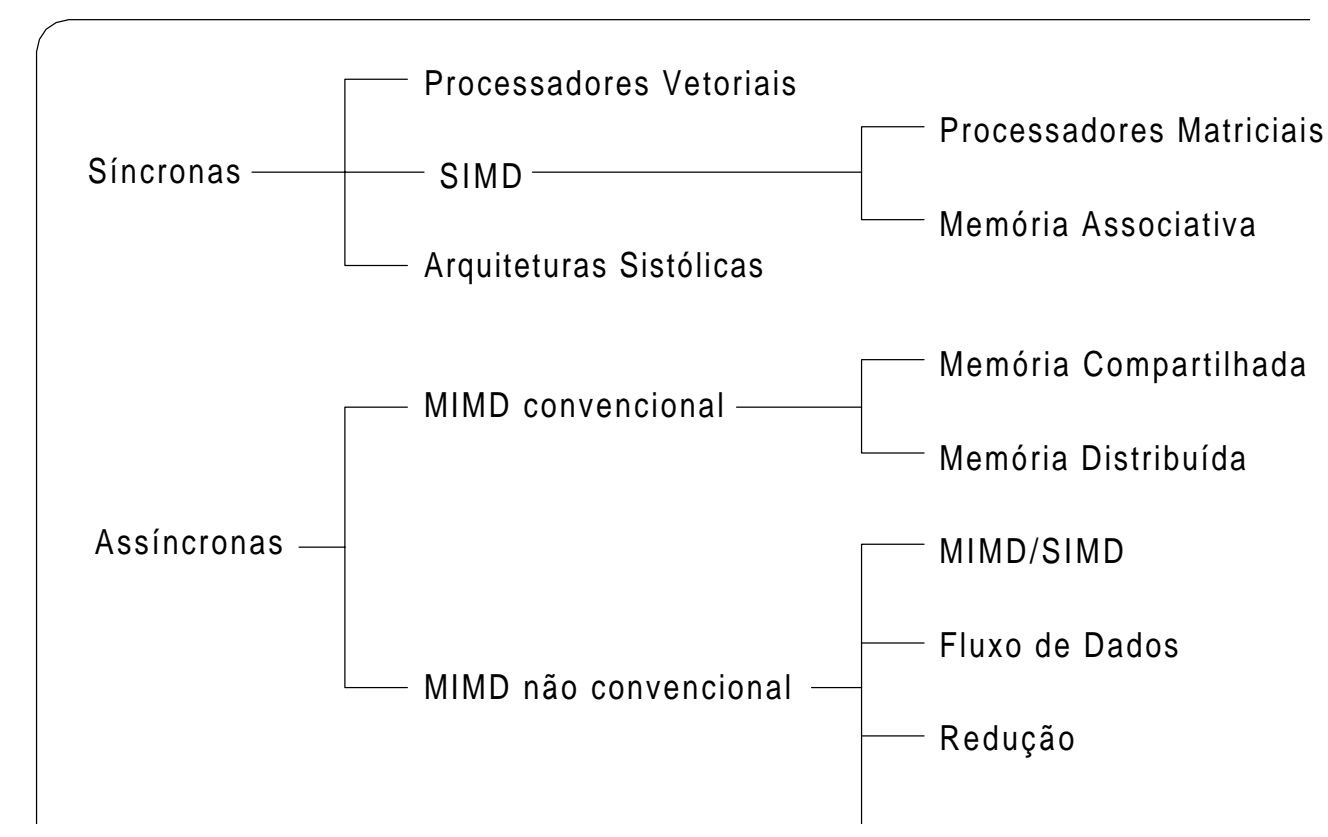

Figura 2.8. Classificação de Duncan

A classificação das arquiteturas segundo Duncan pode ser observada na Figura 2.8 e é dividida em 2 grandes grupos: arquiteturas síncronas e arquiteturas assíncronas. A seguir, cada item da classificação será brevemente discutido.

\section{Arquiteturas Síncronas}

Nas arquiteturas paralelas síncronas os processadores são coordenados sincronamente através de clocks globais, unidades de controle centrais ou controladores de unidades vetoriais [DUN90]. Pertencem a essa categoria: 
- Processadores Vetoriais: possuem um hardware específico para realizar operações sobre vetores. A organização básica de um processador vetorial consiste de: um processador de instrução (busca e decodificação da instrução), uma unidade de processamento vetorial e um processador escalar.

- Arquiteturas SIMD: são máquinas que utilizam uma única unidade de controle e vários processadores. A unidade de controle envia uma instrução para todos os processadores e esses executam a instrução sincronamente sobre diferentes fluxos de dados, como já descrito anteriormente (Figura 2.3). As arquiteturas podem ser organizadas de 2 modos:

Processadores matriciais: projetados especialmente para cálculos científicos em larga escala, sobre matrizes de dados. Fornecem acesso à memória via endereço.

Processadores associativos: processadores que utilizam memória associativa, ou seja, o acesso à memória é feito pelo conteúdo [DUN90].

- Arquiteturas Sistólicas: são arquiteturas projetadas para solucionar problemas de sistemas de propósitos específicos que demandam computação intensa e grande quantidade de operações de E/S. Os processadores são organizados como em uma fila e somente os processadores das pontas possuem comunicação com a memória. Segundo Almasi [ALM94], o nome sistólicas vem do fato dos dados pulsarem sincronamente entre os processadores do mesmo modo que o sangue pulsa no coração.

\section{Arquiteturas Assíncronas}

As arquiteturas assíncronas são caracterizadas pelo controle descentralizado de hardware e são compostas por vários processadores que executam independentemente instruções sobre diferentes dados. Em outras palavras, trata-se das arquiteturas MIMD da classificação de Flynn, que em [DUN90] são classificadas em convencionais e não convencionais.

- Arquiteturas MIMD convencionais: correspondem as arquiteturas MIMD discutidas na classificação de Flynn. A organização da memória é que determina como serão feitas a comunicação e o sincronismo entre os processadores. A organização pode ser compartilhada ou distribuída, como foi visto na seção anterior.

Do ponto de vista de programação é mais fácil utilizar memória compartilhada devido à facilidade de programação porém esta é mais difícil de ser construída. Quanto à expansão do sistema, a utilização de memória distribuída torna-se mais viável pois tanto a dificuldade quanto o custo de desenvolvimento são menores.

- Arquiteturas MIMD não convencionais: máquinas híbridas, de fluxo de dados, de redução e de frente de onda são difíceis de serem classificadas pois possuem características MIMD (assíncronas e múltiplos fluxos de instruções e dados) porém possuem características próprias que dificultam classificá-las como puramente MIMD. Assim, Duncan [DUN90] propôs uma classificação especial para estas máquinas.

Arquitetura híbrida (SIMD/MIMD): são arquiteturas MIMD que possuem partes da arquitetura controlada de modo SIMD. 
Arquitetura de fluxo de dados (dataflow): a principal característica das máquinas de fluxo de dados está no modo de execução sendo que as instruções são habilitadas para execução tão logo todos os operandos tornem-se disponíveis. Deste modo a execução das instruções é baseada na dependência dos dados, permitindo explorar a concorrência a nível de tarefas, rotinas e instruções [DUN90].

Arquitetura de redução: são arquiteturas dirigidas por demanda, uma vez que os processadores só executam os comandos quando as expressões são requeridas como operandos para a execução de outra instrução [DUN90]. O conceito de redução está na substituição de partes do código fonte original por seus resultados [KIR91]. Foram criadas para explorar um novo conceito de paralelismo para prover um suporte arquitetural para linguagens de programação funcionais. [DUN90].

Arquitetura de frente de onda: esta arquitetura combina as estruturas pipeline sistólicas com a execução assíncrona do fluxo de dados (dataflow). Tem por objetivo conservar as vantagens das arquiteturas sistólicas (balanceamento entre processamento e E/S) e eliminar algumas de suas desvantagens [DUN90, KIR91].

\subsection{CONCEITOS BÁSICOS DE PROCESSAMENTO PARALELO}

Segundo Hwang [HWA84], a definição de processamento paralelo é:

"Uma forma eficiente do processamento da informação com ênfase na exploração de eventos concorrentes no processo computacional."

Segundo Almasi [ALM94], a definição de processamento paralelo é:

"Conjunto de elementos de processamento que podem se comunicar e cooperar para solucionar grandes problemas (de uma maneira mais rápida que em um processamento seqüencial)."

Para simplificar, o processamento paralelo pode ser definido como o uso de múltiplos processadores para executar diferentes partes do mesmo programa simultaneamente.

Para exemplificar o processamento paralelo, considere o problema de colocar em ordem as cartas de um baralho. Uma primeira solução é separar primeiramente por naipes e em seguida ordenar cada naipe. Se houver duas pessoas para ordenar, pode-se dividir o baralho no meio e cada uma ordenaria da mesma maneira descrita acima combinando o resultado no final, ou então uma poderia ordenar por naipe enquanto a outra ordenaria por valor, simultaneamente.

Vários fatores justificam a necessidade do processamento paralelo. A mais importante, que é a razão comercial do surgimento do processamento paralelo, é a capacidade de aumentar o processamento em uma única máquina, ou seja, aumentar o desempenho e diminuir o tempo para se obter o resultado do problema [NAV89, ALM94]. Outros fatores que contribuem para a grande evolução do processamento paralelo são: 
- limitação da velocidade das máquinas seqüenciais (velocidade da luz). No entanto, quando agrupados, esses processadores produzem um significativo ganho do poder computacional (desempenho);

- existência de problemas intrinsecamente paralelos.

Contudo, introduzir processamento paralelo não é tão simples. Existem diversas formas de organizar os processadores em paralelo além da necessidade de manter as informações que trafegam pela máquina coerentes e de gerenciar elementos de processamento (processadores).

Retornando ao exemplo do baralho, pode-se verificar que o aumentando do número de ajudantes é até certo ponto benéfico mas, após esse ponto, a eficiência começa a cair.

Alguns conceitos básicos de processamento paralelo são introduzidos nas próximas seções, como paralelismo e concorrência, níveis de paralelismo, speedup e eficiência, pipeline e modelos de acesso à memória.

\subsubsection{Paralelismo e Concorrência}

Entende-se por concorrência quando dois ou mais processos já iniciaram sua execução mas ainda não terminaram. A concorrência pode ocorrer tanto em sistemas de um único processador quanto em sistemas de mais de um processador. Quando ocorre em um sistema com um único processador é denominado pseudo-paralelismo. Em sistemas de vários processadores pode-se explorar paralelismo verdadeiro executando um processo em cada processador ou uma mistura de pseudo-paralelismo e paralelismo verdadeiro quando existe mais eventos em execução do que o número de processadores. No caso de pseudo-paralelismo é dado ao usuário a falsa impressão de que todos os processos estão sendo executados ao mesmo tempo.

\subsubsection{Níveis de PARALELISMO}

Nível de paralelismo (ou granulosidade) está relacionado com o tamanho médio das subtarefas executadas pelos processadores. Vários autores classificam de modos diferentes a granulosidade [HWA84, NAV89, KIR91, ALM94]. No modo mais simples, a granulosidade pode ser classificada em fina, média e grossa.

A granulosidade grossa significa um paralelismo a nível de processos e programas e um pequeno número de processamento grandes e complexos. A granulosidade fina significa um paralelismo a nível de instruções e operações e um grande número de processamento pequenos e simples. Normalmente implementada em hardware.

A granulosidade média implica em um paralelismo a nível de blocos e sub-rotinas [NAV89, KIR91].

A granulosidade fina pode limitar o speedup (ver 2.4.3) devido a grande quantidade de sincronismo necessário. Isto pode ser visto no exemplo do baralho novamente, quando utiliza-se 52 ajudantes, cada um ordenando uma carta. É muito difícil coordenar as atividades, ou seja, obter sincronismo sem gerar uma sobrecarga excessiva. 


\subsubsection{SPEEDUP E EFICIÊNCIA}

Como já foi visto, um dos fatores que justifica a necessidade de processamento paralelo é a capacidade de aumentar a velocidade de processamento. Com esse aumento de processamento houve também um aumento da velocidade com que os processadores chegam a solução. Para quantificar esse aumento utiliza-se diferentes parâmetros, entre eles speedup e eficiência.

Speedup (Sp) pode ser definido como o aumento da velocidade observado quando se executa um algoritmo paralelo em um computador paralelo em relação ao seqüencial, ou seja, quão mais rápida é a execução paralela [KIR91].

$$
S_{p}=\frac{t_{1}}{t_{p}}
$$

onde: $t_{1}=$ tempo para executar o programa em um processador

$$
\mathrm{t}_{\mathrm{p}}=\text { tempo para executar o programa em } p \text { processadores. }
$$

O caso ótimo é obtido quando $\mathrm{Sp}=\mathrm{p}$, ou seja, na medida em que se aumenta o número de processadores, aumenta-se diretamente a velocidade de processamento [QUI87].

A eficiência (E) de um algoritmo paralelo é definida como a relação entre o Speedup (Sp) e o número de processadores (p), ou seja, é o quanto os processadores estão sendo utilizados.

$$
E_{p}=\frac{S_{p}}{p}
$$

A eficiência varia entre 0 e 1, para eficiências variando de $0 \%$ e $100 \%$, respectivamente [ALM94]. Dificilmente obtêm-se eficiência igual a 1 pois sempre haverá perdas na paralelização do algoritmo e sobrecarga de comunicação e sincronismo entre os processadores [KIR91].

\subsubsection{Pipeline}

Para a execução de uma tarefa em um pipeline esta deve ser dividida em subtarefas. Cada subtarefa será executada por um estágio de hardware e/ou software específicos que trabalhará concorrentemente com os outros estágios do pipeline [NAV89, HWA84]. Devido a sua característica de execução de subtarefas sobrepostas no tempo, o pipeline é classificado como paralelismo temporal.

Atualmente, pipeline é uma importante técnica de implementação usada para desenvolver, entre outras aplicações, UCPs velozes [HEN90]. As arquiteturas RISC, utilizam esta técnica com grande eficiência uma vez que as instruções são praticamente do mesmo tamanho.

Dois tipos de pipeline são freqüentemente utilizados na implementação de processadores: aritmético e de instruções. No pipeline aritmético os dados vão atravessando os estágios e sendo processados, como pode ser observado na Figura 2.9 [NAV89]. Enquanto o processo $n$ está no estágio $i$, o processo $n+1$ está no estágio $i+1$ e assim por diante. No pipeline 


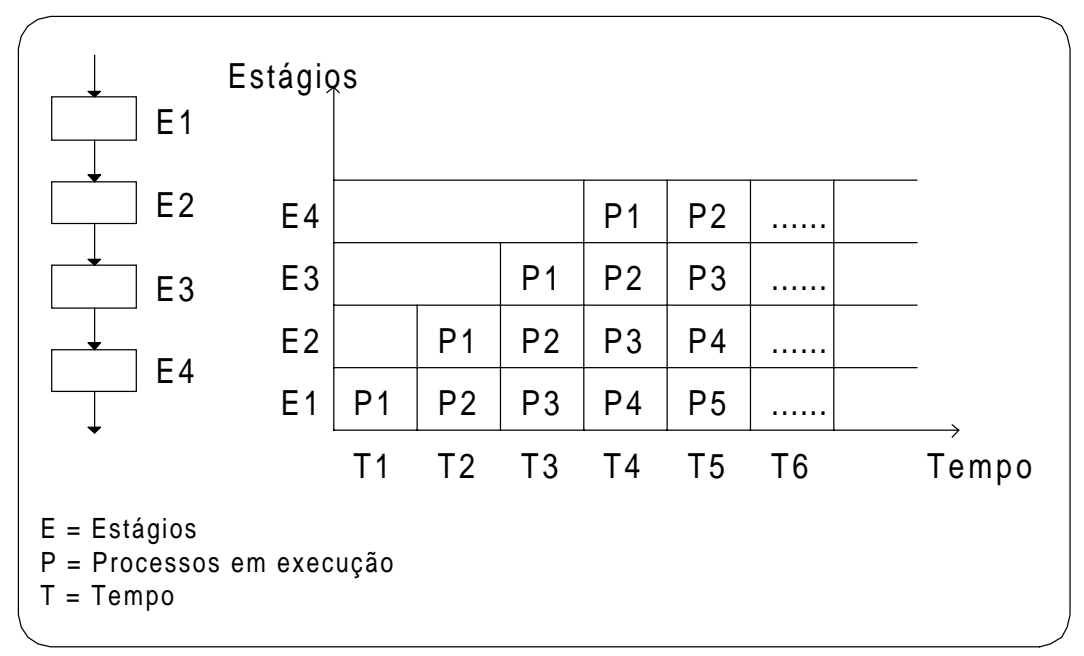

Figura 2.9. Execução de um pipeline

de instruções o paralelismo está nas etapas de busca da instrução (fetch), decodificação, busca dos operandos, execução e armazenamento. Cada estágio executa um "pedaço" da execução de cada instrução. O estágio seguinte só inicia sua execução quando o estágio anterior já houver finalizado sua execução.

O resultado de um pipeline não é a execução mais rápida de uma instrução, mas um ótimo desempenho quando diversas instruções são executadas. Se um pipeline leva quatro ciclos para processar uma instrução, ele irá levar cinco ciclos para completar duas instruções, seis ciclos para três instruções, e assim por diante.

\subsubsection{MODELOS DE ACESSO À MEMÓRIA}

Para coordenar as tarefas dos vários elementos de processamento (processadores) que trabalham na solução do mesmo problema é necessário alguma forma de comunicação entre processadores para:

- transportar informações e dados entre os processadores

- sincronizar as tarefas

O modo como os processadores se comunicam e se sincronizam depende do modo de $\mathrm{n}$ acesso à memória. $\mathrm{O}$ acesso à memória significa o modo, do ponto de vista do programador, pelo qual as informações serão armazenadas e isto afeta diretamente como os programas paralelos são escritos. Para memória compartilhada utiliza-se acesso a variáveis compartilhadas, controlado através de semáforos, monitores, etc. Para memória distribuída pode-se utilizar trocas de mensagens seguindo as técnicas ponto a ponto, Rendvouz ou RPC. 


\subsection{COMENTÁRIOS FINAIS}

As arquiteturas de von Neumann são constituídas basicamente por 3 subsistemas: Unidade Central de Processamento (UCP), memória principal e dispositivos de entrada/saída. Estes 3 subsistemas estão interligados por linhas de comunicação denominadas barramentos. Os processadores mais conhecidos da arquitetura de von Neumann são os processadores da família 80 x 86 da Intel.

Flynn [FLY72] classificou as arquiteturas conforme a presença de um ou vários fluxos de instruções e dados. A classificação de Flynn engloba tanto arquiteturas sequienciais quanto arquiteturas paralelas. As categorias são: SISD (um fluxo de instruções e um fluxo de dados), SIMD (um fluxo de instruções e vários fluxos de dados), MISD (vários fluxo de instruções e um fluxo de dados) e MIMD (vários fluxos de instruções e vários fluxos de dados). Esta classificação se tornou defasada pois as arquiteturas paralelas evoluíram muito. Duncan [DUN90] propôs outra classificação só para arquiteturas paralelas. Esta classificação divide basicamente as arquiteturas em dois grupos: arquiteturas síncronas e arquiteturas assíncronas.

Alguns conceitos de processamento paralelo, tais como a diferença entre paralelismo e concorrência, níveis de paralelismo, speedup e eficiência, pipeline e modelos de acesso à memória são importantes no estudo das arquiteturas paralelas. 


\section{Simulação}

\subsection{INTRODUÇÃO}

A análise de desempenho engloba diferentes abordagens tais como: análise de sistemas existentes, análise de sistemas ainda em desenvolvimento ou a comparação de sistemas. Para cada uma destas situações, existe uma ferramenta que apresenta melhores resultados.

A simulação é uma das ferramentas disponíveis para análise de desempenho de sistemas computacionais e vem se tornando cada vez mais atuante nas mais diversas áreas de aplicação devido a sua flexibilidade e baixo custo [PEG91]. Como exemplo de utilização de simulação de um modo geral, pode-se citar sistemas urbanos, meteorologia, projetos de engenharia, projetos aeroespaciais, sistemas ecológicos, na avaliação de redes de comunicação [SHA92], etc.

Originalmente, a palavra simular significa imitar. Portanto, para simular é necessário imitar algo [ROB83]. Usualmente se começa com a descrição de um problema físico e a primeira coisa a fazer para resolvê-lo é a descrição do problema através de um modelo [MEU92]. Um modelo constitui uma abstração do sistema e pode ser feito em diferentes níveis.

Neste capítulo são apresentadas inicialmente (seção 3.2) as ferramentas utilizadas na análise de desempenho. Nas seções seguintes são discutidos os conceitos básicos de simulação de sistemas, que é a ferramenta para análise de desempenho utilizada neste trabalho.

\subsection{TÉCNICAS PARA AVALIAÇÃO DE DESEMPENHO}

Diversas técnicas estão hoje disponíveis para a avaliação (ou análise) de desempenho. As técnicas de avaliação se referem aos métodos pelos quais as informações, associadas aos parâmetros que estão em análise, são colhidas [FER92].

Estas técnicas podem ser divididas em 2 grupos: técnicas de aferição e técnicas de modelamento (Figura 3.1). Nas técnicas de aferição, as informações são obtidas a partir de medidas efetuadas no próprio sistema. Nas técnicas de modelamento, as informações são obtidas através de um modelo representativo do sistema. A seguir são discutidas estas duas técnicas. 


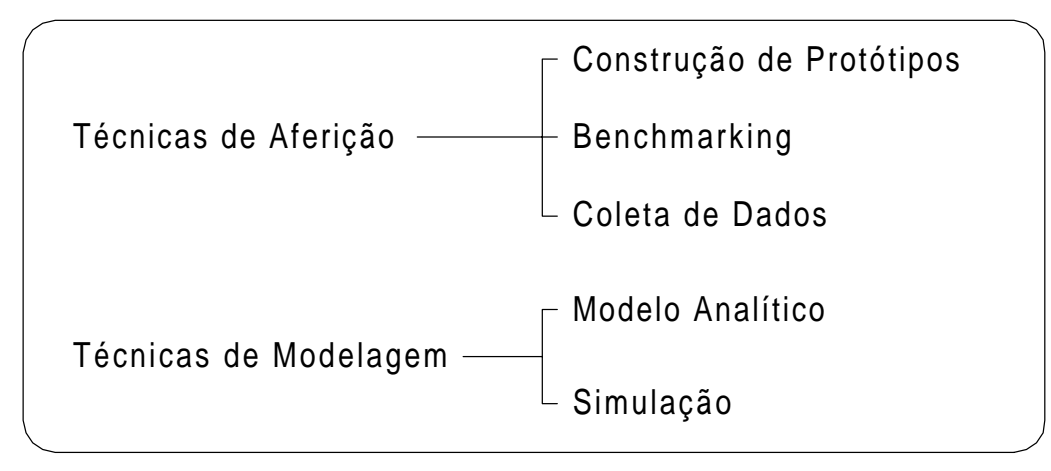

Figura 3.1. Técnicas para avaliação de desempenho

\section{Técnicas de aferição}

As técnicas de aferição são ferramentas utilizadas para análise de desempenho através de sua experimentação. Essa experimentação pode ser efetuada utilizando software (como por exemplo os benchmarks) ou hardware (como por exemplo monitores de hardware).

Coleta de dados: essa técnica deve ser conduzida sobre sistemas reais, operando em condições normais, através da inserção de algum hardware ou do acréscimo de algum software, específicos para esse fim. Essa técnica é a que fornece resultados mais precisos, entretanto sua aplicação requer que o sistema em questão esteja fisicamente disponível. Cuidado especial deve ser tomado para que as próprias instruções que compõem essa técnica não interfiram de maneira significativa nos resultados da análise [KOB78, SAN90a, FER92]. O tempo e o custo consumidos no emprego dessa técnica são determinados pelo tipo e complexidade da coleta de dados a ser efetuada. Normalmente, a coleta por monitores de hardware fornece resultados mais precisos, mas consome um tempo maior que a coleta por monitores de software.

Benchmarking: em algumas situações, como na aquisição de novos equipamentos, é interessante que o desempenho de diferentes sistemas sejam comparados. Para isso, é necessário que o desempenho seja obtido com todas as máquinas operando sobre as mesmas condições, ou seja, a mesma carga de trabalho deve ser executada em cada uma delas. A carga de trabalho utilizada nesse procedimento (que pode ser uma aplicação qualquer do usuário ou um procedimento específico para esse objetivo), é chamada benchmark [WEI90, FER92, NAI95]. Esse tipo de ferramenta, normalmente, não é de alto custo estando disponível no mercado.

Construção de protótipos: é uma técnica empregada quando se deseja obter dados de um sistema ainda não disponível. O protótipo nada mais é que uma aproximação simplificada do sistema real [FER92]. É um método que oferece boa precisão nos resultados, porém a construção de protótipos torna-se algumas vezes inviável devido aos custos envolvidos com a construção, testes e modificações do mesmo. Além disso essa técnica não é adequada para testar diferentes alternativas, devido ao custo e às dificuldades na modificação do sistema físico. 


\section{Técnicas de modelagem}

Nestas técnicas é necessário o desenvolvimento de um modelo que represente as características essenciais do sistema a ser avaliado. Esse modelo pode então ser resolvido através da solução analítica ou por simulação

Modelamento analítico: permite escrever uma relação funcional entre os parâmetros do sistema e os critérios de desempenho escolhidos, em termos de equações que podem ser resolvidas analiticamente [SOA92]. Essa técnica fornece resultados precisos, mas a medida que aumenta a complexidade do sistema sendo modelado, aumenta também a dificuldade da resolução analítica. Muitas vezes é possível a construção de modelos que representem bem o sistema e que possam ser resolvidos com algumas simplificações e suposições. Geralmente utilizam-se redes de filas para a representação do modelo e subseqüente resolução [KOB78, SAN90, SAN90a, SOA92]. Essa técnica possui um custo relativamente baixo e o tempo para obter a solução desejada depende da complexidade do problema.

Simulação: consiste em modelar o sistema para então transformá-lo em um programa que represente com fidelidade o sistema real. É uma técnica prognostica que examina as conseqüências possíveis quando diferentes seqüências de comportamentos do sistema são geradas [SAN90a]. É uma técnica flexível podendo ser aplicada a sistemas existentes ou inexistentes. A dificuldade dessa técnica reside na validação dos resultados obtidos (essa mesma dificuldade é encontrada nos modelos analíticos) [KOB78, MAC87, SAN90, SAN90a, SOA92].

A utilização de cada uma dessas técnicas irá depender do problema e do estágio do trabalho. As técnicas de aferição são utilizadas quando o sistema está pronto ou quando deseja-se fazer uma seleção de sistemas. Já as técnicas de modelagem são utilizadas tanto quando o sistema existe como para a validação e avaliação de um projeto. As técnicas de modelagem oferecem grande flexibilidade a baixo custo [SAN90]. Modelos analíticos oferecem em alguns casos soluções mais simplificadas, mas na maioria das vezes os sistemas são complexos determinando simplificações e suposições exaustivas para que as equações possam ser resolvidas. Além disso, quando se deseja efetuar alguma modificação no sistema, é necessário refazer todo o modelo e ainda solucioná-lo. Os modelos de simulação permitem refletir essas alterações no modelo de forma mais simplificada. A simulação requer, entretanto, um tempo extensivo de processamento para algumas aplicações.

A próxima seção discute modelagem e teoria de redes de filas, conceitos importantes para a representação de modelos.

\subsection{MODELAGEM}

Para utilizar as técnicas de modelagem para avaliação de desempenho tem-se que construir e analisar modelos que representem o sistema. O principal passo em um processo de modelagem é abstrair as características do sistema em um modelo [MAC87]. Um modelador deve ter a capacidade de definir quais características são essenciais e estabelecer uma relação entre essas características. A inclusão de muitos detalhes pode introduzir complicações 
desnecessárias enquanto que a exclusão de características importantes pode invalidar o modelo [SOA92].

Os modelos podem ser classificados segundo dois parâmetros: quando à natureza do modelo e quanto ao nível de detalhamento:

\section{Quanto à natureza do sistema [SOA92]:}

Modelos discretos: representam sistemas onde as mudanças no seu estado ocorrem em pontos específicos e descontínuos do tempo simulado, alterando o estado do sistema espontaneamente. Nesse tipo de modelo normalmente há disputa por recursos e filas onde os elementos do sistema esperam pela liberação do recurso solicitado (seção 3.3.1). Os atrasos entre mudanças de estado são determinados estatisticamente, com o intervalo selecionado de acordo com alguma distribuição amostral (seção 3.3.1) [SHA88];

Modelos contínuos: são modelos nos quais as variações de estado podem ocorrer continuamente ao longo do tempo de simulação. Normalmente são descritos através de equações diferenciais.

\section{Quanto ao nível de detalhamento[MAC87]:}

Os modelos podem ser classificados quanto a sua granulosidade:

Nível de circuito: análise do chaveamento de estados;

Nível de portas: análise de um conjunto de transistores, resistores, etc.

Nível de registradores: análise de um conjunto de registradores, multiplex e somadores.

Nível de sistema: análise de tudo acima do nível de registradores.

Este trabalho fará uso do desenvolvimento de simulação utilizando-se modelos discretos, a nível de sistema.

Uma importante teoria deve ser considerada para a construção de modelos. É a teoria de redes de filas, que é discutida a seguir.

\subsubsection{Redes de Filas E Modelos BASEAdOS EM REDES de FilaS}

O compartilhamento de recursos limitados dentro de um sistema é um ponto fundamental na operação do mesmo. Se não há disputa, a análise de desempenho se torna mais fácil. Porém, a ausência de disputa em sistemas reais não é uma suposição realista. Como exemplo, tem-se jobs em um computador competindo pela UCP, unidades de E/S, canais, etc; mensagens em redes de comunicação competindo por enlaces, buffers, permissão, janelas, etc; e tarefas em uma linha de montagem competindo por ferramentas, áreas de estocagem, robôs, mecanismos de transporte, etc. [SOA92].

A disputa faz com que entidades esperem um certo tempo por serviços. As linhas de espera são denominadas filas e modelagem de filas é uma parte essencial no estudo de simulação [MAR80]. 
Uma rede de filas é composta de entidades denominadas por centro de serviço e clientes. Os recursos modelados no sistema correspondem aos servidores, os quais prestam serviços aos clientes. Um centro de serviço pode ter um ou mais servidores e uma área de espera (fila) para clientes que estão requisitando serviços e não são atendidos prontamente devido ao(s) servidor(es) estar(em) ocupado(s). A UCP é um exemplo de um centro de serviço.

Devido ao fato de o modelo ser uma abstração do sistema, pode-se classificá-los baseando-se na estrutura usada em sua construção. A estrutura de redes de filas será utilizada no processo de modelagem para simulação. Deste modo, será estudado agora como os modelos podem ser classificados de acordo com a constituição do centro de serviço.

O modelo mais simples é o que possui um centro de serviço constituído de um servidor e uma fila e pode ser observado na Figura 3.2. [MAR80, MAC87]. Os clientes chegam ao centro de serviço e, se o servidor está ocupado, o cliente une-se a fila associada àquele centro de serviço e espera. O cliente é selecionado para atendimento de acordo com a disciplina da fila. O serviço é então realizado pelo servidor, e após a execução, o cliente deixa o centro de serviço. Como exemplo de um sistema assim, tem-se a fila de um caixa em um supermercado.

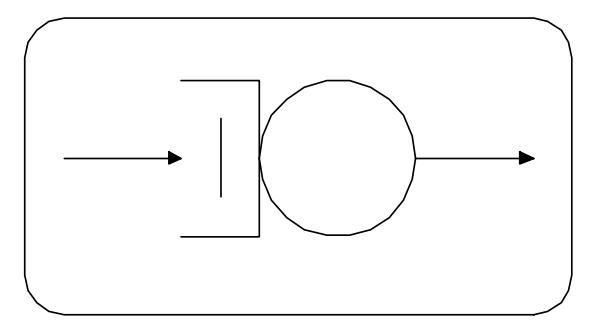

Figura 3.2. Centro de Serviço: uma fila, um servidor

Outras variações possíveis são: centro de serviço com uma fila e vários servidores (Figura 3.3), centro de serviço com várias filas e um servidor (Figura 3.4) e centro de serviço com várias filas e vários servidores (Figura 3.5).

No caso da Figura 3.3 tem-se como exemplo a fila única de um banco com vários caixas (servidores) atendendo. Como exemplo da Figura 3.4 pode-se considerar um guichê de uma repartição pública que atende a clientes os quais formam duas filas diferentes. Uma das filas se destina aos aposentados, e a outra atende as demais pessoas. $\mathrm{O}$ atendente dá preferência para

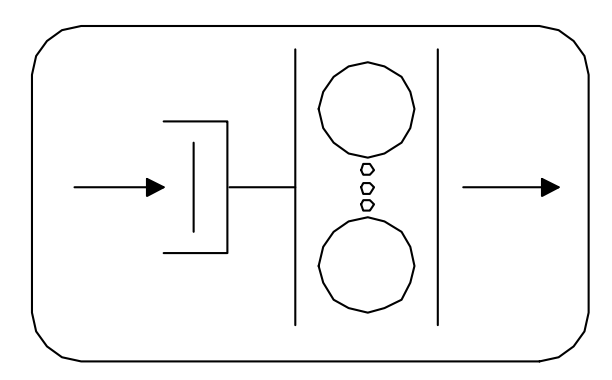

Figura 3.3. Centro de Serviço: uma fila, vários servidores 
a fila especial, só atendendo a outra fila quando não houver mais nenhum aposentado aguardando atendimento. Como exemplo da Figura 3.5 pode-se considerar uma agência bancária onde os vários caixas atendem a clientes que formam duas filas: uma para os clientes em geral e outra para idosos, gestantes e portadores de deficiências físicas. Os clientes em geral só são atendidos quando não houver ninguém na fila especial

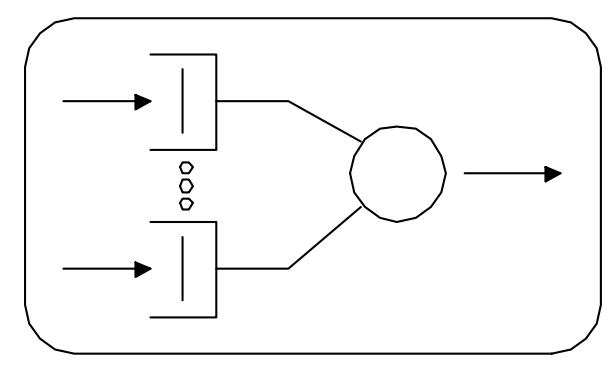

Figura 3.4. Centro de Serviço: várias filas, um servidor

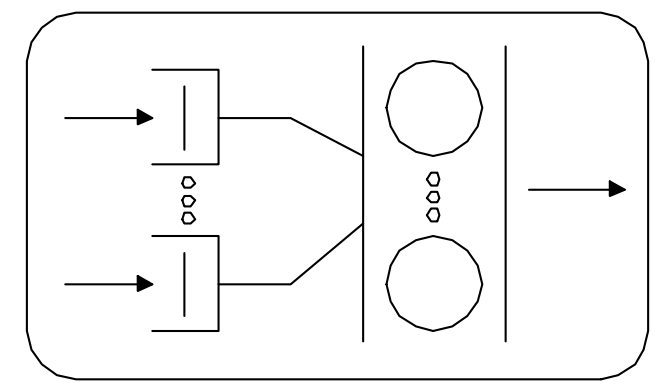

Figura 3.5. Centro de Serviço: várias filas, vários servidores

Nestes quatro casos existem parâmetros que devem ser estimados nos elementos de um modelo baseado em redes de filas, como padrão de chegada, mecanismo de serviço e disciplina da fila [KOB78].

\section{Padrão de chegada}

O padrão de chegada é a freqüência com que os cliente chegam ao sistema. Essa freqüência pode ser regular, ou seja, os clientes chegam em instantes igualmente espaçados. No entanto, a chegada regular é irreal em muitas situações. O outro modo são as chegadas completamente aleatórias [KOB78]. Neste caso, os dados podem ser obtidos através de tabelas ou pela utilização de uma distribuição de probabilidade. Algumas distribuições importantes são [SOA92]:

- Distribuição Uniforme;

- Distribuição Triangular;

- Distribuição Exponencial;

- Distribuição de Poisson;

- Distribuição Normal;

- Distribuição de Erlang. 


\section{Distribuição do serviço e capacidade de serviço}

O serviço solicitado por um cliente será denominado demanda de serviço ou simplesmente trabalho. A unidade de serviço varia dependendo da natureza do servidor e dos clientes. Pode ser uma instrução se o servidor for uma UCP e o cliente um programa. Se o servidor é uma linha de transmissão, os clientes são mensagens, a unidade de serviço pode ser bit ou byte. A demanda de serviço pelos clientes seguirá uma distribuição que será denominada distribuição de serviço.

Deve-se especificar também a capacidade (ou razão de processamento) do servidor, que significa quão rápido o servidor realiza o serviço. A unidade da capacidade irá também depender do servidor e dos clientes. No caso da UCP, a unidade poderia ser instruções/seg ou MIPS e no caso da linha de transmissão a unidade poderia ser bps ou kbps.

Se a demanda de serviço de um cliente é $\mathrm{S}$ [unidades de serviço] e o correspondente servidor possui capacidade C [unidades de serviço / seg], então a razão S/C [seg] é chamada de tempo de serviço. Em outras palavras, é o tempo necessário para que um servidor execute um serviço. Normalmente é especificado por uma distribuição de probabilidade [KOB78].

\section{Disciplina da fila (Disciplina de escalonamento)}

A disciplina da fila irá determinar como os clientes são escalonados e servidos. A disciplina mais comum é a disciplina "first come, first served" (FCFS) na qual os primeiros clientes a chegar são os primeiros a serem servidos. Existe também a disciplina "last come, first served" (LCFS) que possui a estrutura de pilha e os últimos clientes a chegar são os primeiros a serem atendidos. Na disciplina Round Robin (RR), os clientes são atendidos por um pequeno intervalo de tempo, denominado "quantum". Se esse "quantum" não foi suficiente para o servidor realizar o serviço do cliente, este volta para o fim da fila e aguarda novamente a sua vez.

Algumas vezes, alguns clientes são mais importantes que outros e merecem tratamento melhor. O procedimento que diferencia alguns clientes dos outros é chamado procedimento de escalonamento com prioridade e o sistema é referido como fila com prioridade. As disciplinas de filas com prioridades pode ser dividida em 2 tipos: preemptiva e não preemptiva. Se um cliente que está sendo servido pode ser interrompido e voltar para a fila sempre que um cliente de maior prioridade entrar na fila então a disciplina da fila é preemptiva. Se o cliente não é interrompido com a chegada de um outro com maior prioridade a disciplina da fila é não preemptiva [KOB78, SOA92].

A notação padrão para sistemas baseados em redes de filas é: $A / S / c / k / m$, onde $A$ representa a distribuição do tempo de chegada, $S$ representa a distribuição do tempo de serviço, $c$ é o número de servidores, $k$ é o número máximo de clientes no sistema e $m$ é o número de clientes disponíveis na fonte. Os símbolos mais usados para as distribuições são: D (tempo de chegada ou de serviço constante), M (distribuição exponencial), Ek (distribuição k-Erlang), Hk (distribuição hiperexponencial k-estágios) e G (distribuição geral) [MAC87]. 


\subsection{FASES DO DESENVOLVIMENTO DE UMA SIMULAÇÃO}

O desenvolvimento de simulação pode ser dividido em 3 fases: desenvolvimento, testes e análise, como pode ser observado na Figura 3.6. É importante ressaltar que apesar de a figura apresentar um fluxo seqüencial, na realidade esses passos devem ser sobrepostos e em alguns casos deve-se retornar a fases já desenvolvidas para reavaliar os resultados obtidos [MAC87]. As seções 3.4.1 a 3.4.3 discutem as fases para desenvolvimento de uma simulação.

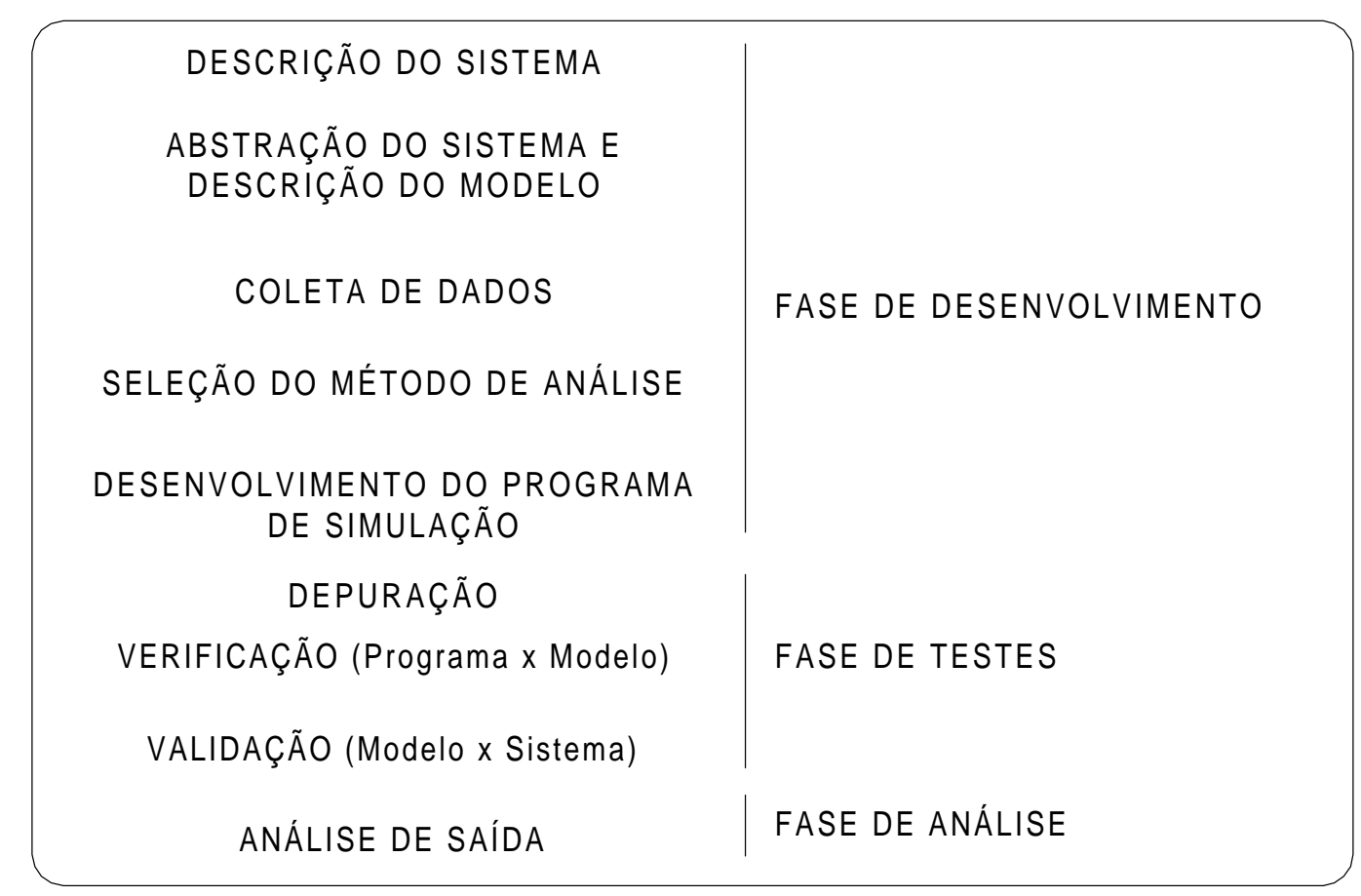

Figura 3.6. Processo de desenvolvimento de uma simulação

\subsubsection{FASe De DeSenvolvimento}

\section{Descrição do sistema}

Para descrever o sistema deve-se ter um bom entendimento deste para que se possa apresentá-lo sem dubiedade, sem negligenciar características relevantes ou considerar detalhes desnecessários que pode resultar em futuros erros. É nesta fase que se traça os objetivos a serem alcançados [MAC87]. O tempo gasto na organização e descrição do sistema será compensado na eliminação dos futuros erros. A forma de descrever um sistema depende do tipo de sistema a ser modelado. A maneira mais usada é um diagrama de fluxo de dados.

\section{Abstração do sistema e descrição do modelo}

Uma vez que o sistema está descrito é necessário abstraí-lo em um modelo, o qual irá representar uma visão particular deste.

Um modelo deve ser de fácil compreensão, sem que haja perda das características importantes e essenciais para determinação do desempenho. A quantidade de detalhes incluídos deve variar de acordo com o propósito de construção do modelo [SOA92]. 
Nesta fase deve-se fazer uma descrição do que será representado no modelo. A escolha do método de análise será feito posteriormente [MAC87].

\section{Coleta de dados}

Ao gerar a descrição do modelo surge a necessidade de definir quais os tipos e o nível dos dados que irão fluir no sistema. Esses dados serão os dados de entrada e servirão de parâmetros do modelo [MAC87]. Em geral são valores hipotéticos (quando não se tem um sistema de referência) ou baseados em alguma análise preliminar (quando o sistema de referência existe) [SOA92].

\section{Seleção do método de análise}

É nesta fase que deve ser decidido qual método de análise será usado para transcrever a descrição do modelo. Como foi visto, as técnicas de modelagem permitem seguir dois caminhos: método analítico ou simulação. Essa escolha é baseada em parte nos requerimentos do sistema e na representação dos dados e em parte nas ferramentas disponíveis e na habilidade do modelador [MAC87]. Alguns autores [MAC87, DAV89, SOA92] defendem a utilização de ferramentas analíticas sempre que for viável. Porém, a falta de flexibilidade (uma simples modificação no sistema pode implicar em reformulação do modelo) e a dificuldade em representar muitos detalhes (aumentar os detalhes em um modelo analítico pode aumentar a complexidade da solução analítica) faz com que as técnicas analíticas muitas vezes não sejam viáveis. Em casos como esses, a simulação deve ser escolhida.

\section{Desenvolvimento do programa de simulação}

Após a decisão por simulação como método de análise de desempenho é necessário transformar a descrição do modelo em programa de simulação, isto é, em uma forma aceitável pelo computador [MAC87]. A escolha do computador, linguagem e ferramentas depende do sistema a ser simulado, dos recursos disponíveis e das preferências do usuário. Pode-se seguir um dos seguintes enfoques[SAN90, SAN90a]: desenvolvimento do programa de simulação em uma linguagem convencional, utilização de um pacote de uso específico para criar o programa de simulação, uso de linguagens de simulação de uso geral ou através de uma extensão funcional de uma linguagem de programação de uso geral. Cada uma dessas abordagens é discutida na seção 3.7.

\subsubsection{FASE DE TESTES}

\section{Depuração do programa}

Nesta fase deve-se conferir o programa de simulação para que ele produza resultados coerentes, sem erros (de lógica, de programação, etc).

\section{Verificação}

A fase de verificação consiste em verificar se o programa de simulação é uma implementação válida do modelo [SAR84, MAC87, SOA92]. Para pequenos modelos, isto pode 
ser óbvio apenas inspecionando. Para grandes modelos, alguma análise mais detalhada se torna necessária [MAC87]. A técnica mais utilizada consiste em uma revisão cuidadosa no programa e no modelo [SAN90a]. Outra forma é através da comparação com modelos analíticos. O programa de simulação é modificado para representar um modelo que possui solução analítica. Os resultados da simulação e da solução analítica são comparados. Esta técnica permite que se elimine erros no processo de descrição do modelo.

\section{Validação}

$\mathrm{Na}$ fase de validação deve-se demonstrar que o modelo proposto é uma representação do sistema atual, ou seja, deve reproduzir o comportamento do sistema com suficiente fidelidade para satisfazer os objetivos de análise. A validação pode ser considerada em dois casos: quando o sistema simulado existe e pode ser medido, e quando o sistema modelado não existe, ou melhor, existe somente um projeto. No primeiro caso, o objetivo da análise é avaliar uma mudança proposta no sistema e a validação é baseada na comparação dos resultados do modelo com as medidas reais do sistema. No segundo caso, o objetivo da análise é estimar o desempenho do projeto ou mesmo avaliar projetos alternativos. Neste caso, o modelo é validado baseando-se nos resultados esperados no projeto do sistema e cada suposição e abstração são justificadas. Outra possibilidade para avaliação é através de comparações com outros modelos do projeto já validados, como por exemplo, modelos analíticos [MAC87, SOA92], ou através de situações em que os resultados já são conhecidos.

\subsubsection{FASE DE ANÁliSE}

\section{Análise de saída}

Algumas perguntas que surgem no processo de simulação são relacionadas com o tempo de que uma simulação deve ser executada e quantas vezes executá-la. Estas perguntas podem não fazer muito sentido pois é necessário que o programador defina por quanto tempo ou quantas vezes o programa de simulação deve ser executado. No entanto, nestas perguntas está implícita a seguinte frase: "para obter uma determinada precisão".

Como as entradas de uma simulação são baseadas na geração de valores aleatórios e as saídas são funções dessas variáveis de entrada, a análise dos resultados de uma simulação é um problema estatístico. Os métodos para análise destes resultados baseiam-se em estimar o intervalo de confiança dos valores médios obtidos na simulação [MAC87]. Isto quer dizer que a simulação pára quando a estimativa da variância da média está dentro de uma certa tolerância especificada (intervalo de confiança). Entre os métodos para análise de saída pode-se destacar os métodos regenerativo, por replicação e batch mean.

O desenvolvimento de uma simulação deve seguir esses passos e, às vezes, como já foi descrito, deve-se retornar a fases já desenvolvidas para reavaliar os resultados obtidos. Neste caso, pode ser necessário alterar o enfoque do modelo. Os enfoques são discutidos na próxima seção. 


\subsection{SIMULAÇÃO DISCRETA}

Um modelo descreve a composição dinâmica do sistema, ou seja, a maneira como este executa um determinado trabalho. Três entidades (atividades, processos e eventos) são utilizadas para descrever o comportamento dinâmico de sistemas discretos e sobre os quais as linguagens de simulação para esses sistemas são baseados. Um sistema é visto dinamicamente como uma coleção de processos interativos, cada um composto por diversas atividades, com as interações controladas e coordenadas pela ocorrência de eventos [MAC87, SOA92]. A relação entre essas três entidades pode ser melhor entendida observando a Figura 3.7.

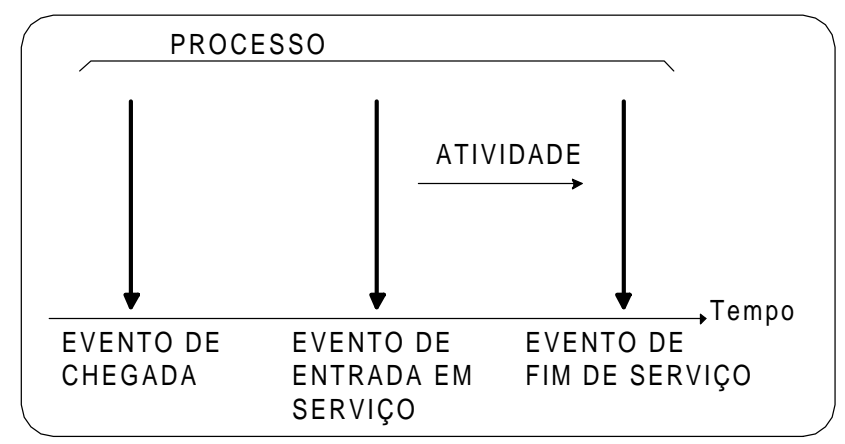

Figura 3.7. Relação entre evento, atividade e processo

A atividade é a menor unidade de trabalho. Desde que é uma unidade de trabalho, toda atividade tem associada a ela um tempo de execução. Um conjunto de atividades logicamente relacionadas constitui um processo. O tempo de execução de um processo é (sem contar com a concorrência) a soma dos tempos de execução e espera das atividades. A definição dos processos de uma simulação depende do nível de abstração adotado. Por exemplo, um programa inteiro pode ser visto como um processo (compreendendo atividades de computação, leitura e escrita de dados). Em um outro nível, a execução de uma atividade de escrita pode ser vista como um processo compreendendo posicionamento, latência e transferência de dados. Um evento causa uma mudança de estado de alguma entidade do sistema. A inicialização ou o término de uma atividade são eventos [MAC87].

\subsection{ABORDAGEM PARA SIMULAÇÃO DISCRETA}

Um modelo para simulação discreta pode ser visto sob 3 enfoques, cada um baseado em uma das 3 entidades básicas (evento, atividade e processo) [MAC87, SOA92].

- orientação a evento: o sistema é modelado pela definição das mudanças que ocorrem no tempo de evento;

- orientação a atividade: o sistema é modelado através da descrição das atividades nas quais os objetos do sistema se envolvem;

- orientação a processo: o sistema é modelado por meio da descrição dos processos através dos quais os objetos fluem. 


\subsubsection{SimulaÇÃo ORIENTAdA A EVENTO}

Na simulação orientada a evento, a tarefa do modelador é determinar os eventos que podem causar a mudança no estado do sistema e então desenvolver a lógica associada com cada tipo de evento. A simulação do sistema é produzida pela execução dessa lógica, em uma seqüência no tempo [SOA92].

Um mecanismo de escalonamento de eventos mantém a seqüência ordenada dos eventos no tempo. Esse mecanismo utiliza uma estrutura de lista. Quando um evento, como por exemplo a chegada do próximo cliente, está para ser escalonado, o processo escalonador é chamado para criar e adicionar uma entrada na lista de eventos. Nesta entrada é incluído o instante da ocorrência do evento, a identificação do evento que vai ocorrer e a identificação do cliente associado.

Como exemplo, considere o atendimento a clientes, por caixas de um banco [MAR80]. Ao chegar ao banco, o cliente entra na fila e espera sua vez de ser atendido. Após terminar suas operações no caixa, o cliente deixa a agência bancária. Mudanças de estado no sistema ocorrem devido aos seguintes eventos:

- um cliente chega;

- um cliente já foi atendido por um caixa e parte do sistema.

A lógica associada aos eventos pode ser descrita da seguinte forma [SOA92]:

\section{Evento Chegada de Cliente}

Escalone a próxima chegada

Se o caixa está ocupado então

Aumente o número de clientes na fila

Senão

Torne o estado do caixa ocupado

Escalone o fim de atendimento para tempo_corrente + tempo_atendimento

\section{Evento Término de Atendimento}

Se existe algum cliente na fila então

Retire um cliente da fila para atendimento

Escalone o fim de atendimento para tempo_corrente + tempo_atendimento Senão

Torne o estado do caixa desocupado 
O programa de simulação pode ser organizado da seguinte forma:

Escalone a primeira chegada

Selecione o primeiro evento

Avance o tempo de simulação para o tempo de ocorrência do evento

Se final de simulação então

Imprima estatísticas

Senão

Se evento $=$ Chegada de Cliente então

Trata chegada do Cliente

Senão

Trata término de atendimento

\subsubsection{Simulação Orientada a Processo}

O programa de simulação é organizado como um conjunto de processos, os quais executam concorrentemente durante a simulação. A descrição de um processo tem a forma de um procedimento de uma linguagem de programação [MAC87].

Como na orientação a evento, também existe um mecanismo de escalonamento e uma estrutura de lista, com a diferença de que cada entrada na lista define um processo e seu ponto de reativação (para processos que são bloqueados e novamente postos para executar).

Basicamente uma simulação orientada a processo deve seguir os seguintes passos [SPO94]:

- definir as entidades do sistema;

- criar um processo para cada objeto do sistema descrevendo suas etapas;

- executar concorrentemente os processos.

No exemplo dos clientes sendo atendidos por caixas de uma agência bancária, descrito na seção anterior, seguindo este tipo de orientação tem-se o processo cliente organizado da seguinte forma:

\section{Processo Cliente}

Se o caixa está desocupado então

Torne o estado do caixa ocupado

O Cliente ocupa o caixa pelo tempo de atendimento (escalone processo para tempo_corrente + tempo_atendimento)

Torne o estado do caixa desocupado

O Cliente parte do sistema

Senão

O Cliente entra na fila de espera 
A chegada de novos clientes ao sistema (o banco) pode ser descrita como no processo Chegada de Clientes:

\section{Processo Chegada de Clientes}

Indique chegada de novo cliente

Escalone processo para tempo_corrente + tempo_chegadas

O programa de simulação executa sincronamente vários processos Cliente que chegam segundo uma distribuição de probabilidade, requisitam serviços e vão embora.

\subsubsection{Simulação Orientada a Atividade}

Na simulação orientada a atividade, o modelador descreve cada atividade possível para cada entidade do sistema, definindo as condições que causam seu início e seu término. Os eventos que iniciam ou terminam uma atividade não são escalonados pelo modelador, mas são iniciados a partir das condições específicas para a atividade. Com o avanço do tempo simulado as condições para o início ou o fim de uma atividade são examinadas, e no caso de alguma condição ser satisfeita, a atividade correspondente é escalonada para execução no tempo de simulação corrente. Esta orientação é pouco utilizada para a modelagem de sistemas [MAC75, MAR80, SOA92].

No exemplo dos clientes sendo atendidos por caixas de um banco, tem-se as seguintes atividades:

- Chegada de um cliente;

- Término de atendimento.

A estrutura básica do programa de simulação é mostrada a seguir:

Início

tempo de simulação $=1$

Enquanto não fim da simulação faça

Verificar o conjunto de atividades

Se chegada de cliente então

Processa chegada

Se término de atendimento então

Processa término

tempo de simulação $=$ tempo de simulação +1

Imprima estatísticas 
Para a implementação de uma simulação segundo uma das orientações apresentadas, existem linguagens e pacotes de simulação que possibilitam ao modelador escrever programas de simulação orientados a evento, processo ou atividade, como será visto na próxima seção.

\subsection{PACOTES E LINGUAGENS PARA SIMULAÇÃO}

O intenso uso de simulação como uma abordagem de análise de desempenho de sistemas deu origem a uma série de ferramentas específicas projetadas para este fim. Estas diversas linguagens e pacotes de modelagem impõem uma certa estruturação nos modelos e simplificam suas soluções [SOA92].

Um requisito importante para as linguagens de simulação é a presença de mecanismos para representação do tempo. Enquanto o sistema sendo modelado executa em tempo real, a simulação trabalha com um relógio próprio, que marca a passagem do tempo no programa de simulação [MAC75]. Outro requisito importante é a capacidade de fornecer facilidades para coletas de estatísticas e emissão de relatórios.

Como foi visto na seção 3.4.1. pode-se usar os seguintes enfoques para a implementação de um modelo de simulação:

- linguagens de programação convencionais;

- linguagens de simulação;

- pacotes de uso específico;

- extensões funcionais.

\subsubsection{LINGUAGENS DE PROGRAMAÇÃO CONVENCIONAIS}

Em princípio, toda linguagem de programação é uma candidata a linguagem de simulação [SAY85, PEG91]. Porém, para desenvolver um programa de simulação em uma linguagem convencional (como Modula 2 ou C), o programador deve criar todo um ambiente necessário para a simulação pois estas linguagens não oferecem todas as ferramentas (estrutura de dados, facilidades para manipulação de listas, abstração de dados, coleta de estatísticas e emissão de relatórios) necessárias para um ambiente de simulação.

A desvantagem de se utilizar linguagens convencionais é que o programador deve ter conhecimento tanto da linguagem como de simulação para poder criar um ambiente de simulação.

Uma vantagem é que o programador não necessita aprender uma nova linguagem já que ele tem a liberdade de utilizar uma que já é de seu conhecimento. Esta abordagem oferece ainda uma grande flexibilidade uma vez que o usuário pode utilizar todos os recursos oferecidos pela linguagem. 


\subsubsection{LinguAGENS DE SIMULAÇÃo}

São linguagens projetadas para a modelagem de sistemas de vários tipos [SOA92]. Estas linguagens já contém todas as estruturas necessárias para a criação de um ambiente de simulação, livrando o programador da necessidade de executar tal tarefa. As linguagens são classificadas em orientadas a evento, atividade ou processo e a escolha irá depender se o modelo é orientado a evento, atividade ou processo.

\section{Linguagens orientadas a evento}

Nas linguagens orientadas a evento, o programa de simulação é organizado como um conjunto de rotinas ou seções de eventos [MAC75].

Essas linguagens tendem a impor uma visão global e de alto nível do sistema ao modelador, o que as tornam mais adequadas a modelos de pequeno e médio porte. Com o aumento da complexidade, sugere-se a estruturação do modelo para utilização de uma linguagem orientada a processo. Exemplos de linguagens de simulação orientadas a evento são: SIMSCRIPT [MAC75, KOB78], e SLAM II [SOA92].

\section{Linguagens orientadas a processo}

Uma linguagem orientada a processo é mais utilizada em análise de sistemas mais complexos, como por exemplo sistemas das áreas de robótica, projeto de sistemas computacionais e redes de comunicação [SAY85].

Nesta abordagem o sistema é visto como uma coleção de processos interativos. Um processo tem as seguintes características [SAY85]:

- pode ser ativado, ficar em estado suspenso ou encerrar sua execução em certo instante de tempo ou baseado em alguma condição;

- uma vez ativado, repete o seu comportamento até ser colocado no estado suspenso ou terminar sua execução.

Programas de simulação escritos nestas linguagens são construídos de uma forma mais natural, tornando o sistema e o modelo similares. Exemplos de linguagens de simulação orientadas a processo são: GPSS [SOA92], Q-GERT [SOA92], ASPOL [MAC75, SOA92], SIMULA [MAC75, SAY85], SOL [MAC75], SIMPL/I X [SAY85], RESQ, SLAM II [SOA92].

\section{Linguagens orientadas a atividade}

Para escrever um programa em uma linguagem orientada a atividade deve-se descrever as atividades existentes no sistema. Para certos tipos de problemas essa abordagem provê um modelo conciso, adequado para situações onde a duração da atividade é indefinida [SOA92]. Um exemplo de linguagem orientada a atividade é CSL [MAC75].

\subsubsection{PACOTES de USO ESPECífico}

Os pacotes de uso específico são voltados para a avaliação de sistemas particulares. Devido ao fato de serem muito específicos para uma dada aplicação, estes pacotes oferecem 
facilidades em pontos particulares da aplicação para a qual foi desenvolvidos, mas são pouco flexíveis a mudanças [SAN94]. Nestes pacotes, a formulação do modelo é construída na própria ferramenta, sendo os parâmetros do modelo especificados de forma definida pelo pacote. Alguns exemplos são [SOA92]:

- BEST / 1, CMF, FIVE, PERFORMS, UM Predictor, XL: para modelagem de sistemas de computação e seus receptivos sistemas operacionais;

- PET, NETWORK 11.5: para modelagem de redes de computadores;

- BETHSIM: para modelagem de operações de siderurgia;

- IDSS 2.0: para modelagem de sistemas aeroespaciais.

\subsubsection{EXTENSÕES FUNCIONAIS}

Para facilitar o trabalho do programador, algumas bibliotecas (conjunto de rotinas disponível ao programador) podem ser inseridas em linguagens convencionais (chamadas hospedeiras), compondo assim um ambiente completo de simulação. $\mathrm{O}$ trabalho do programador é facilitado pois este não precisa aprender uma nova linguagem.

Algumas extensões são:

- extensões da linguagem C: SMPL [MAC87] (orientada a evento), CSIM [EDW92] e EFC [SOU92] (orientadas a processo);

- extensões da linguagem C++: SIMPACK [FIS95];

- extensões da linguagem Modula 2: EFM2 [SPO92], HPSIM [SHA88] (orientadas a processo).

A extensão funcional SMPL é utilizada neste trabalho e será detalhada na seção 3.8.

\subsubsection{ESCOLHA DA LingUagem PARA SimulaÇão}

A princípio toda linguagem pode ser usada na implementação de um sistema de simulação. É importante adotar aquela que vai ao encontro do enfoque (evento / atividade / processo) de modelagem determinada anteriormente pelo modelador, já que este vem implícito na linguagem [MOR95]. [SOA92]:

Vários fatores devem ser analisados na escolha de uma linguagem de simulação

- Portabilidade: disponibilidade da linguagem em outros computadores, incluindo microcomputadores e supercomputadores;

- Tempo de execução: velocidade de compilação e execução;

- Capacidade de memória: gerenciamento adequado do espaço de armazenamento;

- Depuração: facilidade de depuração, documentação adequada; 
- Aprendizado: facilidade de aprendizado da linguagem e treinamento disponível;

- Considerações de processamento: disponibilidade de facilidades para coleta estatística e para processamento de listas. Geração de relatórios padrão e facilidade para geração de relatórios personalizados.

\subsection{SMPL}

SMPL é uma extensão funcional da linguagem de programação $\mathrm{C}$ e orientada a eventos e será explicada com maiores detalhes devido ao fato de ser a extensão utilizada neste trabalho. Em SMPL, o sistema é constituído por três entidades: facility, tokens e events.

- Facility: representa algum recurso (hardware ou software) executando alguma tarefa no sistema.

- Tokens: representam as entidades ativas no sistema. Um token pode indicar por exemplo, uma tarefa em um computador.

- Event: representa qualquer mudança de estado nas entidades do sistema, sendo indicado pelo seu número.

Um programa SMPL é composto por uma rotina que prepara o ambiente para simulação, uma rotina de controle (que seleciona o número do próximo evento a ocorrer e transfere o controle para a rotina de evento associada) e rotinas de evento (responsáveis pela geração dos eventos).

Um programa em SMPL que simula um modelo de fila M/M/1 (um sistema com uma única fila, um único servidor, tempo entre chegadas de clientes e tempo de serviço exponencialmente distribuídos e população infinita de clientes) pode ser observado na figura 3.8.

\subsection{CONSIDERAÇÕES FINAIS}

As técnicas para avaliação do desempenho de sistemas computacionais podem ser divididas em 2 grupos: técnicas de aferição e técnicas de modelamento. As técnicas de aferição obtêm as informações para a análise a partir do próprio sistema. As técnicas de modelamento obtêm as informações através de um modelo representativo do sistema.

Dentre as técnicas disponíveis para a avaliação do desempenho de sistemas computacionais, a simulação é a mais flexível e de baixo custo. Para o desenvolvimento de uma simulação é necessário abstrair o sistema em um modelo. Este modelo deve representar o sistema com fidelidade. A teoria de redes de filas é utilizada para a representação dos modelos.

O desenvolvimento de uma simulação pode ser dividido em três fases: desenvolvimento, testes e análise. O sistema pode ser modelado segundo um dos seguintes enfoques: evento, processo ou atividade. 
A ampla utilização de simulação deu origem a uma série de ferramentas específicas para seu desenvolvimento. Pode-se optar por linguagens de programação convencionais, linguagens de simulação, pacotes de uso específico ou extensões funcionais.

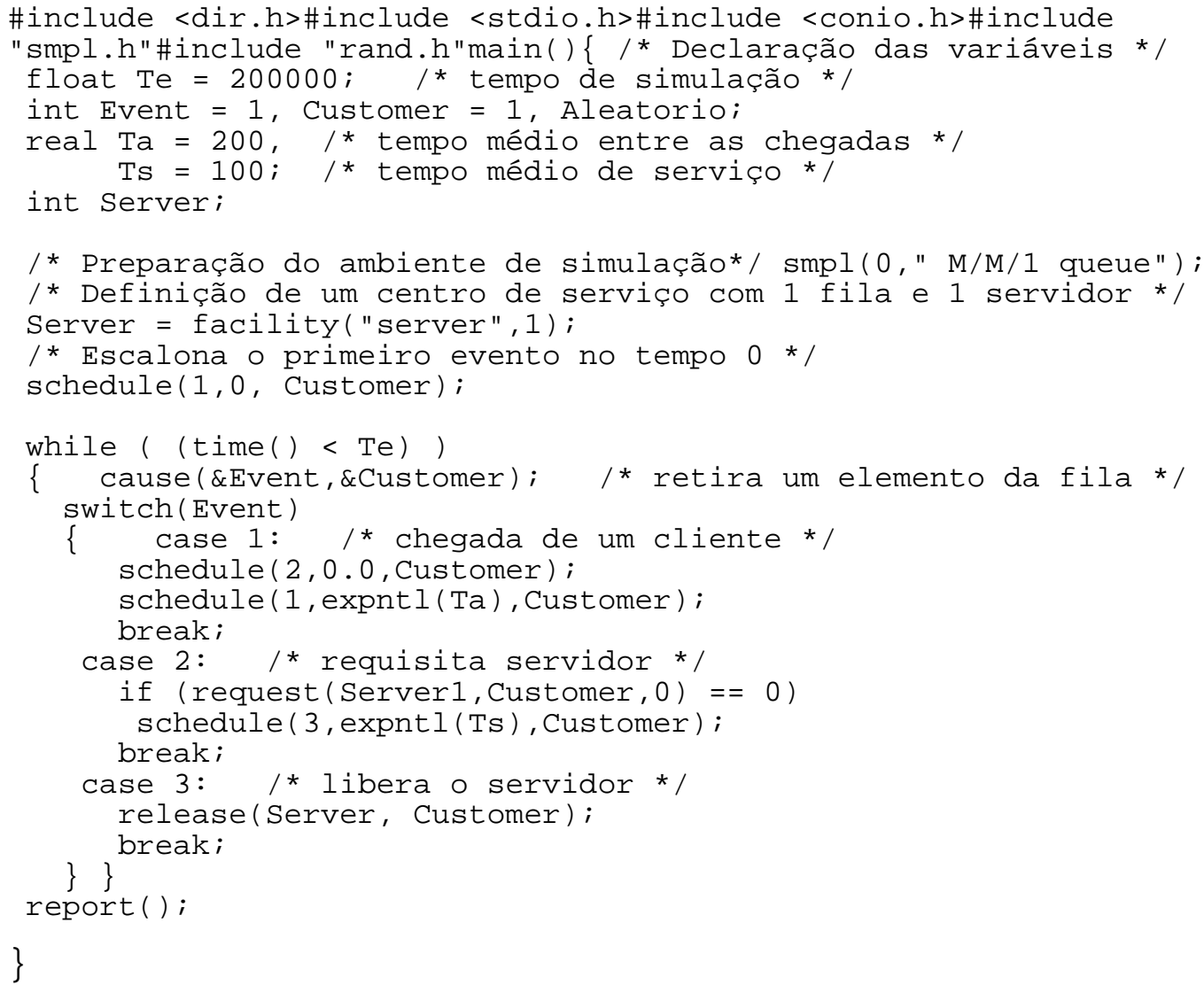

Figura 3.8. Código fonte de um modelo M/M/1 


\section{Ambientes de Simulação Automáticos}

\subsection{INTRODUÇÃO}

Para o desenvolvimento de um projeto de simulação é necessário passar pelos estágios descritos na seção 3.4 (Figura 3.6). Para ajudar o usuário neste processo, o conceito de ambiente de simulação tem sido desenvolvido [TAN94]. Esses ambientes são ferramentas que oferecem ao usuário uma série de recursos para a elaboração de uma simulação. Por exemplo, o programa de simulação pode ser gerado e executado automaticamente a partir de uma representação gráfica do modelo do sistema a ser avaliado. Para isto é necessário a inclusão de editores gráficos, interpretadores, compiladores e otimizadores. O ambiente de simulação é definido então como um ambiente de simulação automático.

Nos ambientes de simulação automáticos, uma característica importante é a programação visual [OZD91]. Utilizando a programação visual o modelo de simulação é criado graficamente na tela. A partir deste modelo, o programa de simulação é gerado automaticamente e o usuário interage com este programa fornecendo parâmetros. A saída é também gráfica e o usuário observa o comportamento do sistema através de gráficos ou animações [SHA92, OZD91, MEL85]. A programação visual é particularmente desejável e vantajosa uma vez que o homem pode manipular informações de um modo mais eficiente se estas forem apresentadas graficamente [SPO94].

Esta metodologia de programação visual deve [OZD91]:

- servir como um bom meio de comunicação para as pessoas.

- facilitar o uso do ambiente de simulação;

- ter fácil programação gráfica;

- aumentar a produtividade do modelador;

- minimizar erros de programação;

- facilitar a visualização do problema;

Será apresentado nas próximas seções alguns ambientes de simulação automático e o ASiA (Ambiente de Simulação Automático), desenvolvido no ICMSC-USP.

\subsection{SISTEMAS EXISTENTES}

Esta seção apresenta alguns software que oferecem um ambiente para simulação. 


\section{QMG [RAC90]}

QMG (Queueing Model Generator) é um módulo do ambiente de simulação PASION (PAScal SIMulation - extensão funcional da linguagem PASCAL). Este módulo contém um editor de blocos-diagramas que permite ao usuário definir a estrutura do modelo, e um gerador de programas que gera o correspondente código PASION. Este código é automaticamente transportado para PASCAL. QMG é transparente (isto é, os códigos em PASION e PASCAL não são visíveis para usuários que não sabem programar). Entretanto, se o usuário tem conhecimento sobre as linguagens PASION e PASCAL, o código resultante pode ser alterado, resultando em modelos mais complexos. O ambiente PASION permite também a apresentação dos resultados obtidos através de gráficos e histogramas.

\section{Q+ [FUN91]}

O simulador Q+é um sistema para simulação de eventos discretos que utiliza a interação para modelagem, permitindo que um usuário descreva seu modelo da maneira mais simples: desenhando. O comportamento do sistema é observado também graficamente, através de animações. A interface com o usuário é através de menus pop-down.

Q+ possui 6 componentes: um editor gráfico, um editor de texto, um simulador Monte Carlo, um interpretador, um brownser e um conjunto de utilitários.

\section{BONeS [SHA92]}

BONeS (Block Oriented Network Simulator) é um ambiente para simulação de redes de comunicação. É baseado no modelamento hierárquico e orientado a blocos. Foi desenvolvido para prover um ambiente visual para modelamento e simulação do fluxo de informações em redes de comunicação e em sistemas distribuídos.

Os modelos são construídos graficamente usando um editor de blocos BONeS (BDE). O usuário especifica os parâmetros dos blocos antes da simulação. Uma vez que os modelos estão prontos é verificado se há erros e checada a consistência, transformando automaticamente o modelo gráfico em um programa C. Durante a simulação, $\mathrm{BONeS}$ coleta dados em vários pontos, utilizando várias pesquisas. O usuário especifica a localização e o tipo das pesquisas. Os dados coletados durante a simulação são analisados e mostrados graficamente para o usuário.

\section{SIGMA [KEL94]}

O sistema SIGMA (Scientists' Intelligent Graphical Modeling Assistant) provê um ambiente de programação visual feito para cientistas da NASA. Estes utilizam a interface gráfica do SIGMA para programar visualmente usando uma linguagem de modelamento pelo fluxo de dados.

SIGMA utiliza uma extensa base de conhecimento de domínio científico que ajuda o usuário durante o processo de modelagem. Essa base checa a consistência e a coerência do modelo que está sendo construído. Utilizando o conhecimento sobre o problema modelado e o domínio científico, SIGMA pode automaticamente interpretar o modelo de alto nível como um 
programa executável, e o executa, livrando o cientista de detalhes de implementação. Os resultados são mostrados graficamente e podem ser analisados.

\section{ASSERTS [CCT94]}

ASSERTS é um software que permite usuários simularem e avaliarem a execução de tarefas em tempo real em um ambiente distribuído. As ferramentas possuem facilidades para incorporar detalhes de topologia de interconexão, desempenho de UCPs, estratégias de escalonamento e detalhes de execução de tarefas em tempo real. Uma interface gráfica com o usuário oferece facilidades para a entrada dos dados e análise dos resultados.

\section{ARENA [SWA95, BAN96]}

ARENA é um ambiente de simulação comercial de propósito geral baseado no SIMAN $\mathrm{V}$. Este ambiente permite a construção de modelos utilizando métodos do ponto e clique. ARENA originou o uso de templates de simulação. Com isto, o software é facilmente adaptado para uma indústria específica, uma companhia ou um projeto. Um Editor Profissional ARENA permite que o usuário projete seus próprios templates.

\subsection{ASiA - AMBIENTE DE SIMULAÇÃO AUTOMÁTICO}

O ASiA (Ambiente de Simulação Automático) é um ambiente de simulação no qual o programa é automaticamente gerado pelo sistema, baseado em uma especificação gráfica do modelo fornecida pelo usuário.

Esse ambiente tem por objetivo afastar o usuário da tarefa de transcrição do modelo em um programa de simulação. O usuário fornece o modelo do sistema considerado e os parâmetros necessários para a simulação através de um editor gráfico. As demais tarefas serão executadas automaticamente pelo ASiA.

Três estágios básicos são necessários para a obtenção dos resultados no sistema de simulação automático (figura 4.1)

- Editor gráfico: fornece ao usuário uma interface amigável e organiza e testa a consistência dos dados de entrada;

- Gerador de aplicações: responsável pela geração do programa de simulação;

- Estágios de saída: análise dos dados e saída gráfica.

O editor gráfico fornece um ambiente que permite ao usuário inserir seu modelo e os parâmetros necessários para a simulação através de um ambiente gráfico.

A segunda fase do sistema de simulação automática não depende da interferência direta do usuário. As informações coletadas e organizadas pelo editor gráfico em estruturas de dados previamente definidas, alimentam um gerador de aplicações que fornecerá como saída o programa de simulação. Esse programa é descrito de acordo com a linguagem de simulação adotada (podendo ser uma das abordagens discutidas no capítulo 3). Na atual versão do ASiA, a 
ferramenta adotada é o SMPL [MAC87]. Após isso o programa de simulação gerado é executado e os resultados são obtidos.

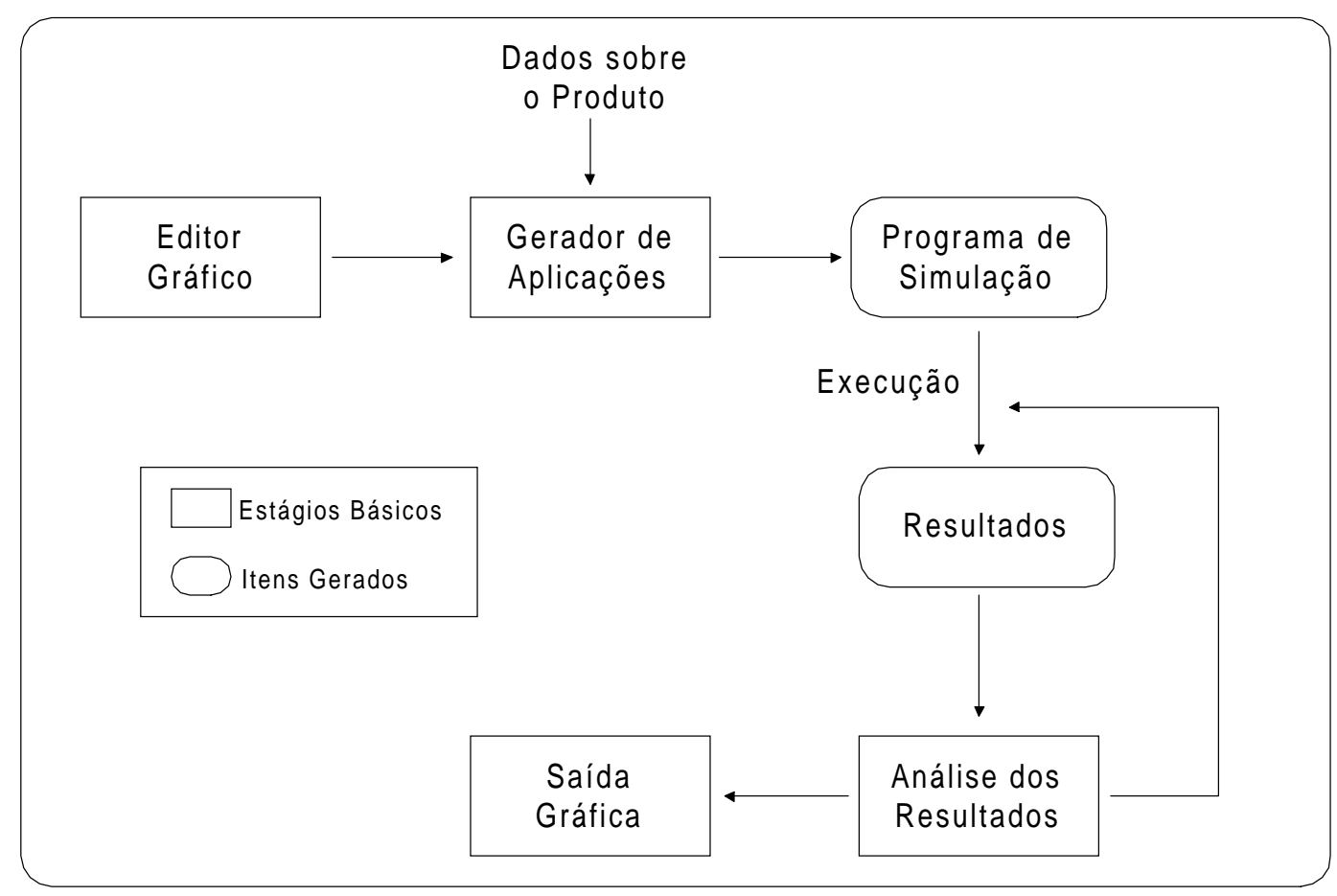

Figura 4.1. Visão geral do ASiA

O último estágio do sistema de simulação automático oferece ao usuário a possibilidade de visualização gráfica dos resultados obtidos na simulação [PED96]. Está em andamento um trabalho que introduzirá no estágio de saída uma análise estatística dos resultados [OLI96]. Os três estágios básicos do ASiA são detalhados a seguir.

\subsubsection{EDITOR GRÁFICO}

Através do editor gráfico o usuário compõe na tela de um monitor os elementos do modelo que representam um sistema discreto (basicamente um modelo de redes de filas). $\mathrm{O}$ editor permite que sejam efetuadas modificações no modelo. Uma vez definido o modelo, o editor requisita do usuário os parâmetros necessários para a simulação. As demais tarefas são executadas automaticamente pelo sistema.

A interface do editor segue os objetivos de um projeto de interfaces com o usuário com o propósito de facilitar o processo de aprendizagem e modelagem. Os objetivos são [SPO94]:

- Velocidade de aprendizagem: diz respeito a quanto tempo um usuário inexperiente com a interface leva para aprender a utilizá-la (quanto mais amigável a interface, mais rápida é a aprendizagem);

- Velocidade de utilização: refere-se a quanto tempo um usuário experiente leva para executar alguma tarefa dentro do sistema; a velocidade para definição de uma tarefa e a resposta do sistema devem ser suficientemente rápidas; 
- Taxa de erros: mede o número de erros cometidos pelo usuário. Essa taxa pode afetar tanto a velocidade de aprendizagem como a velocidade de utilização do sistema, pois se o usuário comete erros com facilidade, o aprendizado leva mais tempo e a velocidade para o desenvolvimento de uma tarefa fica comprometida pois o usuário deve corrigir os erros;

- Rápida recordação de como utilizar a interface: o usuário pode passar algum tempo sem fazer uso da mesma sendo que o retorno às atividades não deve implicar em um grande esforço para uma reaprendizagem;

- Ser consistente: o propósito básico da consistência é permitir ao usuário generalizar conhecimento sobre um aspecto do sistema para outros aspectos. Por exemplo, o botão de confirmação de uma atividade fica sempre à esquerda enquanto que o botão de cancelamento fica à direita.

O Editor Gráfico do ASiA (EdGraf - Editor Gráfico) constitui o módulo de interface entre o usuário e o módulo Gerador de Aplicações. O EdGraf foi implementado utilizando-se a linguagem $\mathrm{C}$ e os recursos oferecidos pelo Microsoft Windows 3.1, para plataformas tipo IBMPC compatíveis [SAN96].

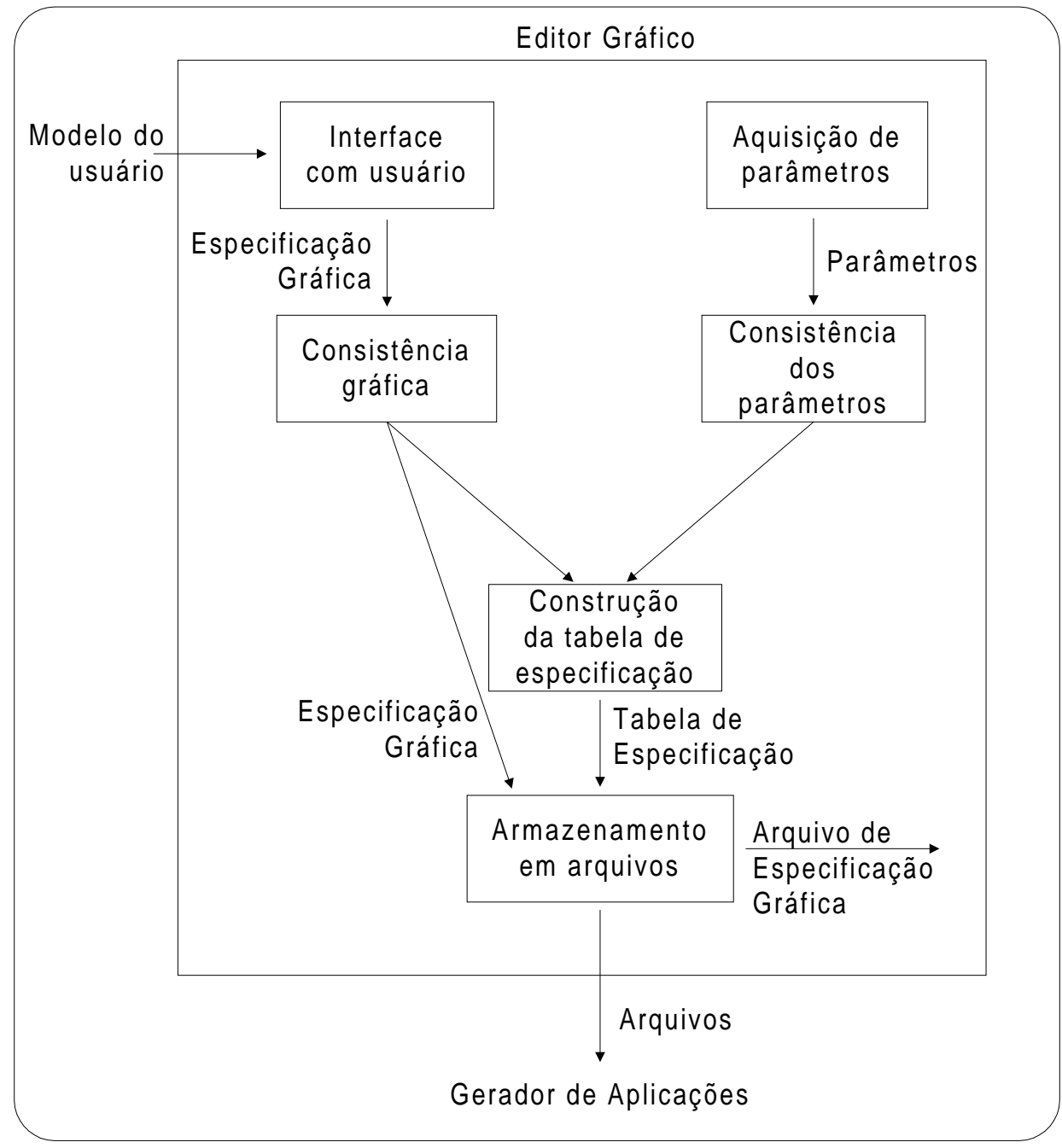

Figura 4.2. Visão Geral do Editor Gráfico do ASiA 
A figura 4.2 apresenta uma visão geral dos sub-módulos do Editor Gráfico e o relacionamento entre eles. Como pode ser observado, entre o modelo do usuário e a geração dos arquivos existe uma série de operações que o editor executa, a fim de trabalhar as informações obtidas da especificação gráfica e da parametrização do modelo. EdGraf transforma todas as informações vindas do modelo de simulação em um conjunto de dados consistente e organizado de forma que possa ser utilizado pelo Gerador de Aplicação.

O sub-módulo Interface com Usuário é responsável por fornecer ao usuário uma interface de fácil aprendizado e utilização, e também pela manutenção da parte gráfica, possibilitando desenhar (com verificação automática de consistência), apagar elementos de um modelo, gravar arquivos, recuperar arquivos previamente definidos, etc [SAN96].

A tela principal do EdGraf, apresentada na Figura 4.3, mostra barras de ferramentas e a de menus. A barra de ferramentas possibilita ao usuário desenhar os recursos do modelo em questão (centros de serviços com uma ou várias filas e um ou vários servidores), selecionar um recurso para parametrização, indicar qual o caminho a ser seguido por um cliente do sistema sendo modelado e apagar qualquer símbolo desenhado. Com a barra de menus, o EdGraf possibilita ao usuário executar operações relacionadas com arquivos (abrir um arquivo de especificação completo, salvar a especificação de um modelo), fornecer os parâmetros do modelo e definir distribuições de probabilidade (na forma de tabelas). A barra de menus oferece também um sistema de ajuda on-line.

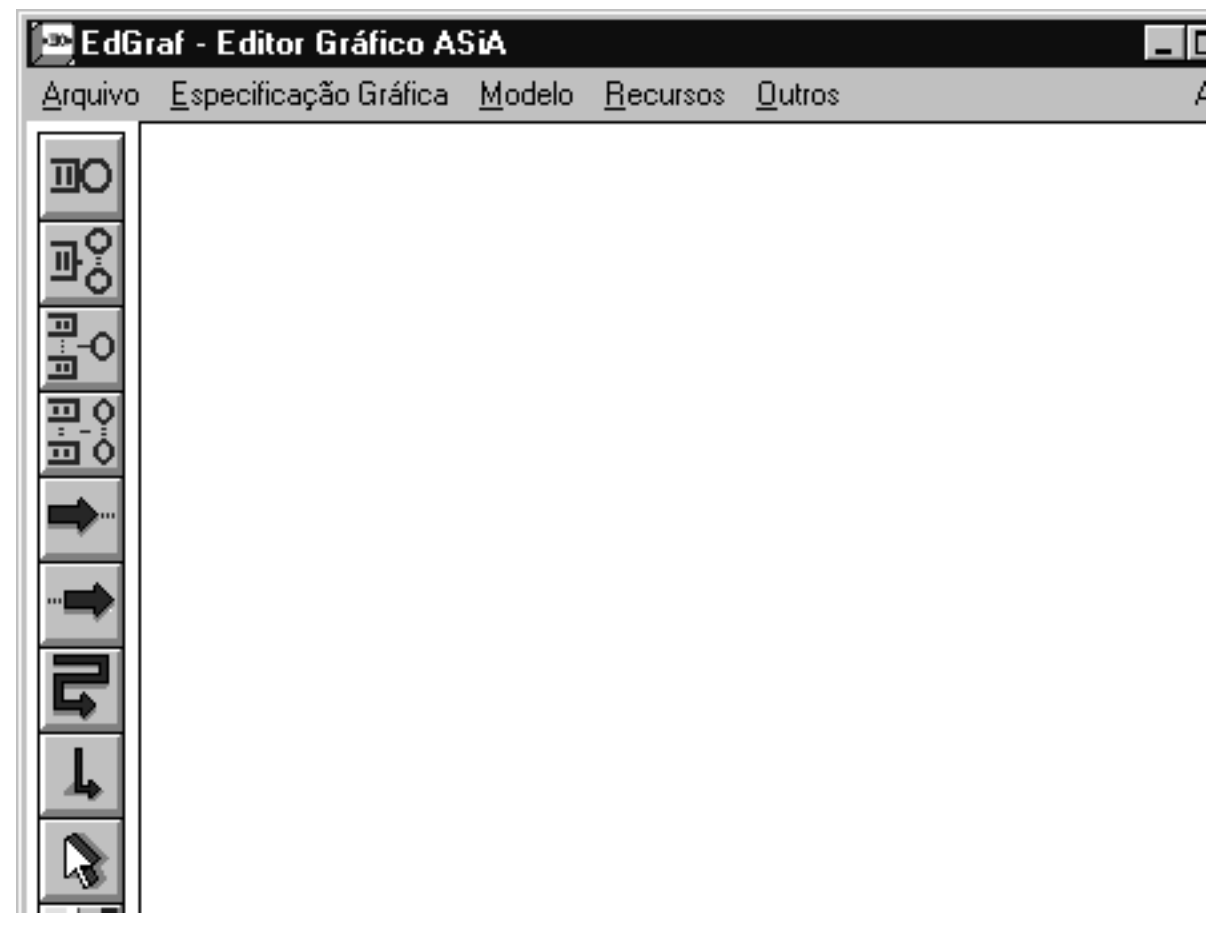

Figura 4.3. Tela principal do EdGraf

Todas as informações necessárias para a geração automática de um programa de simulação são captadas pelo EdGraf, através de uma análise da própria especificação gráfica e da 
obtenção dos parâmetros do modelo fornecidos pelo usuário por meio dos menus e caixas da interface.

À medida que os símbolos gráficos vão compondo o modelo, vão sendo armazenados em memória. O mesmo ocorre com todos os parâmetros fornecidos. É na forma de arquivos que as tabelas contendo a especificação do modelo definido pelo usuário são transferidas pelo Gerador de Aplicação [SAN96].

\subsubsection{GERADORES DE APLICAÇÃO}

Com o avanço da computação e o barateamento do hardware, atualmente muitas pessoas possuem acesso aos computadores. No entanto, muitos desses novos usuários não possuem um conhecimento razoável da máquina que estão utilizando. Para atender esse tipo de usuário, facilitar o trabalho do programador e ainda baixar o custo de desenvolvimento de software (que ultrapassou o custo do hardware) pode-se utilizar os geradores de aplicação ou geradores de programas [SPO94, SPO94b].

Geradores de aplicação são ferramentas que ajudam no desenvolvimento de software. Essencialmente é um utilitário que, a partir de uma especificação em alto nível de um problema, transforma automaticamente essa especificação na implementação do problema. As vantagens são claras: ajudam a melhorar a qualidade dos sistemas produzidos, aumentam a produtividade, facilitam a manutenção e escrita da especificação.

Os geradores são, normalmente, compostos por 3 módulos, como pode ser observado na Figura 4.4 .

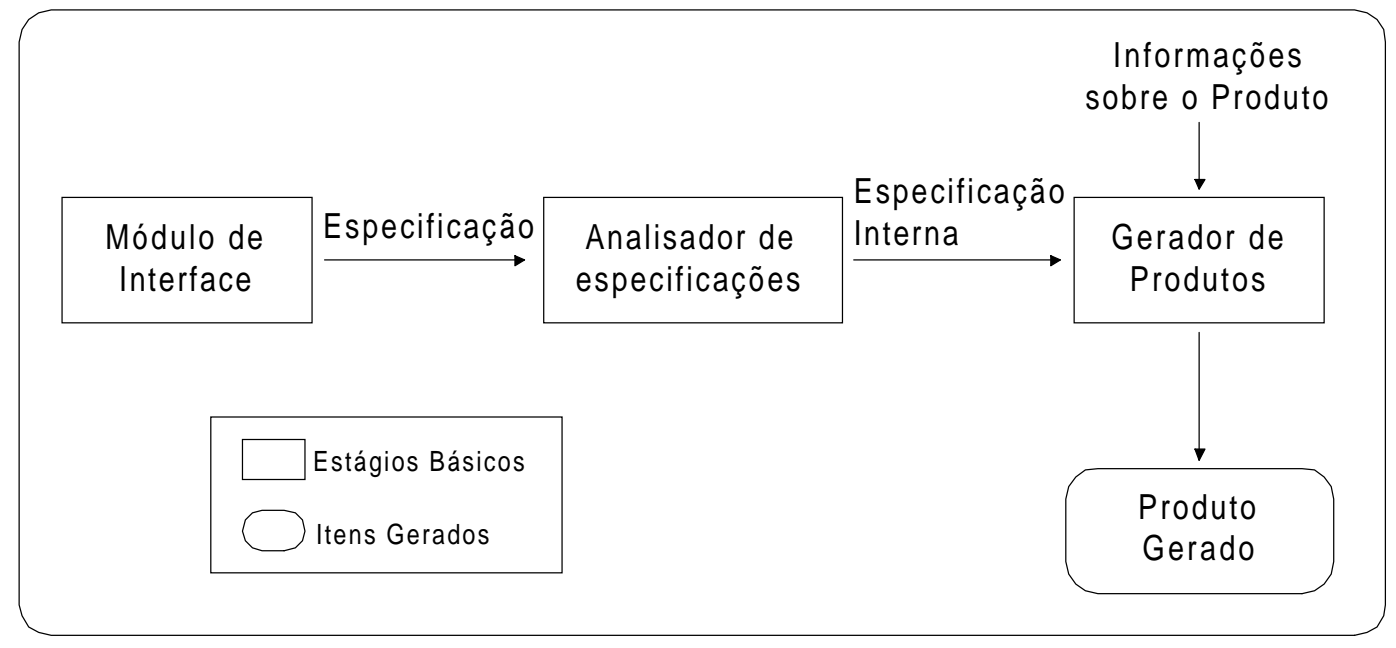

Figura 4.4. Estrutura de um Gerador de Aplicações

O módulo de interface com o usuário pode não aparecer explicitamente em todos os geradores e, nesse caso, a especificação de entrada é textual, podendo ser fornecida num arquivo preparado por algum editor de texto. Quando ele existe, torna mais amigável o uso do gerador, escondendo dificuldades da linguagem de especificação. 
O analisador de especificações é responsável pelas análises sintática e semântica das entradas e deve produzir como resultado estruturas de dados intermediárias, que são utilizadas pelo módulo seguinte.

O módulo gerador de produtos é responsável por gerar o produto desejado pelo usuário. Para isso, ele possui um conjunto de rotinas para acesso às estruturas de dados geradas pelo analisador de especificações e reconhece descrições de produtos em uma linguagem própria, que deve indicar as manipulações necessárias na estrutura de dados intermediária e o formato final do produto [SPO94, SPO94a].

O Gerador de Aplicações do ASiA é implementado através dos seguintes sub-módulos: Núcleo do Gerador, Ferramentas e Descrição de Produtos [SAN96].

\section{Sub-módulo Núcleo do Gerador}

Representa o núcleo do gerador de aplicação, possibilitando a geração dos principais comandos da extensão SMPL, responsáveis pelas atividades de preparação do modelo, definição e controle dos recursos, escalonamento e geração de eventos, geração de variáveis aleatórias, depuração do código, coleta de dados e emissão de relatório com estatísticas sobre a simulação [SPO94a].

\section{Sub-módulo Ferramentas}

É constituído por conjunto de ferramentas utilizadas pelos diversos módulos do sistema [SPO94a].

\section{Sub-módulo Descrição de Produtos}

Como o Gerador utiliza na produção dos programas de simulação as informações fornecidas pelo usuário, essas são estruturadas em tabelas. Através delas, o Gerador obtém todas as informações genéricas sobre o modelo e as particularidades de cada um dos recursos que o compõem, além de informações sobre o escalonamento de eventos e definições de ciclos.

A descrição de produtos é um tipo de gabarito, parecido com o produto final, onde trechos de código na linguagem alvo (SMPL) estão combinados com comandos que indicam ao Gerador como buscar as informações necessárias nas várias tabelas que serão utilizadas. Os trechos de código são copiados para o produto final, enquanto os comandos precedidos pelo caracter \% determinam que primitivas do Gerador devem ser executadas. Dependendo do identificador que sucede o caracter $\%$, um grupo de primitivas será considerada.

Todo o processo de geração do código é controlado por um procedimento especial que identifica os comandos no gabarito e decide qual primitiva do Gerador deve ser executada. Cada uma dessas primitivas é responsável por criar um trecho específico no código final, utilizando as informações contidas nas diversas tabelas [SPO94a].

O fluxo de dados no Gerador de Aplicações do ASiA pode ser observado na Figura 4.5. 


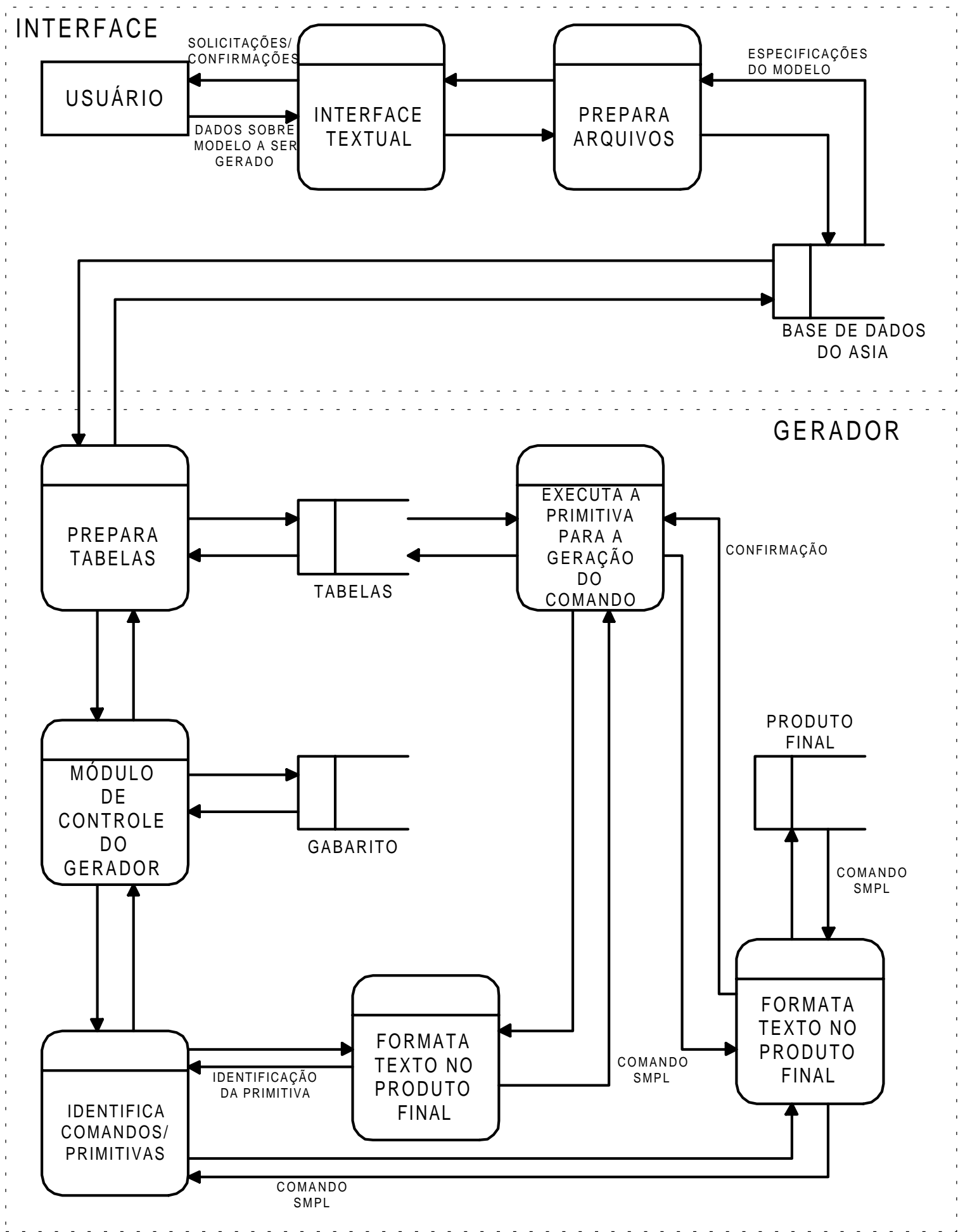

Figura 4.5. Fluxo de dados no Gerador de Aplicações

\subsubsection{ESTÁGIO DE SAÍDA}

O estágio de saída permite a visualização dos resultados obtidos através de gráficos. $\mathrm{O}$ usuário define (através de ícones, caixas de diálogo, etc) que tipo de gráfico deve ser considerado (barras, pontos, linha, etc), qual informação deve ser plotada em cada eixo, a escala a ser utilizada, etc [PED96]. Este estágio irá oferecer também um conjunto de ferramentas para a 
análise e validação [OLI96] (trabalho em desenvolvimento), já que os resultados de uma simulação baseiam-se em um conjunto de números aleatórios, o que torna importante o controle da precisão dos resultados obtidos [MAC87]. Como visto no capítulo 3, uma série de testes estatísticos devem ser executados sobre os resultados para verificar se atingem a precisão desejada, envolvendo a utilização de métodos como batch means, replicação, etc [SPO94].

\subsection{CONSIDERAÇÕES FINAIS}

Os ambientes de simulação automáticos fornecem ao usuário um ambiente de fácil manipulação que pode ser utilizado tanto por programadores quanto por não programadores. $\mathrm{O}$ usuário pode interagir com o sistema graficamente. O sistema transforma automaticamente o modelo gráfico em um programa de simulação. Os resultados podem ser analisados através de gráficos ou animações.

Alguns sistemas para simulação são: QMG [RAC90], Q+ [FUN91], BONeS [SHA92], SIGMA [KEL94], ASSERTS [CCT94], ARENA [SWA95, BAN96].

Três módulos do Ambiente de Simulação Automático - ASiA, o Editor Gráfico (EdGraf), o Gerador de Aplicações e o Módulo de Saída, foram desenvolvidos no ICMSC-USP, sendo necessária a integração dos três módulos. 


\section{Modificações Introduzidas no ASiA}

\subsection{INTRODUÇÃO}

Os três módulos principais, Editor Gráfico, Gerados de Aplicações e Módulo Visual foram desenvolvidos através dos trabalhos de mestrado [SPO94], [SPO94a]e [PED96], respectivamente.

Melhorias nos módulos e a integração dos sistemas foram implementadas em trabalhos de iniciação científica ([PRI96, OGA97]).

A primeira versão integrada do ASiA (ASiA 1.1) [PRI96] foi desenvolvida utilizando-se a linguagem $\mathrm{C}++$, com o compilador Borland $\mathrm{C}++4.02$ para o ambiente Microsoft Windows 3.11. O ASiA 1.1 utilizava as versões originais do EdGraf, desenvolvido utilizando a linguagem C, com o compilador Borland C++ 3.1 em ambiente Microsoft Windows [SPO94], do Gerador de Aplicações, desenvolvido utilizando a linguagem $\mathrm{C}$, com o compilador Borland $\mathrm{C}++3.1 \mathrm{em}$ ambiente DOS [SPO94a] e do Módulo Visual, desenvolvido utilizando-se a linguagem C++, com o compilador C++ 4.02 em ambiente Microsoft Windows 3.11 [PED96].

Um ponto importante em um sistema como o ASiA é manter a interface com o usuário fácil de ser utilizada e atual. Para tanto, necessita-se manter o sistema atualizado tanto em termos de sistema operacional básico quanto em termos de compilador utilizado. Para a inclusão de diversas características desejáveis no sistema, típicas da interface oferecida pelo Microsoft Windows 95 e que requerem códigos 32 bits, o Editor Gráfico e o Gerador de Aplicações foram remodelados pois as versões originais utilizavam códigos 16 bits, e uma nova integração foi efetuada (ASiA 1.2).

Este capítulo tem por objetivo descrever as principais alterações introduzidas pela autora, em conjunto com a bolsista de iniciação científica Célia Leiko Ogawa [OGA97], nos módulos Editor Gráfico e Gerador de Aplicações, e como foi feita a nova integração desses dois módulos, visando oferecer um ambiente adequado para o desenvolvimento de simulações em geral e em particular de simulações de arquiteturas de computadores, que é o enfoque desta dissertação.

\subsection{ALTERAÇÕES RELEVANTES}

Um primeiro passo na integração dos módulos Editor Gráfico e Gerador de Aplicações foi a migração dos códigos para que estes pudessem ser compilados utilizando o compilador Borland C++ 5.01 [BOR96]. Para que esta migração fosse possível, o Editor Gráfico foi 
"montado" em partes, sendo cada etapa devidamente testada para evitar incompatibilidade com o novo ambiente. Após esta fase, o módulo Gerador de Aplicações, já migrado, foi inserido no mesmo projeto que o Editor Gráfico.

A escolha do Borland $\mathrm{C}++5.01$ deve-se ao fato de que este compilador oferece vantagens em relação as outras plataformas, devido ao fato de que é um compilador para programas a serem executados no ambiente Windows95, e possui uma vasta biblioteca que torna os sistemas mais dinâmicos e mais fáceis de serem utilizados [PET96].

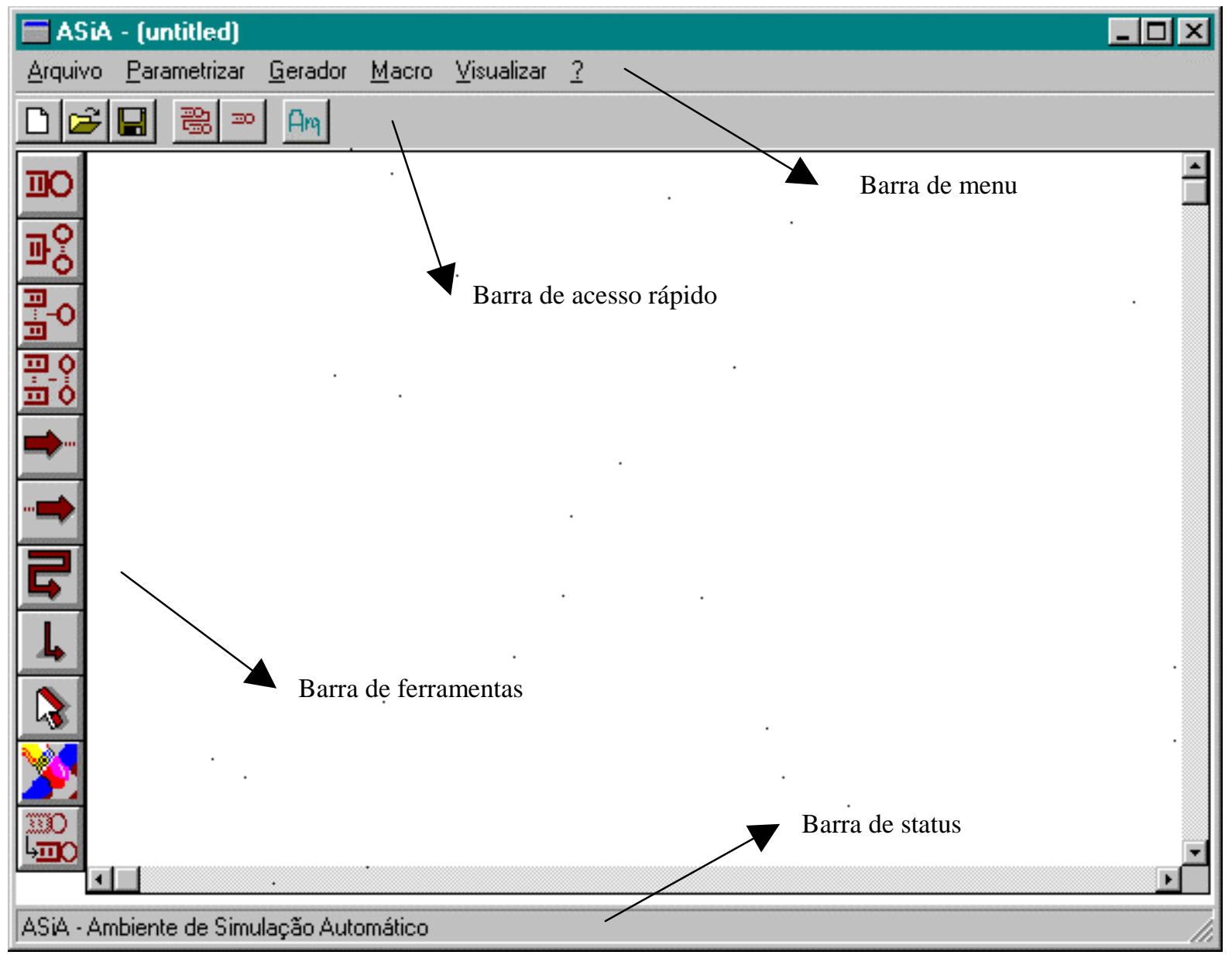

Figura 5.1. Tela principal do ASiA

Um problema encontrado nesta migração foi quanto às caixas de diálogo. Quando o programa era executado, nenhuma caixa de diálogo era aberta pelo sistema, inviabilizando qualquer interação com o usuário. Foram feitas várias tentativas de mantê-las no padrão anterior, o que não foi possível, sendo necessária a adequação ao novo ambiente.

Quando foi feita a migração para o compilador Borland C++ 5.01, várias alterações foram efetuadas com o objetivo de melhorar a interface com o usuário e também a utilização do sistema. As principais alterações estão relacionadas com: menu (alteração inserida no Editor Gráfico), caixas de diálogo (alteração inserida no Editor Gráfico), o modo de selecionar uma ligação e ramificação (alteração inserida no Editor Gráfico) e parametrização do recurso (alteração inserida no Editor Gráfico e também no Gerador de Aplicações), a serem detalhadas ainda neste capítulo. 
Nesta nova versão foram ainda introduzidas novas alterações, cuja implementação tornou-se viável devido as ferramentas oferecidas pelo Borland C++ 5.01, tais como: inclusão de uma barra de acesso rápido (ToolBar), uma barra de status (StatusBar) e em conjunto com estas duas barras, mensagens associadas a cada ação realizada pelo usuário (ToolTips).

A definição das alterações a serem introduzidas basearam-se em um estudo realizado pela bolsista de Iniciação Científica, Célia Leiko Ogawa [OGA96], onde o ASiA foi utilizado para o desenvolvimento de diversas aplicações e foi também comparado com o ARENA (ver seção 4.2).

O ARENA é um sistema de simulação comercial bastante utilizado e seus exemplos indicam que ele se destina principalmente à indústria de manufatura, sendo seu principal objetivo otimizar linhas de produção (ou processo de produção). A principal vantagem encontrada no ARENA foi a possibilidade de simulação com animação, que permite ao usuário visualizar o comportamento do sistema ao longo do tempo, diagnosticando possíveis problemas do sistema que está sendo simulado. Devido ao fato de ser um programa de grande porte, este necessita no mínimo $16 \mathrm{Mb}$ de memória RAM disponível para executar e pelo fato de haver animação, o aprendizado da construção de modelos é mais difícil [SYS95].

A Figura 4.3 mostra a tela principal do EdGraf original e a Figura 5.1 mostra a tela principal do ASiA 1.2. Comparando-se as telas pode-se observar que a migração do código para o compilador Borland $\mathrm{C}++5.01$ torna a interface com o usuário muito mais atrativa.

A seguir serão discutidas as principais alterações introduzidas no código do ASiA, visando torná-lo um sistema mais amigável.

\subsubsection{A Alteração do MenU}

Um ponto inicial a ser revisto é a estrutura do menu do EdGraf. Algumas características que faziam sentido na versão inicial, tornaram-se, após a integração, desnecessárias.

Um exemplo deste fato é a forma como era implementada a opção de se salvar um modelo. Como vários arquivos (.esp, .mod, .rec, .lig, .lop, .eve, .cpp) são gerados para a especificação de um modelo, no ASiA 1.1 o usuário podia optar em salvar cada arquivo individualmente. Analisando esta característica observou-se que seria mais interessante que a existência destes vários arquivos ficassem transparentes para o usuário.

Outras alterações no menu foram necessárias para tornar sua utilização mais amigável e para tornar a integação entre os diversos módulos do sistema mais natural.

Assim, a barra de menu do EdGraf que possuía a estrutura observada na Figura 5.2 passou a ter a estrutura observada na Figura 5.3

Comparando-se as duas estruturas observa-se que as seguintes alterações foram consideradas: 


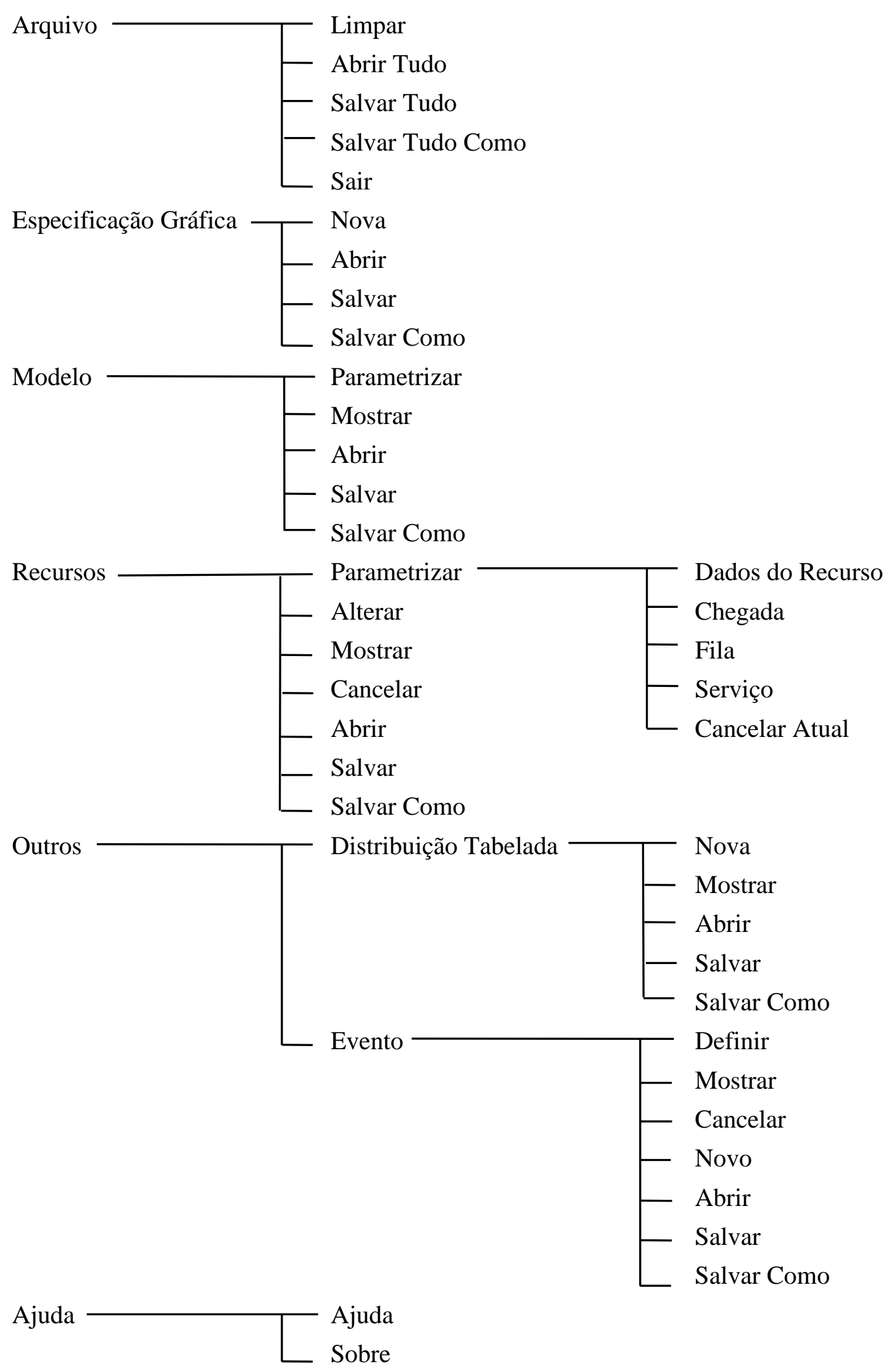

Figura 5.2. Estrutura do menu do EdGraf 


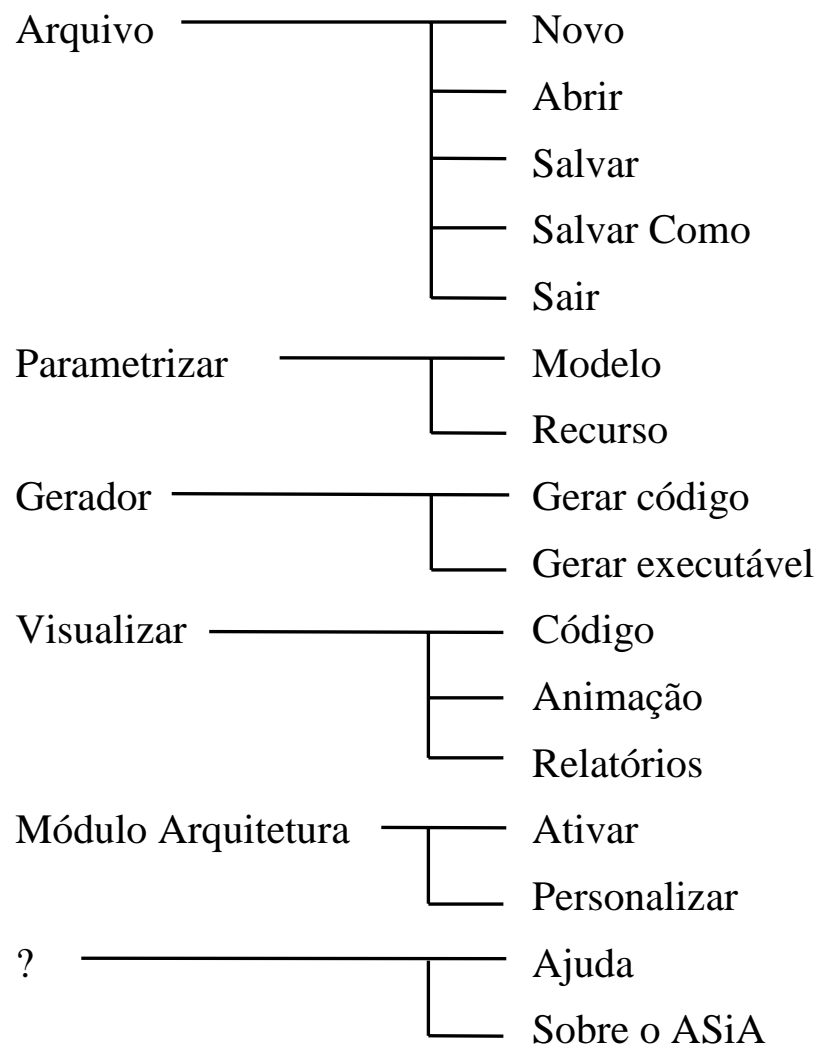

Figura 5.3. Estrutura do menu do ASiA 1.2

- As opções Abrir, Salvar e Salvar Como do menu Arquivo, respectivamente, abrem, salvam e salvam como todos os arquivos que são gerados na especificação de um modelo, com o mesmo nome dado à especificação gráfica. Isto elimina as opções Abrir, Salvar e Salvar Como dos menus Especificação Gráfica, Modelo, Recursos, Distribuição Tabelada e Eventos;

- Devido às alterações citadas acima, criou-se um menu Parametrizar com as opções Modelo e Recurso e eliminaram-se os menus Modelo e Recursos;

- As parametrizações de Chegada, Fila e Serviço foram inseridas como botões dentro da caixa de diálogo Recurso, o que aconteceu também com as opções Distribuição Tabelada e Eventos (a ser detalhado em 5.2.2);

- Devido ao fato do Gerador de Aplicações estar integrado no ambiente (a ser detalhado em 5.2.8), foi criado o menu Gerador, com as opções Gerar código e Gerar executável e também o menu Visualizar com as opções Código, Animação (não implementada) e Relatórios;

- O menu já possui a extensão para simulação de Arquiteturas de Computadores (a ser descrito no próximo capítulo) e este pode ser ativado pela opção Ativar do menu Módulo Arquitetura. 


\subsubsection{AlteraÇão das Caixas de Diálogo}

As caixas de diálogo foram modificadas com o objetivo de facilitar a parametrização dos recursos pelo usuário.

Para parametrizar um recurso o usuário precisava selecionar o recurso e fazer chamadas a quatro caixas de diálogo através do menu. Uma única caixa de diálogo integrando toda a parametrização foi criada. Deste modo as caixas de diálogo Recurso, Chegada, Fila, Serviço e Eventos foram unificadas em uma caixa de diálogo Recurso que possui botões que fazem chamadas para as outras caixas de diálogo, como pode ser observado na Figura 5.4.

Acionando-se o botão Chegada, obtém-se a caixa de diálogo para definir os parâmetros da chegada dos clientes no sistema, conforme pode ser observado na Figura 5.5. O botão Fila disponibiliza uma caixa (Figura 5.6) que permite a parametrização dos dados referentes ao sistema de filas e o botão Serviço uma caixa (Figura 5.7) para definir os parâmetros referentes ao serviço do servidor. O botão Eventos disponibiliza uma caixa (Figura 5.8) para entrada de valores de tempo. Para os valores de tempo definidos em cada recurso, será gerado no código fonte uma chegada de um cliente no sistema naquele tempo. Esta opção é utilizada em modelos de sistemas fechados.

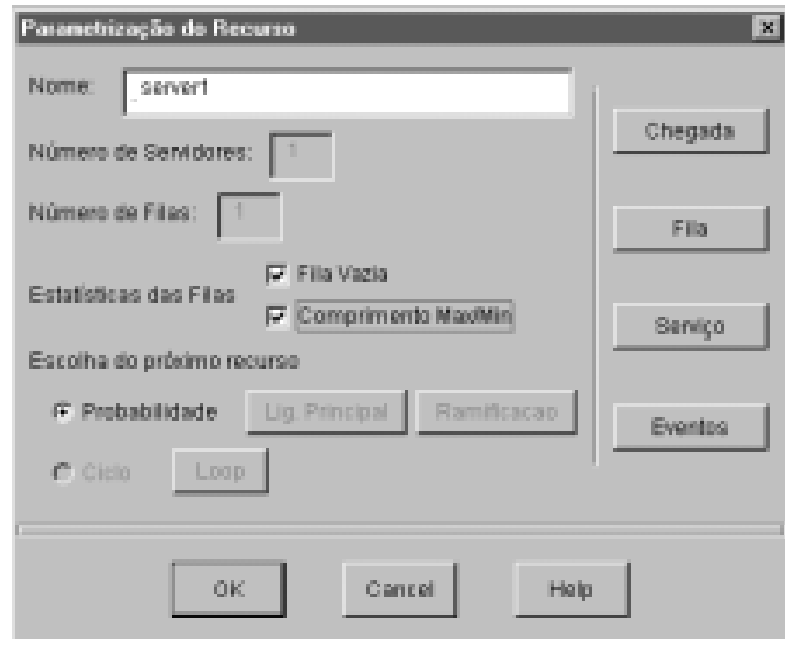

Figura 5.4. Nova caixa de diálogo Recurso

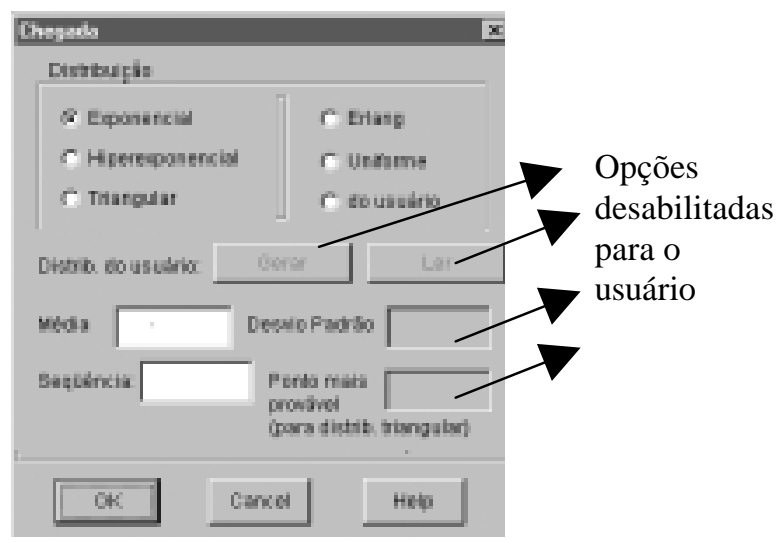

Figura 5.5. Caixa de diálogo Chegada 


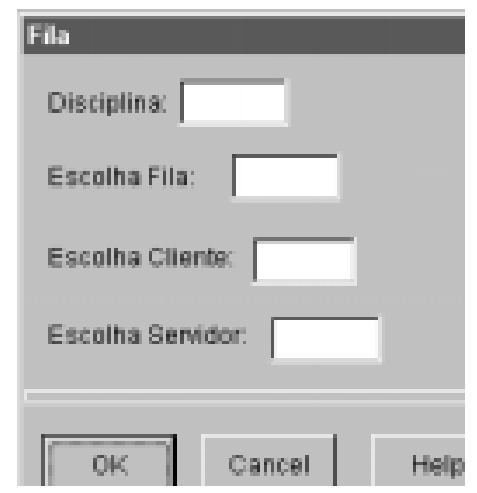

Figura 5.6. Caixa de diálogo Fila

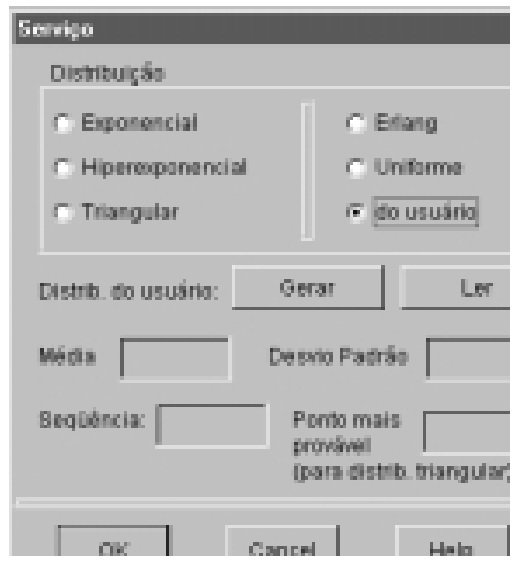

Figura 5.7. Caixa de diálogo Serviço

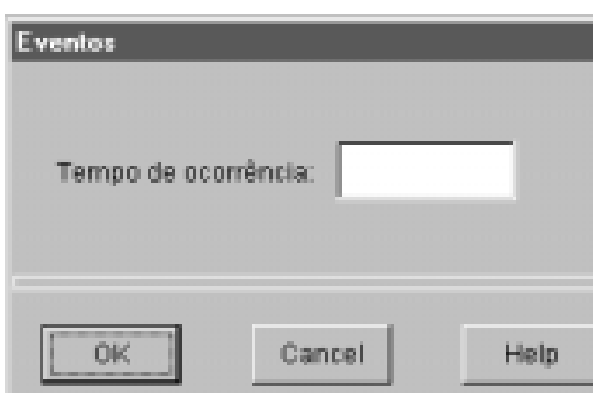

Figura 5.8. Caixa de diálogo Eventos

Além dessas alterações, as caixas de diálogo foram aprimoradas no sentido de não permitir ao usuário fornecer dados desnecessários. Como exemplo, na caixa de diálogo Chegada (Figura 5.5), o usuário não consegue fornecer o dado desvio padrão quando é selecionada a distribuição exponencial, pois uma distribuição exponencial possui desvio padrão igual à média.+ Com esta alteração o usuário comete menos erros e torna a parametrização mais rápida.

Pode-se observar na Figura 5.7 que, quando o usuário seleciona a opção distribuição do usuário, os botões Gerar e Ler tornam-se habilitados. O usuário tem então a opção de fornecer 
os próprios dados para a geração da distribuição de probabilidade ou ler algum arquivo de distribuição já fornecido. Na versão original do EdGraf, para utilizar uma distribuição do usuário, era necessário gerar a distribuição (selecionando uma opção do menu) e associá-la a um número, o qual deveria ser fornecido na antiga caixa de diálogo Serviço. Com esta alteração, o usuário não precisa mais memorizar qual o número da distribuição que deseja utilizar, pois seleciona direto o arquivo a ser utilizado.

\subsubsection{SELECIONANDO UMA LIGAÇão}

Para inserir uma ramificação o usuário tem que pressionar com o mouse sobre uma ligação e sobre o recurso final. Na versão inicial do EdGraf, o usuário só poderia selecionar uma ligação se pressionasse o mouse sobre uma certa parte da ligação. Isto era válido também para o caso do usuário desejar apagar uma ligação.

No sentido de facilitar a seleção da ligação, estas são agora desenhadas com uma linha mais grossa e também é permitido que a seleção de uma ligação seja feita em qualquer parte. A Figura 5.9. ilustra esta nova característica.

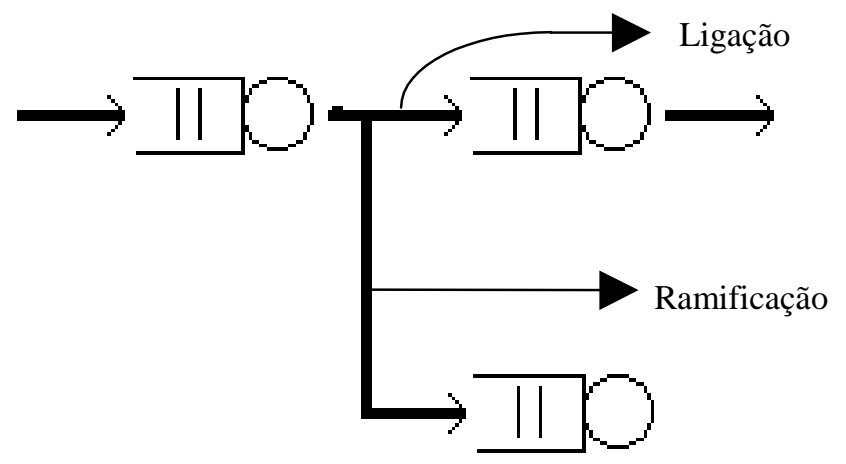

Figura 5.9. Exemplo de uma ligação e ramificação

\subsubsection{Parametrização das Ramificações}

Quando um recurso possui uma ligação e uma ou mais ramificações, é necessário que seja fornecido qual a probabilidade do cliente ir para um recurso ou para o outro. Esta informação é fornecida através de probabilidades e no EdGraf original as porcentagens só poderiam ser números múltiplos de 10. Com a alteração, as porcentagens pode ser um número real, com duas casas decimais de precisão.

Para manter a consistência da parametrização quando um recurso possui ligação e ramificações, a porcentagem da última ramificação é fornecida pelo sistema, não permitindo qualquer alteração pois a soma das porcentagens tem que ser 100.

\subsubsection{EXIBIÇÃO DOS DADOS QUANDO O RECURSO/MODELO JÁ FOI PARAMETRIZADO}

Ao selecionar um recurso para parametrizar, se este ainda não foi parametrizado todos os campos são mostrados em branco ao usuário, para que este preencha os dados corretos. Caso o 
recurso já tenha sido parametrizado, então os dados são lidos da lista e mostrados ao usuário para qualquer alteração ou para uma simples verificação.

O mesmo ocorre quando da parametrização do modelo.

\subsubsection{DUPLO PRESSIONAMENTO DO BOTÃO ESQUERDO DO MOUSE}

Além do tratamento do pressionamento dos botões esquerdo e direito do mouse, o Windows permite que seja interpretado também o duplo pressionamento do botão esquerdo. Aproveitando esta característica, o duplo pressionamento do mouse foi inserido em duas situações dentro do ASiA.

$\mathrm{Na}$ versão anterior, quando um usuário selecionava um ícone da barra de ferramentas, este ficava ativo até que um outro ícone fosse selecionado. Nesta nova versão, se o usuário pressiona o botão esquerdo do mouse uma única vez sobre um ícone da barra de ferramentas este fica ativo somente até o momento em que o usuário realiza a ação. Realizada a ação, o ícone volta ao normal. Se o usuário desejar que o ícone continue selecionado mesmo após realizada a ação, basta pressionar duas vezes seguidas o botão esquerdo do mouse sobre o ícone desejado.

A outra situação em que o duplo pressionamento do botão esquerdo do mouse foi utilizado foi na parametrização do recurso. A parametrização do recurso pode ser feita de duas maneiras. Uma primeira é selecionando o recurso e a opção Recurso do menu Parametrizar. A outra é pressionando duas vezes o botão esquerdo do mouse sobre o recurso desejado.

Estas características tornam a definição de um modelo no ASiA mais rápida e amigável.

\subsubsection{RóTULOS NOS RECURSOS DO MODELO}

Uma das alterações necessárias no ASiA era a apresentação dos rótulos (nomes) dos recursos para o usuário. Esta característica é apresentada na maioria dos simuladores e na nova versão do ASiA. Os recursos não possuem um rótulo até o momento em que são parametrizados. Assim que o recurso é parametrizado, o recurso passa a ter um rótulo e este passa a ser visível sem que o usuário precise entrar na caixa de diálogo Recurso para ver qual o recurso representado (Figura 5.10).

\subsubsection{MODIFICAÇÕES INTRODUZIDAS COM A INSERÇÃO DO GERADOR DE APLICAÇÕES}

Com a integração do Editor Gráfico e do Gerador de Aplicações, o usuário pode especificar o modelo e imediatamente gerar o código fonte correspondente. Devido à integração, o Gerador de Aplicações foi alterado no sentido de não ler os arquivos correspondentes ao modelo, já que os dados estão na memória.

Utilizando-se destes dados que estão na memória e de um arquivo de gabarito (Gabarito.dat), o código é gerado selecionando a opção Gerar o código do menu Gerador. Para gerar o código fonte é necessário antes salvar o modelo pois o gerador utiliza o nome do modelo definido pelo usuário para que possa ser gerado o arquivo de saída com os dados do relatório. 


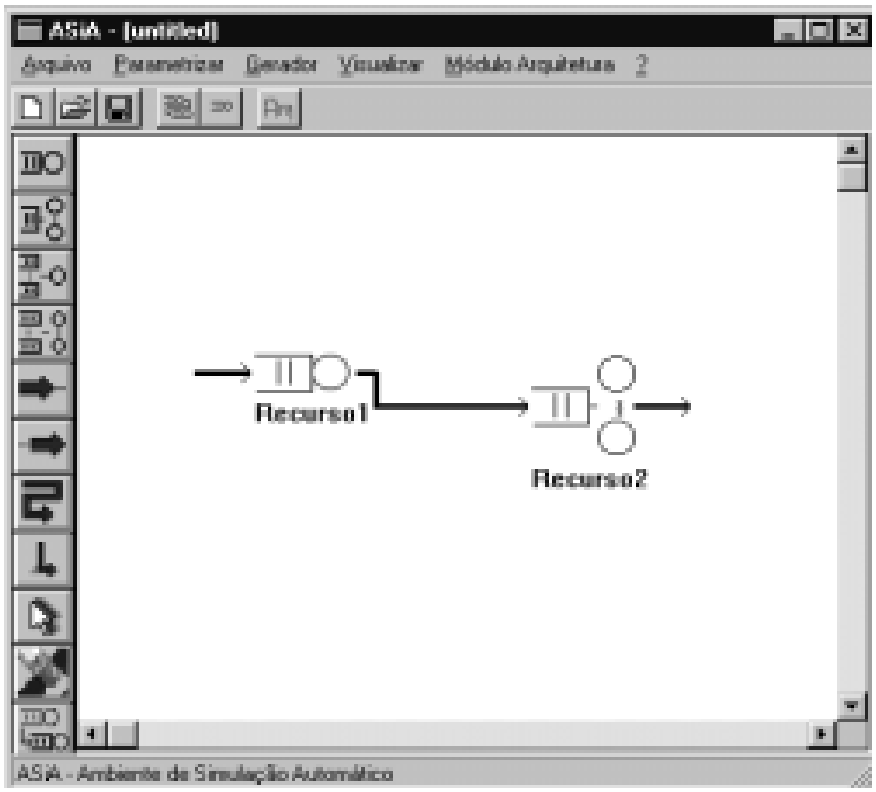

Figura 5.10. Recursos com rótulo

Gerado o código fonte, o usuário pode visualizá-lo, através da seleção da opção Código do menu Visualizar, ou então gerar o executável, o que é feito através da seleção da opção Gerar o executável do menu Gerador. A visualização é feita através de uma chamada ao aplicativo Bloco de Notas do Windows. É importante observar que o usuário poderá fazer qualquer alteração no código gerado pelo ASiA. Neste caso, a responsabilidade de manter o código correto é do usuário.

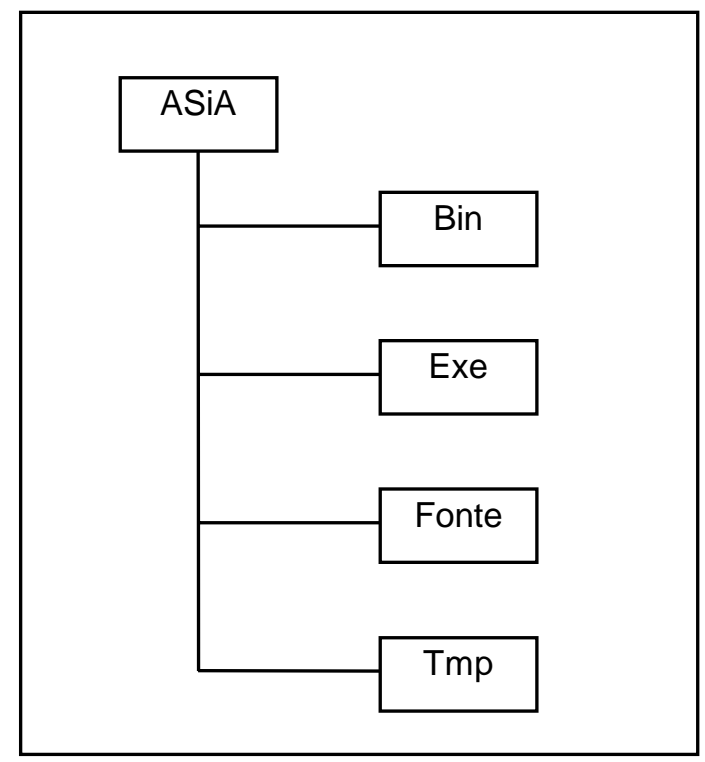

Figura 5.11. Estrutura de subdiretórios do ASiA

Para gerar o executável, foi necessário criar uma estrutura de subdiretórios que pode ser observada na Figura 5.11. Para que o código fonte possa ser compilado e linkado foi criado o subdiretório Tmp. O arquivo fonte (.cpp) é copiado para este subdiretório com o nome asia.cpp, onde se encontram também os arquivos smpl.c, rand.c, smpl.h, rand.h (da extensão SMPL) e 
asia.mak, necessários para que o arquivo seja compilado e linkado. Com o comando make fasia a sia, é gerado o arquivo asia.exe. Esse arquivo é então copiado para o subdiretório Exe com o nome original. Neste subdiretório o arquivo pode ser executado e é gerado o relatório o qual é armazenado em um arquivo com extensão .out. No subdiretório Bin, encontram-se os arquivos do projeto ASiA (ASiA.exe, Gabarito.dat e Dados.dat). No Fonte, encontram-se os arquivos gerados pelo sistema (.esp, .lig, .mod, .rec, .eve, .dis, .cpp).

Com o executável gerado, o arquivo de relatório pode então ser visualizado através da seleção da opção Relatório do menu Visualizar.

\subsection{UM EXEMPLO}

Para demonstrar o funcionamento do ASiA 1.2 é apresentada nesta seção um modelo que possui dois recursos com uma fila e um servidor e um outro recurso que possui uma fila e 2 servidores (Figura 5.12). Os recursos já estão parametrizados e possuem os rótulos Recurso1 (uma fila e um servidor), Recurso2 (uma fila e 2 servidores) e Recurso3 (uma fila e um servidor).

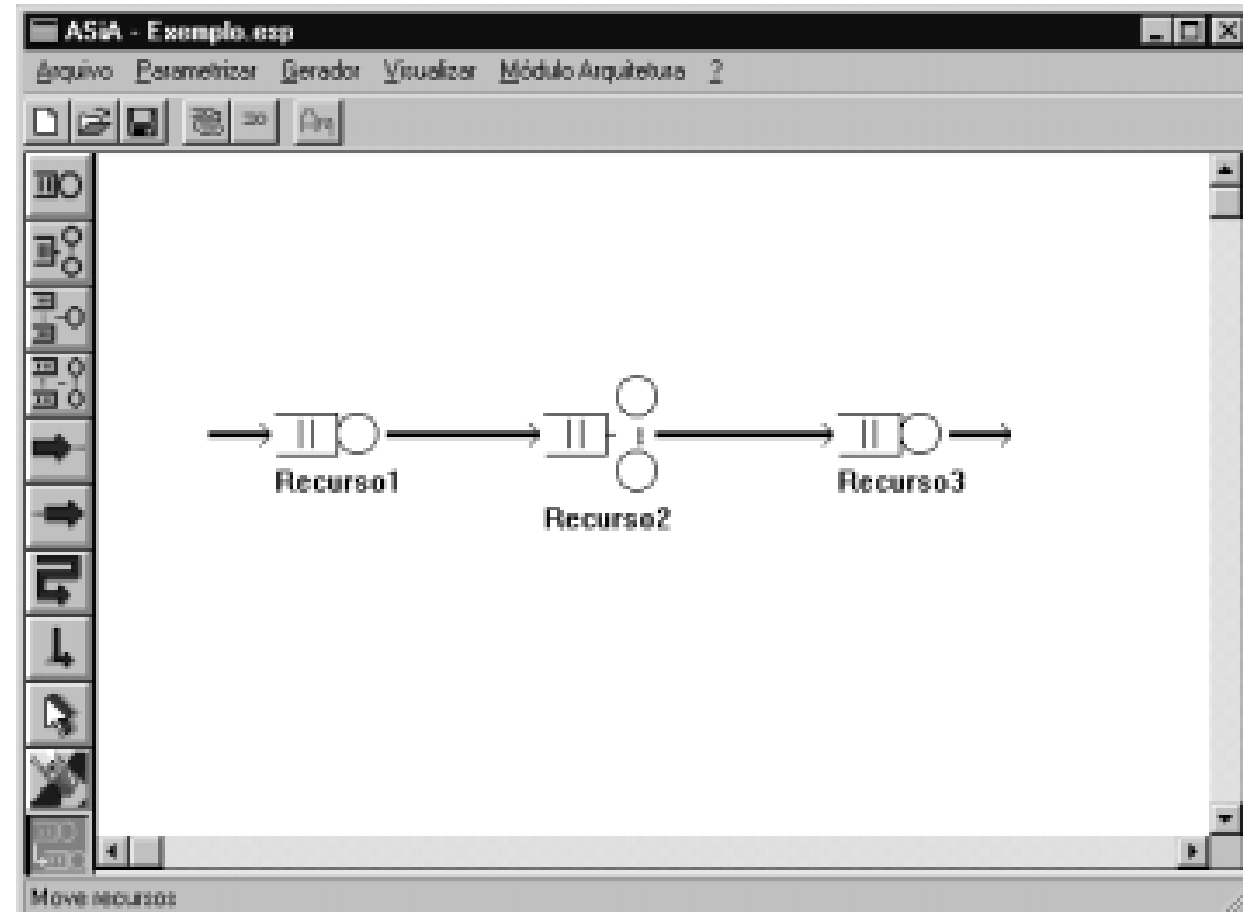

Figura 5.12. Tela do ASiA com um modelo já parametrizado

Os recursos estão parametrizados com os seguintes dados:

\section{Recurso1 e Recurso3:}

Chegada:

Distribuição de probabilidade: exponencial com média 10

Fila:

Disciplina: First come, first served 
Serviço:

Distribuição de probabilidade: exponencial com média 40

\section{Recurso2:}

Chegada:

Distribuição de probabilidade: exponencial com média: 70

Fila:

Disciplina: First come, first served

Escolha do servidor: o primeiro a ficar livre é servido

Serviço:

Distribuição de probabilidade: exponencial com média 100

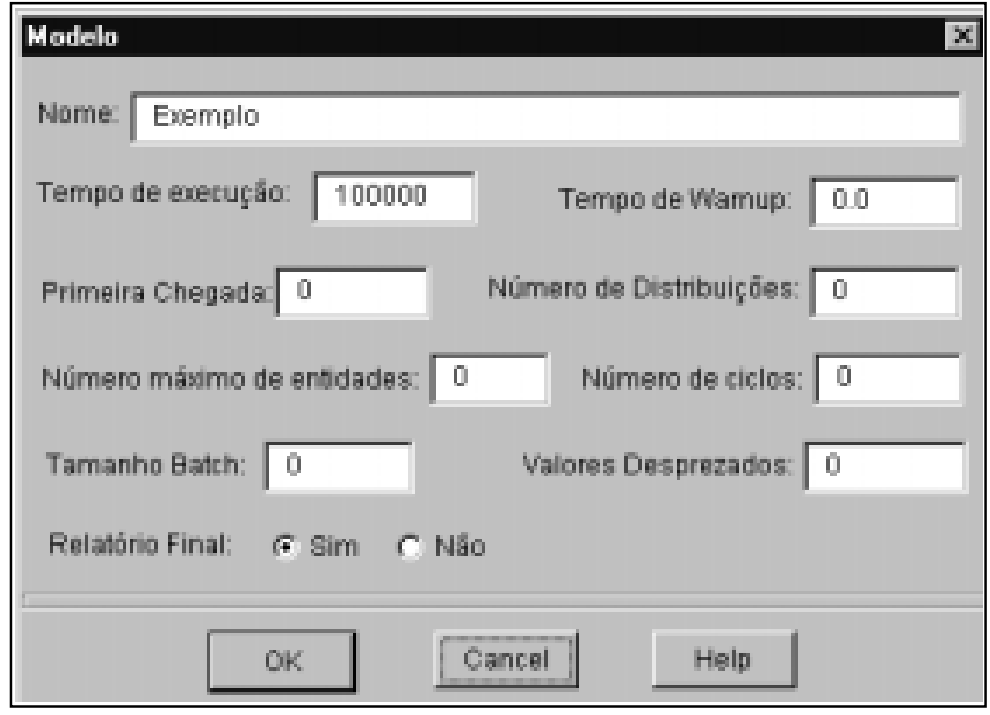

Figura 5.13. Tela de parametrização do modelo

Para gerar o código fonte, o usuário deve primeiramente parametrizar o modelo e os recursos. A figura 5.13 ilustra a tela de parametrização do modelo.

Após o modelo e os recursos estarem parametrizados, o usuário pode gerar o código fonte e, utilizando a opção Código do menu Visualizar, editar e se desejar modificá-lo. As Figuras 5.14 e 5.15 mostram exemplo da visualização do código fonte e do relatório gerado.

\subsection{CONSIDERAÇÕES FINAIS}

Para o desenvolvimento da extensão do ASiA para simulação de arquiteturas de computadores houve a necessidade da integração de dois módulos desenvolvidos em dois Mestrados: Editor Gráfico e Gerador de Aplicações.

Para realizar esta integração e também para tornar o ambiente mais amigável, com maiores recursos, várias modificações foram inseridas nos códigos do Editor Gráfico e do Gerador de Aplicações. Dentre as modificações introduzidas, destaca-se a migração dos códigos 
originais para o compilador Borland $\mathrm{C}++5.01 \mathrm{em} 32$ bits, utilizando-se de toda a potencialidade do ambiente Windows 95.

Além da migração, houve modificações no menu do Editor Gráfico e nas caixas de diálogo, no modo de selecionar uma ligação e ramificação e também alterações na parametrização do recurso. Destaca-se também a introdução da possibilidade de o usuário visualizar o código gerado e o relatório dentro do mesmo ambiente.

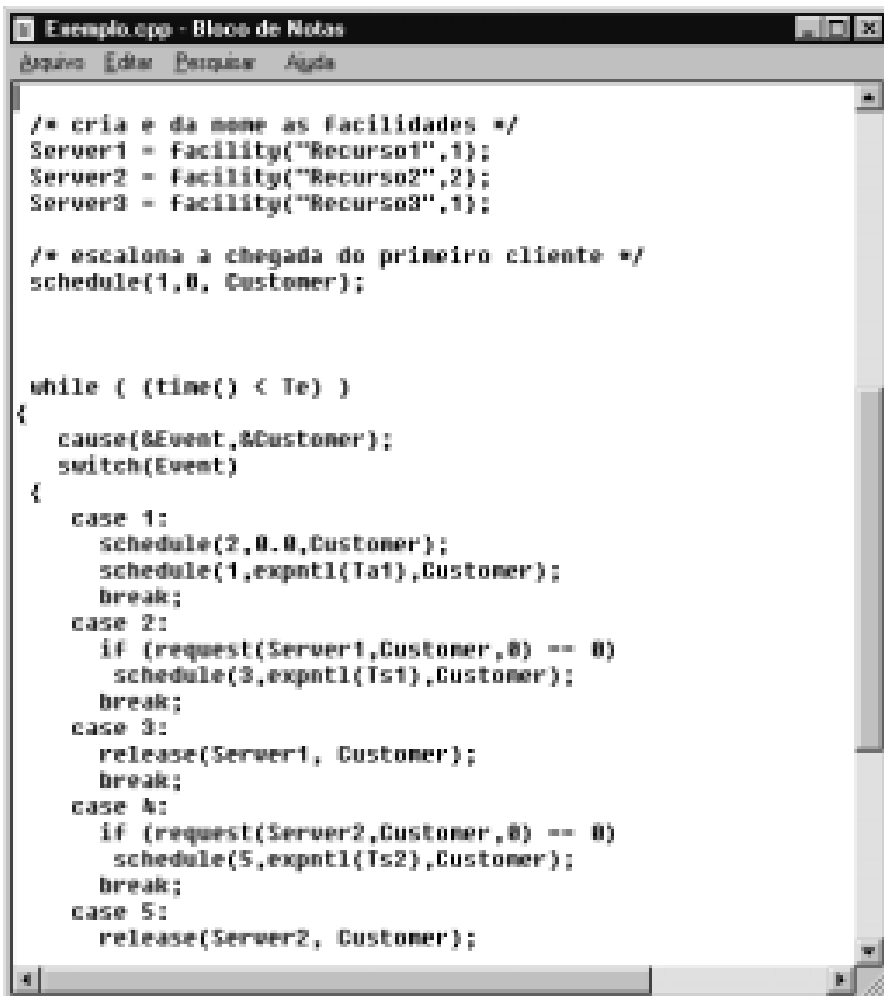

Figura 5.14. Tela de visualização do código gerado

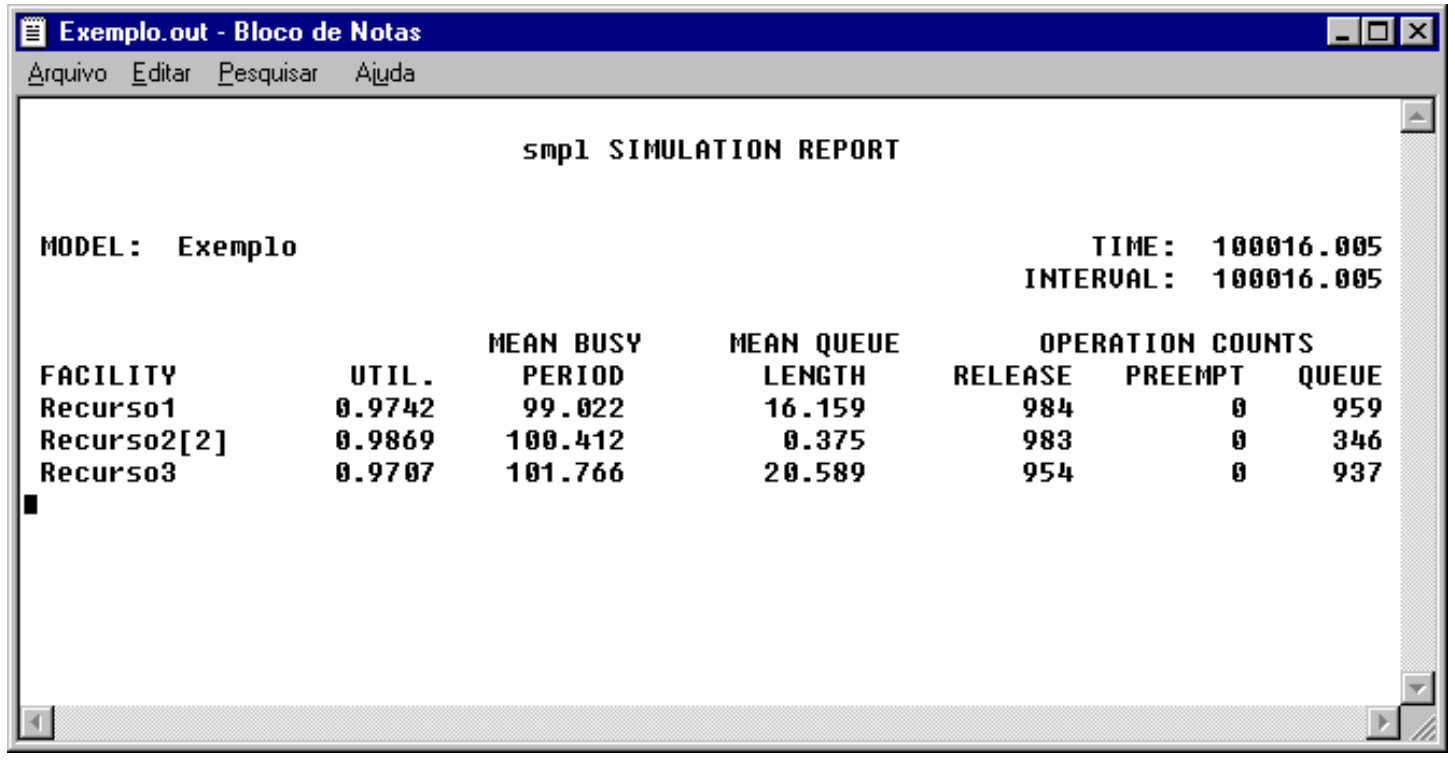

Figura 5.15. Relatório gerado com a execução do exemplo 


\section{Extensão do ASiA para Simulação de Arquiteturas de Computadores}

\subsection{INTRODUÇÃO}

Todas as modificações introduzidas no ASiA, detalhadas no capítulo anterior, tiveram como objetivo preparar o ambiente para que este pudesse receber extensões funcionais, com o intuito de facilitar a simulação de diferentes tipos de sistemas computacionais. Este capítulo discute a implementação e utilização de um módulo para a simulação de arquiteturas de computadores.

Esse módulo, denominado Módulo Arquitetura, tem como objetivo facilitar a construção de modelos que representem arquiteturas de computadores visando validação e avaliação de desempenho das arquiteturas através da simulação. Esse módulo poderá ser utilizado como uma ferramenta de auxílio no ensino de arquitetura de computadores.

A extensão desenvolvida permite que o usuário defina diferentes tipos de arquiteturas, utilizando recursos básicos, tais como: processadores, disco, memória, etc. Além disso, a extensão oferece quatro tipos de arquitetura, cujos modelos já estão definidos: arquitetura de von Neumann, arquitetura de von Neumann com pipeline, arquitetura MIMD com memória compartilhada e arquitetura MIMD com memória distribuída.

A parametrização das arquiteturas já definidas poderá ser modificada, com o intuito de se determinar a influência de diferentes elementos no desempenho de cada arquitetura. Um segundo objetivo das arquiteturas já definidas é servir de base para a elaboração de modelos mais complexos.

\subsection{VISÃO GERAL DA EXTENSÃO}

O Módulo Arquitetura pode ser ativado através da tela principal do ASiA, utilizando-se a opção Ativar do menu Módulo Arquitetura ou o ícone Arq da barra de acesso rápido (Figura 6.1)

O Módulo Arquitetura foi implementado mantendo-se as ferramentas utilizadas para o ASiA. Desta forma, o módulo foi desenvolvido em C, utilizando-se o compilador Borland C++ 5.01 e o ambiente Windows95. 


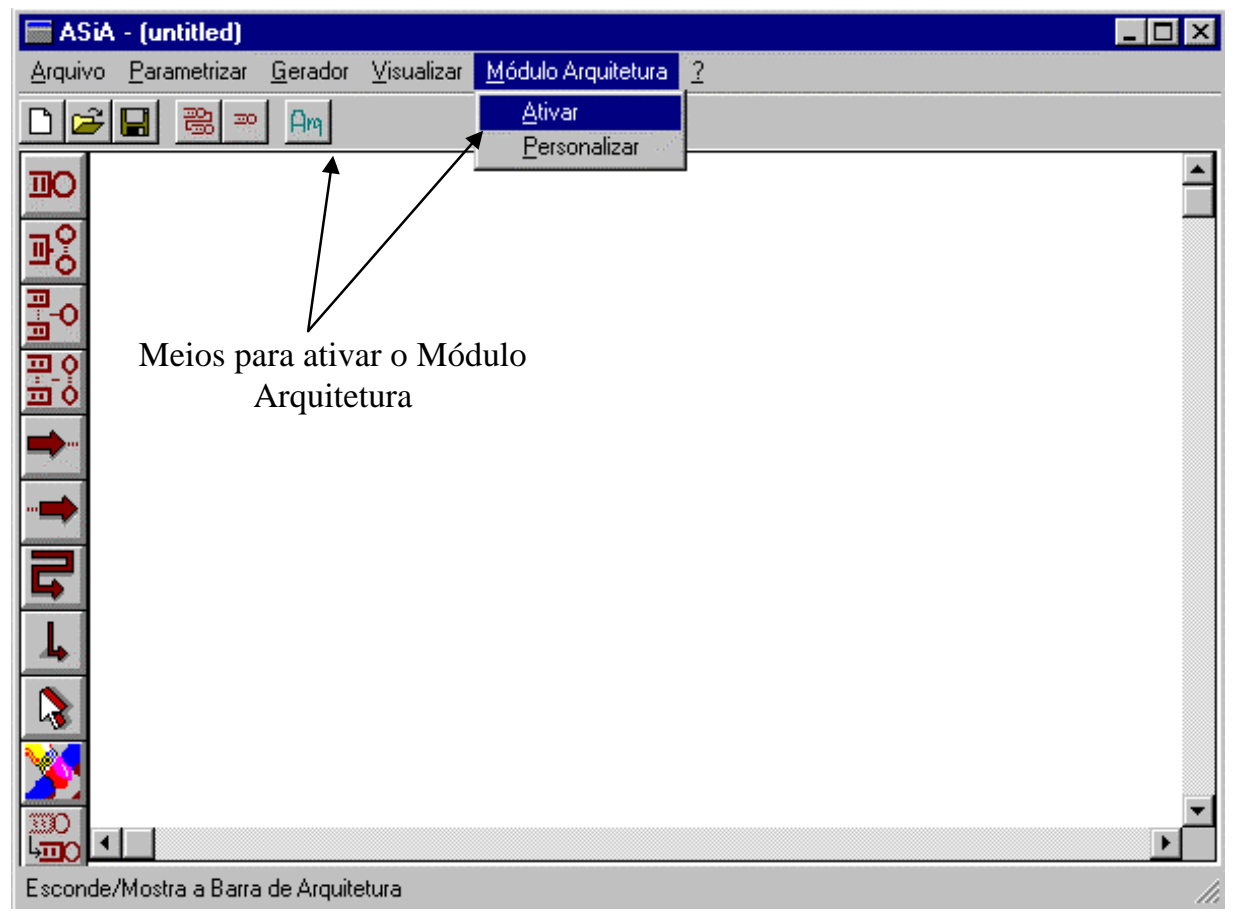

Figura 6.1. Ativando o Módulo Arquitetura

A Figura 6.2 apresenta uma visão geral da estrutura do Módulo Arquitetura. Uma vez ativado, torna-se disponível uma interface gráfica, através da seleção de uma abordagem a ser seguida, que permite a utilização do módulo.

O Módulo Arquitetura pode ser utilizado seguindo-se três abordagens, cuja escolha depende do objetivo do usuário:

1. Utilização de uma arquitetura definida;

2. Utilização de uma arquitetura definida alterando-se seus parâmetros ou configuração;

3. Definição de uma arquitetura nova.

As arquiteturas já definidas no Módulo Arquitetura contêm os respectivos código fonte e relatórios já elaborados. Portanto, para estes casos, o caminho seguido pelo usuário para obtenção dos dados consiste em simplesmente escolher a arquitetura e visualizar o código ou o relatório.

Para o caso em que se pretende utilizar uma das arquiteturas definidas como base para outros módulos, deve-se escolher a arquitetura base e passar para os passos onde serão efetuadas as modificações.

Se a modificação for na especificação gráfica, a nova configuração deve ser definida utilizando-se o editor gráfico e sua consistência deve ser verificada (bloco Verificação da 
especificação gráfica). Após esta etapa, se for o caso, pode-se alterar os parâmetros da arquitetura.

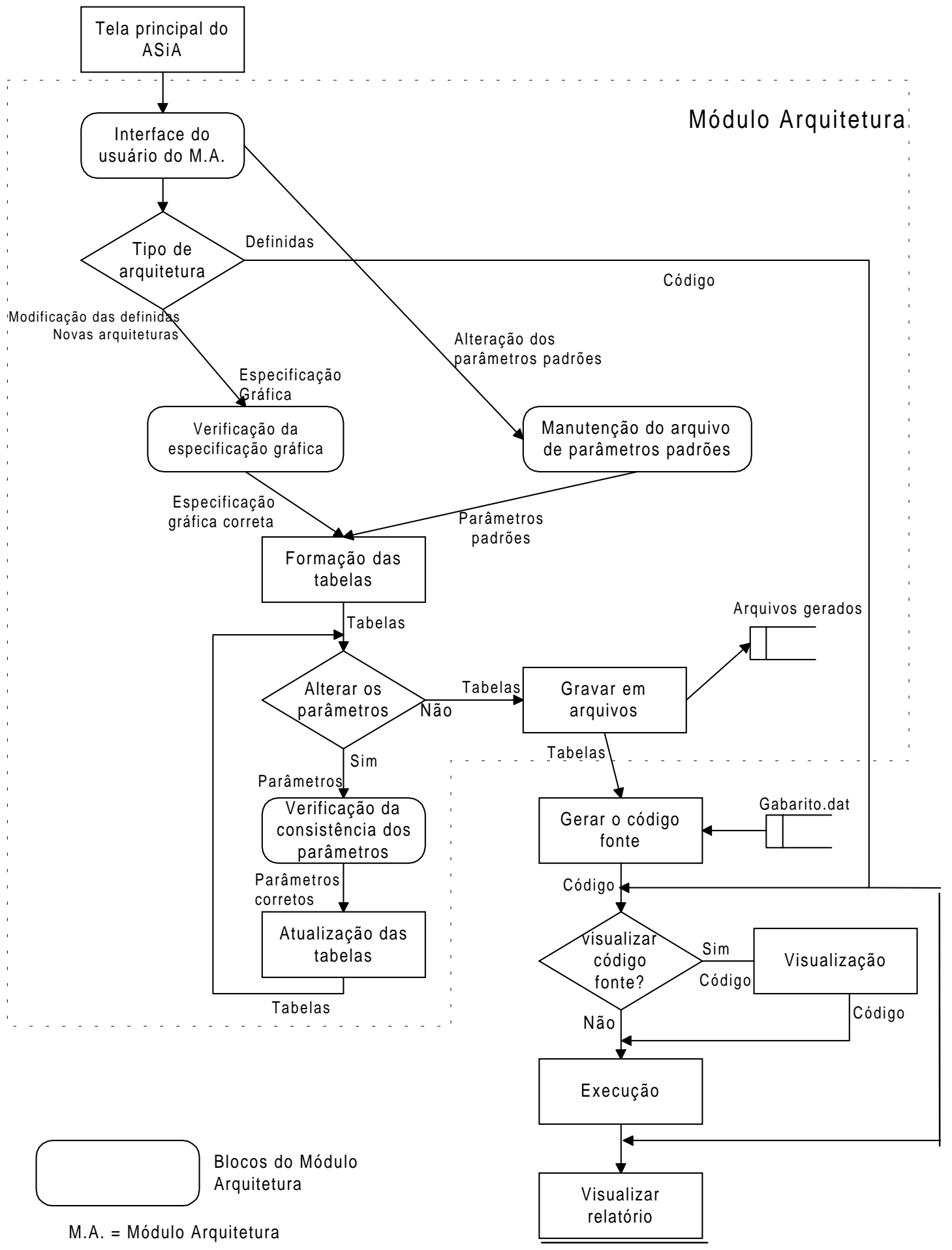

Figura 6.2. Visão geral da estrutura do Módulo Arquitetura

Baseando-se nestes novos valores, as tabelas referentes ao modelo são atualizadas, repetindo-se as modificações e atualização de tabelas até que o usuário obtenha a arquitetura 
desejada. A cada alteração dos parâmetros, a consistência do modelo é avaliada através do bloco Verificação da consistência dos parâmetros. Uma vez especificada a arquitetura, os dados são gravados em arquivos, o código fonte é gerado e segue-se os passos definidos no ASiA.

Para novas arquiteturas os passos a serem seguidos são os mesmos com a diferença de não se ter uma especificação inicial da arquitetura.

O bloco Manutenção do arquivo de parâmetros padrões contém parâmetros padrões para os blocos básicos: memória, disco, processador, etc. Esses parâmetros podem ser alterados pelo usuário, através da interface gráfica do Módulo Arquitetura.

Nas próximas seções será detalhado cada bloco que compõem o Módulo Arquitetura.

\subsubsection{INTERFACE DO USUÁRIO}

O bloco de Interface do usuário é responsável por toda a interface gráfica com o usuário, a qual torna-se acessível quando o Módulo Arquitetura é ativado.

Ao ativar o Módulo Arquitetura, é perguntado ao usuário se este deseja simular uma das arquiteturas já definidas ou definir uma nova arquitetura, como pode ser observado na Figura 6.3. Qualquer que seja a opção escolhida um novo ambiente é disponibilizado para o usuário, contendo ferramentas específicas para a simulação de arquiteturas de computadores, sendo que as principais alterações estão na barra de menu e barra de ferramentas.

\section{Alterações na barra de menu}

O barra de menu apresenta três alterações. No menu Parametrizar, devido ao fato da parametrização ser automática, foi inserida a opção Tudo. Esta opção estará ativa em duas situações:

- na definição de uma nova arquitetura;

- na alteração de um modelo e sua nova parametrização.

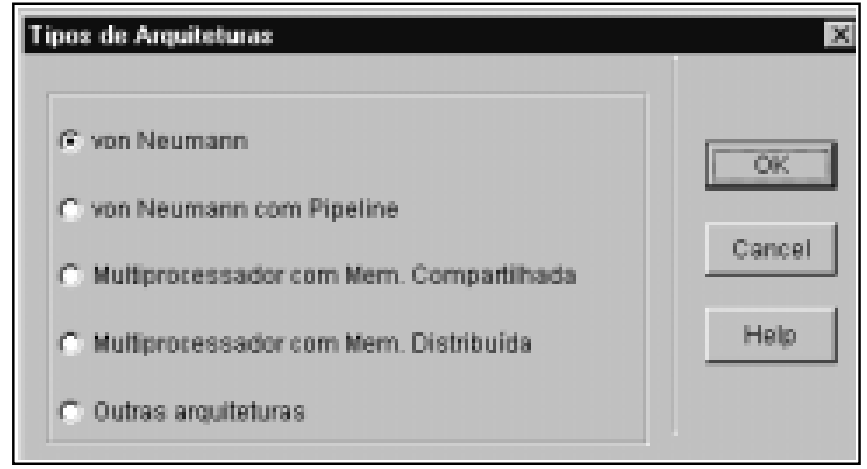

Figura 6.3. Tela de início do Módulo Arquitetura

Para ativar o Módulo Arquitetura, o usuário tinha duas opções (Figura 6.1). Para desativar o Módulo Arquitetura, o usuário continua tendo as mesmas duas opções, sendo que a opção Ativar do menu Módulo Arquitetura passa a ser Desativar. 
Como discutido anteriormente, os parâmetros padrões podem ser alterados. Para efetuar essa alteração, foi inserido a opção Parâmetros no menu Arquivo.

\section{Alterações na barra de ferramentas}

A barra de ferramentas disponível no Módulo Arquitetura pode ser observada na Figura 6.4. A nova barra é composta por 16 ícones que representam as primitivas de desenho, seleção e movimentação dos recursos. A seguir são apresentadas as funções de cada ícone

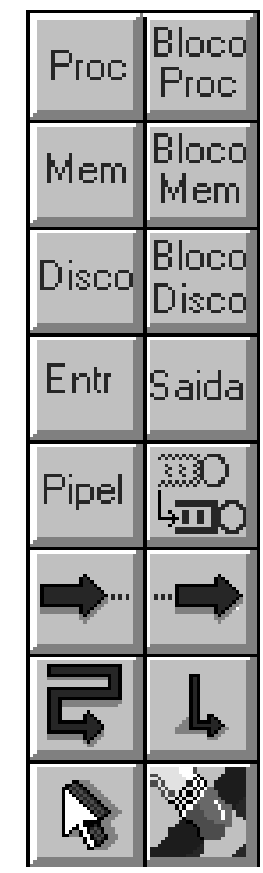

\subsection{Barra de ícones}

\section{Ícones 1, 2, 3, 4 e 12 Proc Mem Disco Entr Saida}

Os ícones 1, 2, 3, 4 e 12 representam processador, memória, disco, entrada e saída, respectivamente. Todos são centros de serviço constituídos por uma fila e um servidor, cada um deles com parâmetros padrões, conforme apresentado na seção 6.2.2.

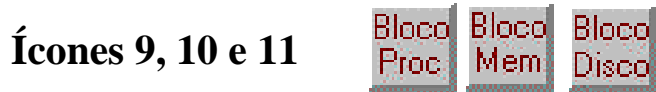

Os ícones 9, 10 e 11 representam, respectivamente, bloco de processador, bloco de memória e bloco de disco. O bloco é composto por mais de um centro de serviço cada um deles constituído por uma fila e um servidor.

O objetivo dos blocos é facilitar o desenho do modelo. Quando um destes 3 ícones é selecionado, é perguntado ao usuário o número de componentes do bloco. Caso este número seja maior que 3, é desenhado na tela somente o primeiro e o último componente do bloco e o número de centros de serviço é especificado no canto direito inferior do bloco.

Desta forma, a utilização dos ícones de blocos é equivalente a diversos acionamentos do respectivo ícone individual. A Figura 6.5 apresenta um exemplo de utilização dos ícones de 
bloco. Neste caso está sendo definido um bloco com 2 processadores e um outro bloco com 5 memórias.

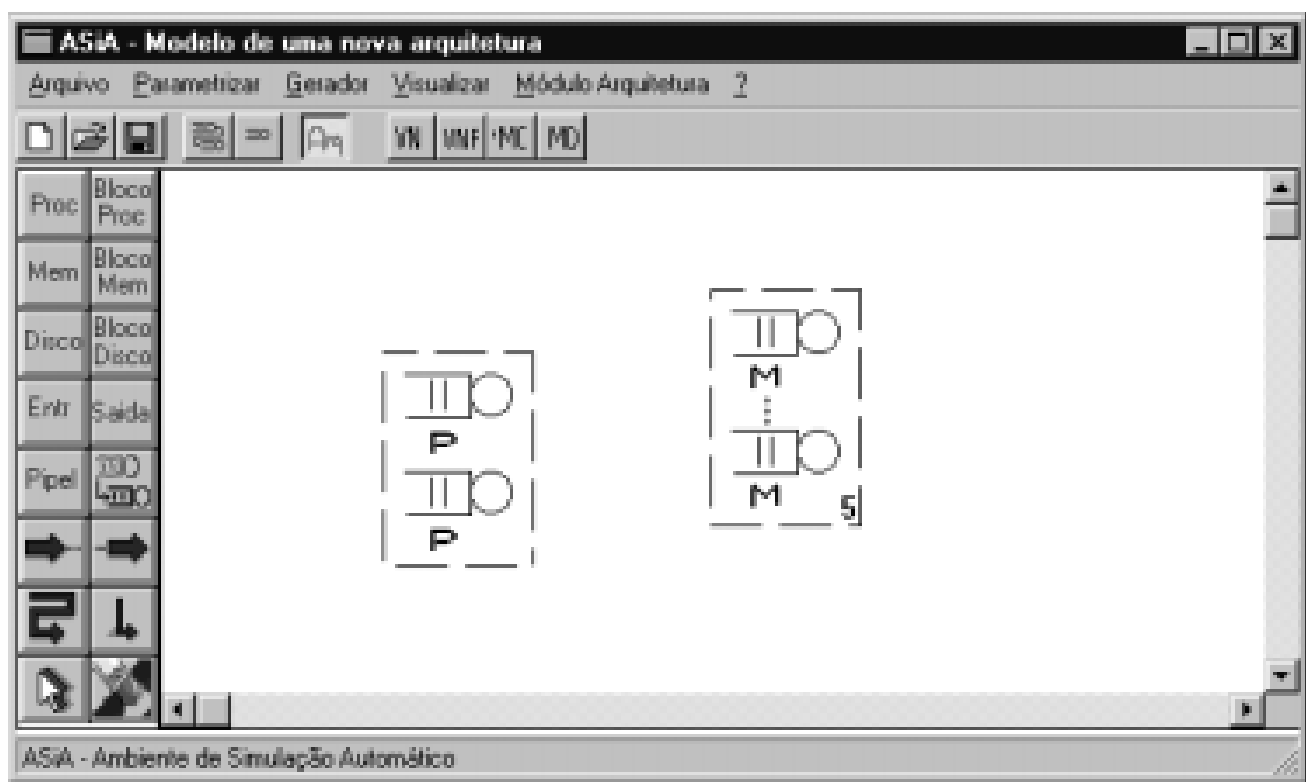

\section{Ícone 5 Pipel}

Figura 6.5. Inserção de blocos

O ícone 5 representa a inserção de pipeline. Cada componente do pipeline é um centro de serviço com uma fila e um servidor. Esta opção, além de inserir os centros de serviço, insere também as ligações entre eles. A saída do primeiro estágio está ligada com a entrada do segundo e assim sucessivamente (Figura 6.6).Quando este ícone é acionado, uma nova caixa é ativada para que o usuário defina o número de estágios do pipeline. Quando o número de estágios é maior que 3, somente o primeiro e o último estágios são desenhados.

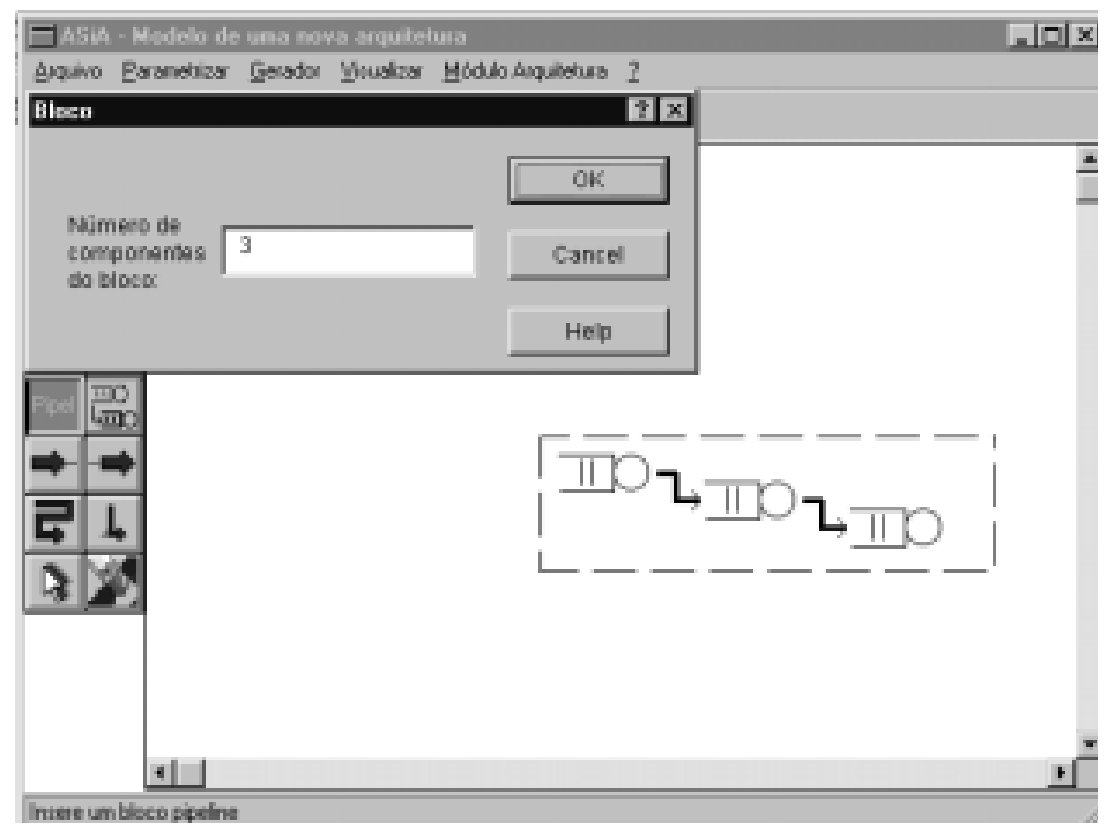

Figura 6.6. Desenho de um pipeline 


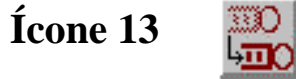

Este ícone é utilizado para movimentar os recursos. Esta opção foi introduzida por [OGA97].

\section{Ícones 6 e 14}

Os ícones 6 e 14 inserem a entrada e a(s) saída(s) do modelo.

\section{Ícones 7 e 15}

Os ícones 7 e 15 possibilitam estabelecer uma ligação entre dois recursos e ramificações das ligações, respectivamente.

Ícone 8

Este ícone é utilizado na seleção do recurso para parametrização.

\section{Ícone 16}

Este ícone permite apagar recursos, ligações e ramificações. Quando um centro de serviço é apagado, todas as ligações e ramificações que chegam ou partem dele também são apagadas.

Os ícones 6, 7, 8, 13, 14, 15 e 16 já faziam parte da barra de ícones do ASiA.

\subsubsection{MANUTENÇÃO DO ARQUIVO DE PARÂMETROS}

O bloco Manutenção de parâmetros padrões é responsável pelo gerenciamento dos parâmetros que são utilizados na parametrização automática. Esse bloco utiliza o arquivo dados.dat para armazenar os parâmetros. Existe um conjunto de parâmetros para cada tipo de recurso básico - processador, memória, disco, entrada e saída. A Tabela 2 mostra os parâmetros associados a cada um dos recursos básicos (o recurso Auxiliar será explicado na seção 6.4).

\begin{tabular}{|l|l|l|l|l|}
\hline & $\begin{array}{c}\text { Distribuição } \\
\text { Chegada }\end{array}$ & $\begin{array}{c}\text { Média } \\
\text { Chegada }\end{array}$ & $\begin{array}{c}\text { Distribuição } \\
\text { Serviço }\end{array}$ & $\begin{array}{c}\text { Média } \\
\text { Serviço }\end{array}$ \\
\hline Processador & Exponencial & $10 \mathrm{~m} \mathrm{seg}$ & Exponencial & $3 \mathrm{~m} \mathrm{seg}$ \\
\hline Memória & Exponencial & $10 \mathrm{~m} \mathrm{seg}$ & Exponencial & $6 \mathrm{~m} \mathrm{seg}$ \\
\hline Disco & Exponencial & $10 \mathrm{~m} \mathrm{seg}$ & Exponencial & $15 \mathrm{~m} \mathrm{seg}$ \\
\hline Entrada & Exponencial & $10 \mathrm{~m} \mathrm{seg}$ & Exponencial & $5 \mathrm{~m} \mathrm{seg}$ \\
\hline Saída & Exponencial & $10 \mathrm{~m} \mathrm{seg}$ & Exponencial & $5 \mathrm{~m} \mathrm{seg}$ \\
\hline Pipeline & Exponencial & $10 \mathrm{~m} \mathrm{seg}$ & Exponencial & $0.3 \mathrm{~m} \mathrm{seg*}$ \\
\hline Auxiliar & Exponencial & $0 \mathrm{~m} \mathrm{seg}$ & Exponencial & $0 \mathrm{~m} \mathrm{seg}$ \\
\hline
\end{tabular}

Tabela 2. Valores dos parâmetros padrões

\footnotetext{
* - Valor para cada estágio do pipeline
} 
Os parâmetros referentes a Fila, em todos os recursos básicos, são:

- disciplina de escalonamento: First Come, First Served (FCFS) sem prioridades ou preempção;

- seleção do servidor: o primeiro a ficar livre é servido.

O usuário tem a opção de mudar os parâmetros padrões através do menu principal do Módulo Arquitetura no menu Arquivo, opção Parâmetros.

\subsubsection{Consistência, Armazenamento e Manutenção}

Todas as informações fornecidas pelo usuário (especificação gráfica e parametrização do modelo e recursos) são constantemente verificadas em relação a consistência, do mesmo modo que é feito quando o Módulo Arquitetura não está ativo [SPO94]. Além desta verificação, uma outra é feita de modo a advertir o usuário que tenta definir uma arquitetura sem a presença de pelo menos um representante de cada um dos elementos do elenco de recursos básicos (processador, memória e disco).

Para realizar a parametrização automática, a lista de recursos do módulo arquitetura é percorrida e os recursos vão sendo parametrizados de acordo com o que eles representam. Deste modo, a consistência dos parâmetros dos recursos somente é verificada depois da parametrização automática na definição de uma nova arquitetura ou quando o usuário deseja alterar algum dado nas arquiteturas já definidas.

Quando é realizada alterações na definição do modelo e esse já foi parametrizado, toda a parametrização é cancelada de modo a manter a consistência.

Toda a especificação gráfica, os parâmetros do modelo, os relatórios gerados, distrituições, etc. devem ser armazenadas em arquivos. A relação a seguir lista a extensão de cada arquivo utilizado pelo Módulo Arquitetura e o tipo de informação que armazena.

$\begin{array}{ll}\text {.esp } & \text { especificação gráfica } \\ \text {.lig } & \text { ligações e ramificações } \\ \text {.mod } & \text { parâmetros do modelo } \\ \text {.rec } & \text { parâmetros dos recursos } \\ \text {.eve } & \text { definição de eventos } \\ \text {.dis } & \text { distribuições definidas pelo usuário } \\ \text {.arq } & \text { tipo (processador, memória, disco, entrada, saida, bloco de } \\ & \text { processador, bloco de memória, bloco de disco ou pipeline) de } \\ & \text { cada recurso } \\ \text {.cpp } & \text { código gerado } \\ \text {.exe } & \text { executável da simulação } \\ \text {.out } & \text { relatório }\end{array}$




\subsection{UTILIZANDO OS MODELOS DE ARQUITETURAS JÁ DEFINIDOS}

Baseando-se no estudo de arquiteturas realizado (capítulo 2), quatro tipos de arquiteturas foram escolhidos e modelados, utilizando teoria de redes de filas, para serem inseridos no sistema: arquitetura de von Neumann (arquitetura dos computadores pessoais), arquitetura de von Neumann com pipeline, arquitetura MIMD com memória compartilhada e arquitetura MIMD com memória distribuída. O motivo da escolha desses tipos foi por serem os mais utilizados, didáticos e interessantes para simulação.

Todos os modelos possuem recursos básicos que são: processador, memória, disco, entrada e saída. Esses recursos são centros de serviço com um servidor e uma fila, como pode ser observado nos modelos (Figuras 6.7, 6.8, 6.9 e 6.10).

A arquitetura de von Neumann é constituída basicamente de um processador, uma memória, um disco e dispositivos de entrada e saída. O modelo utilizado para representar essa arquitetura pode ser observado na Figura 6.7.

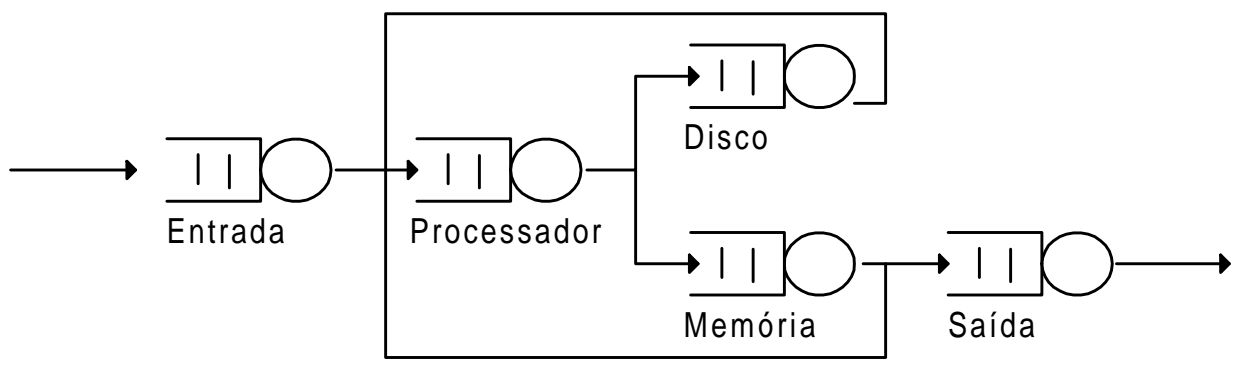

Figura 6.7. Modelo da arquitetura de von Neumann

Para melhorar o desempenho da arquitetura de von Neumann foi introduzido o conceito de pipeline de instruções (ver seção 2.3.4). A instrução é executada em 5 estágios: busca da instrução, decodificação, busca dos operandos, execução e armazenamento. Neste modelo, sai o processador e entra o pipeline de 5 estágios. $\mathrm{O}$ modelo utilizado para representar essa arquitetura pode ser observado na Figura 6.8.

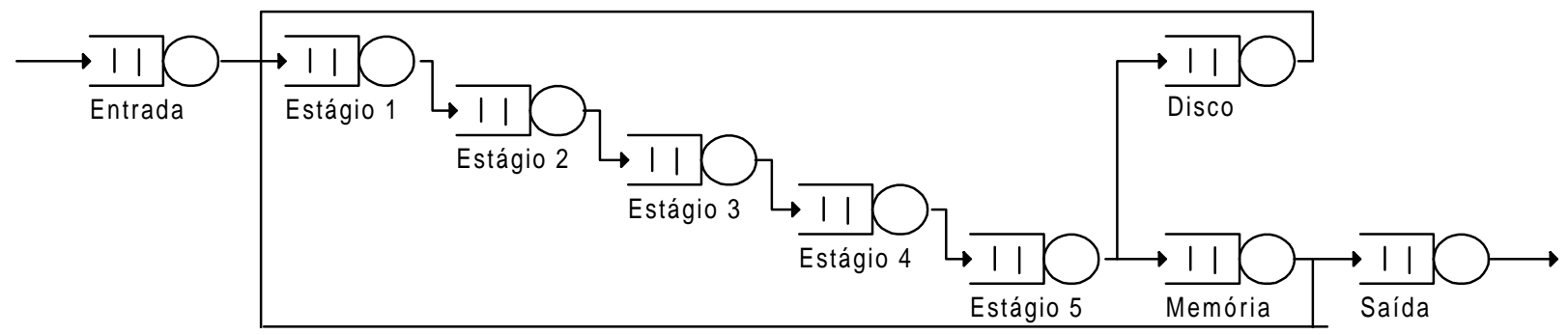

Figura 6.8. Modelo da arquitetura de von Neumann com pipeline 


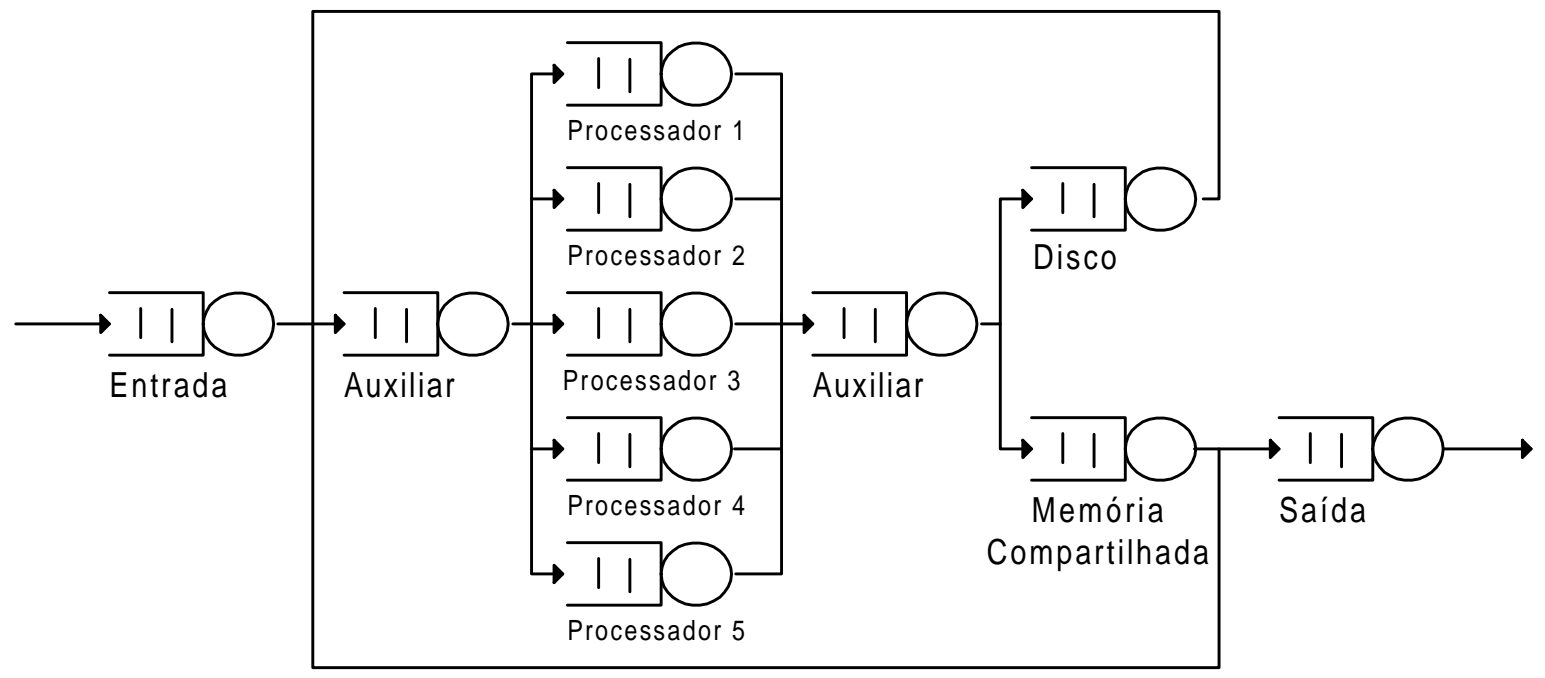

Figura 6.9. Modelo da arquitetura MIMD com memória compartilhada.

Outro modelo inserido no sistema foi a arquitetura MIMD com memória compartilhada. Este modelo possui um bloco de processadores que compartilham uma única memória. Para este modelo foi escolhido o número de 5 processadores, como pode ser observado na Figura 6.9.

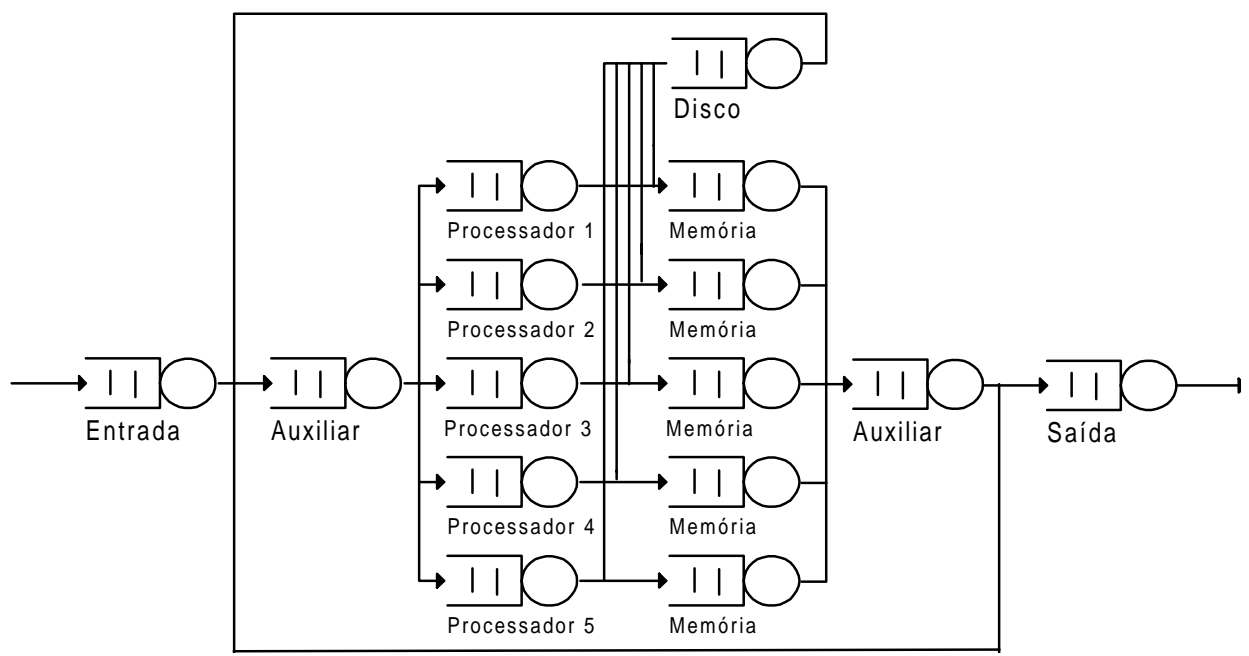

Figura 6.10. Modelo da arquitetura MIMD com memória distribuída

Para uma comparação com a arquitetura MIMD com memória compartilhada foi inserida no sistema a arquitetura MIMD com memória distribuída. Este modelo possui um bloco de processadores independentes, sendo que cada um possui uma memória local, como pode ser observado na Figura 6.10. Para este modelo foi escolhido o número de cinco processadores e cinco memórias.

Nota-se nos modelos das arquiteturas MIMD com memória compartilhada e memória distribuída a existência de um centro de serviço "Auxiliar". Esse recurso tem a finalidade de simplificar a especificação gráfica e será explicado na seção 6.4.

Para utilizar um desses modelos já definidos, o usuário deve selecionar uma dessas quatro arquiteturas quando o Módulo Arquitetura é ativado (Figura 6.3) ou então através de um dos quatro ícones na Barra de Acesso rápido. 
Ao selecionar uma das arquiteturas, é fornecido para o usuário a especificação gráfica e todos os recursos e o modelo já parametrizados. O código fonte, o executável e o relatório já estão gerados.

A tela do ASiA com o Módulo Arquitetura ativado pela seleção da opção Arquitetura de von Neumann pode ser observado na Figura 6.11.

A partir deste momento, o usuário está habilitado a visualizar o código fonte e o relatório ou realizar qualquer alteração que lhe for conveniente na arquitetura, como por exemplo, alterar algum parâmetro dos recursos ou do modelo. Caso seja realizada alguma alteração no modelo como uma inserção ou deleção de algum recurso, ligação ou ramificação, toda a parametrização dos recursos e do modelo são perdidas. O usuário passa então a ter a opção da parametrização automática.

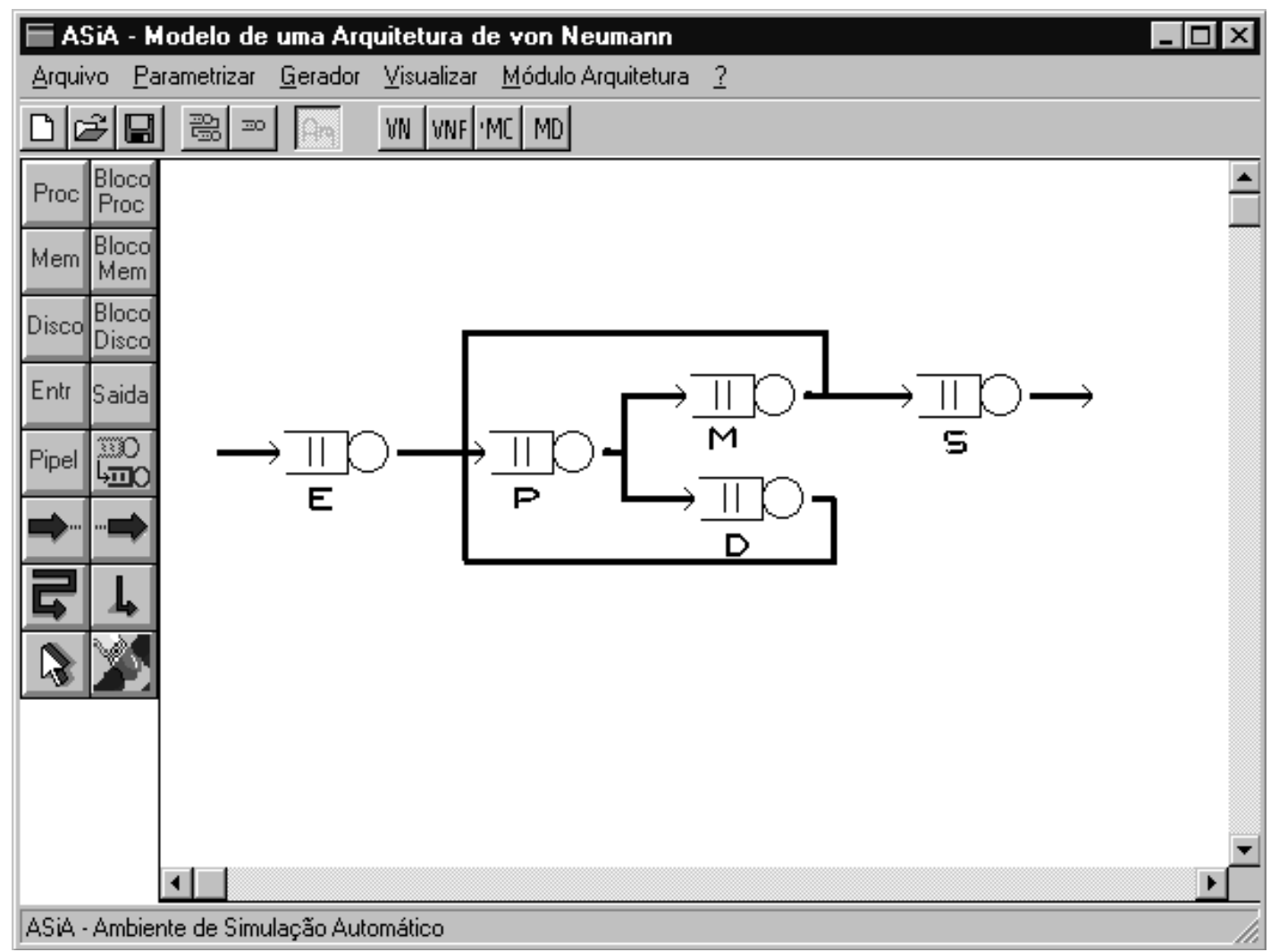

Figura 6.11. Tela principal do ASiA com o Módulo Arquitetura ativo

O código gerado para esse modelo (arquitetura de von Neumann), pode ser observado na Figura 6.12 e o relatório na Figura 6.13.

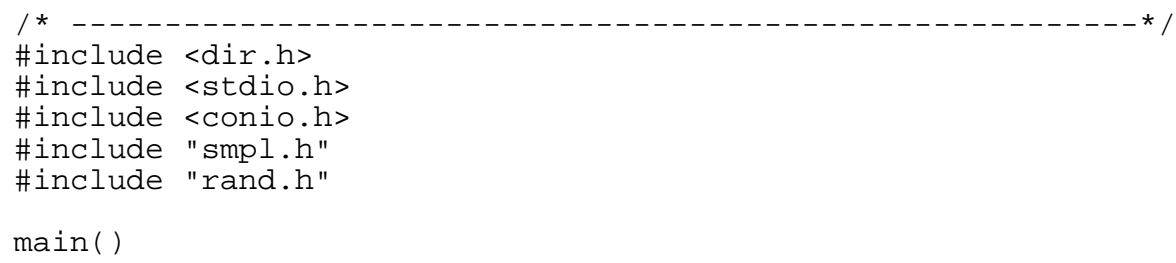




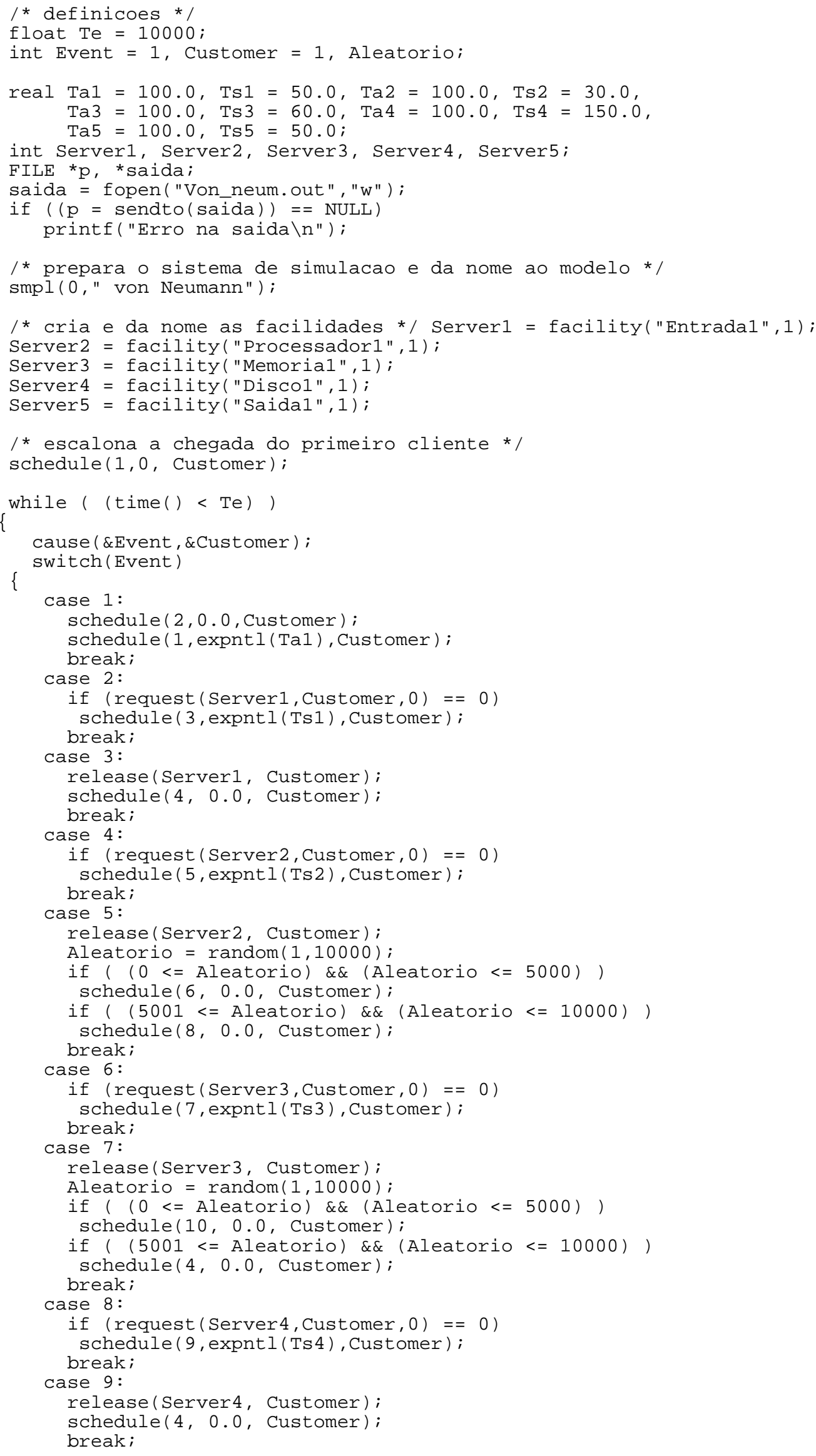




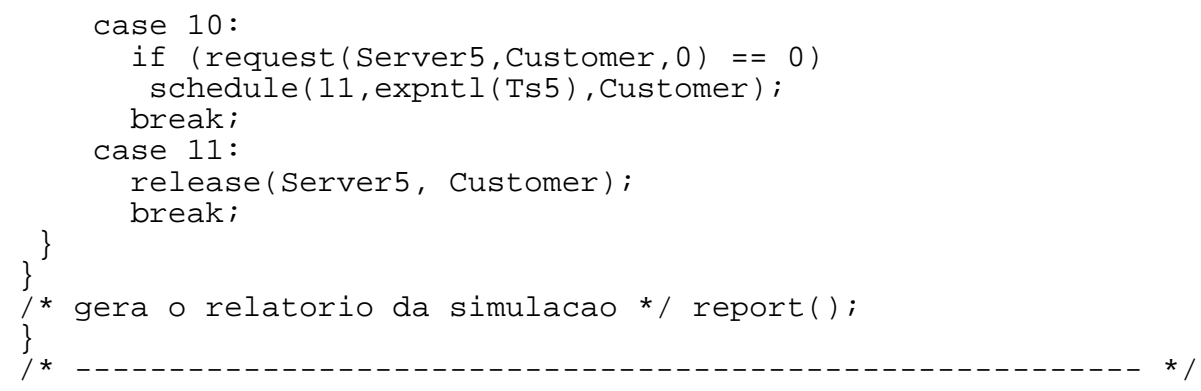

Figura 6.12. Código gerado a partir do modelo da arquitetura de von Neumann

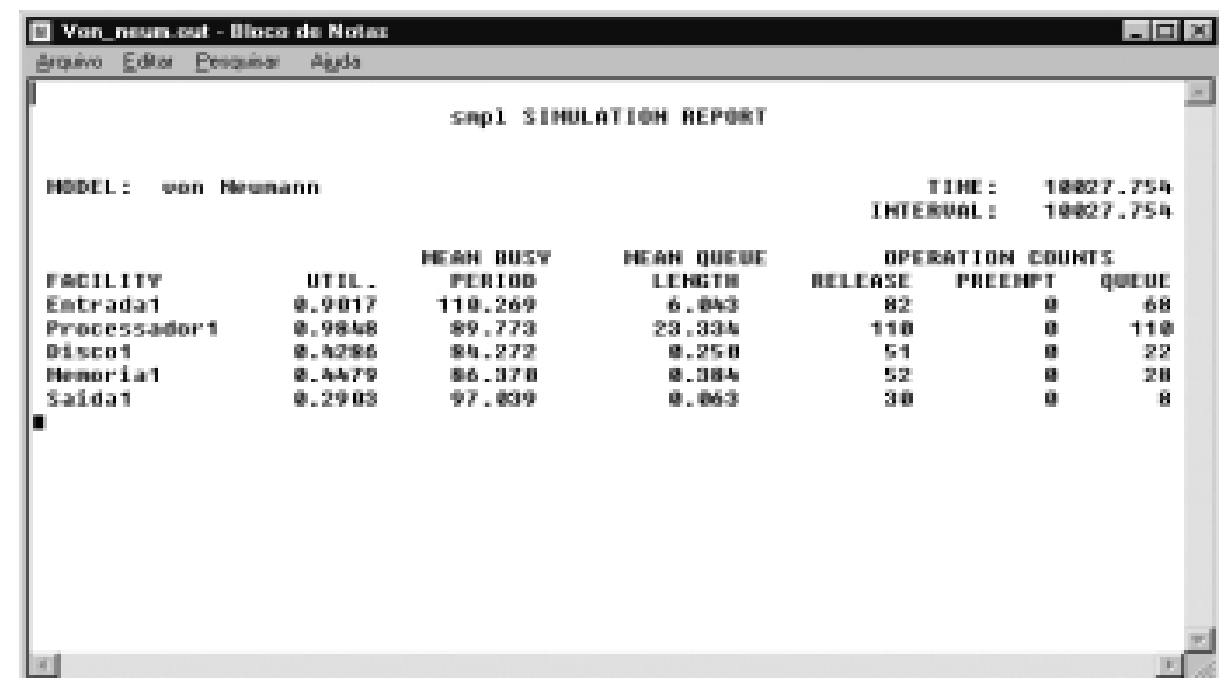

Figura 6.13. Relatório gerado a partir da simulação da arquitetura de von Neumann

\subsection{DEFININDO NOVAS ARQUITETURAS}

Para definir uma nova arquitetura o usuário deve selecionar a opção Outras arquiteturas na caixa de diálogo apresentada na Figura 6.3. Com isso, o usuário tem a sua disposição todo um ambiente para o desenvolvimento de um modelo de uma nova arquitetura, utilizando-se do elenco de recursos básicos disponíveis no Módulo Arquitetura.

Para especificar graficamente um modelo, o usuário utiliza-se da barra de ferramentas que possui as opções de recursos básicos como: processador, memória, disco, entrada e saída, além das opções de inserir um bloco de processador, memória ou disco ou um pipeline.

O objetivo da opção de inserir um bloco de processador, memória ou disco é facilitar a especificação gráfica pelo usuário. Em casos de arquiteturas que possuam mais de um processador ou mais de uma memória, o usuário não precisa inserir um de cada vez, inserindo um único bloco com o número de processadores ou memórias necessárias. Isso facilita também a ligação entre blocos ou então entre blocos e vários recursos. Se o usuário deseja ligar dois blocos com um número igual de componentes, é perguntado se esse deseja ligar um recurso de um bloco com um respectivo no outro bloco ou se deseja ligar todos os componentes de um bloco com todos os outros componentes do outro bloco (Figura 6.14). O resultado da primeira opção pode ser observado na Figura 6.15 e o da segunda opção na Figura 6.16. Pode-se observar que é 
inserido um recurso auxiliar entre os dois blocos quando é selecionada a segunda opção. Esse recurso auxiliar será parametrizado com distribuição exponencial de média 0.0 (ver Tabela 2), não provocando alterações no modelo.

O mesmo procedimento é válido para a inserção de uma ramificação. As opções de mover e apagar também são válidas para blocos, porém o usuário deve selecionar o primeiro elemento do bloco para realizar essas operações.

Realizada a especificação gráfica, o usuário deve selecionar a opção Tudo do menu Parametrizar para parametrizar automaticamente o modelo e os recursos. Essa parametrização percorre uma lista de recursos que contém o tipo de cada recurso (processador, memória, disco, entrada, saída ou auxiliar) e vai parametrizando com dados obtidos no arquivo dados.dat.

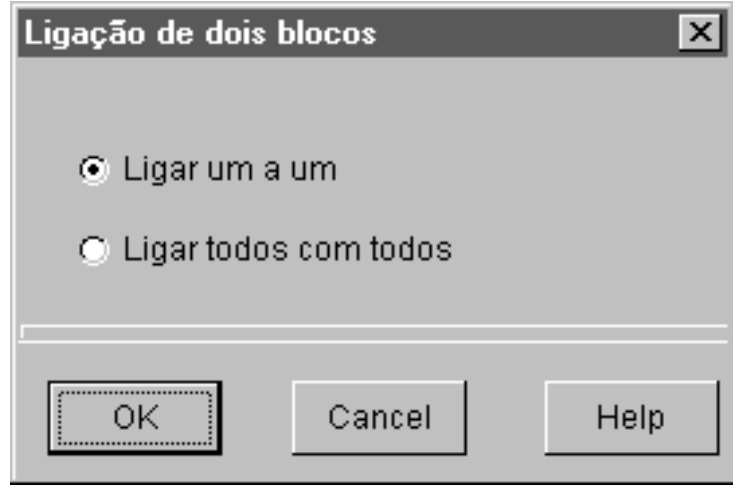

Figura 6.14. Tela para solicitar ao usuário modo de ligação de dois blocos

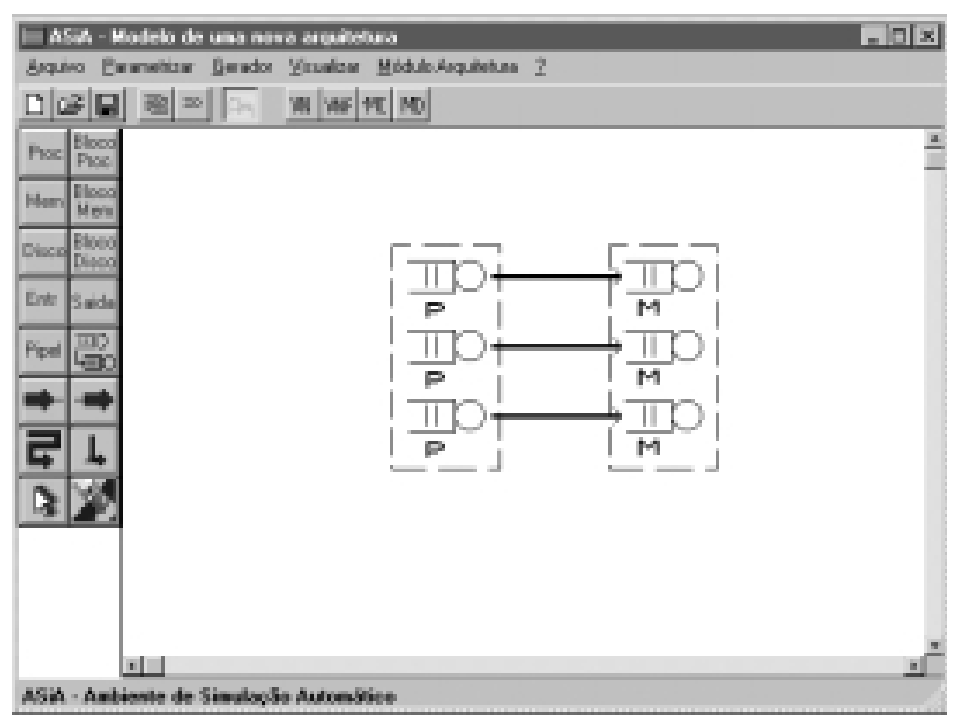

Figura 6.15. Resultado da seleção da opção "Ligar um a um" 


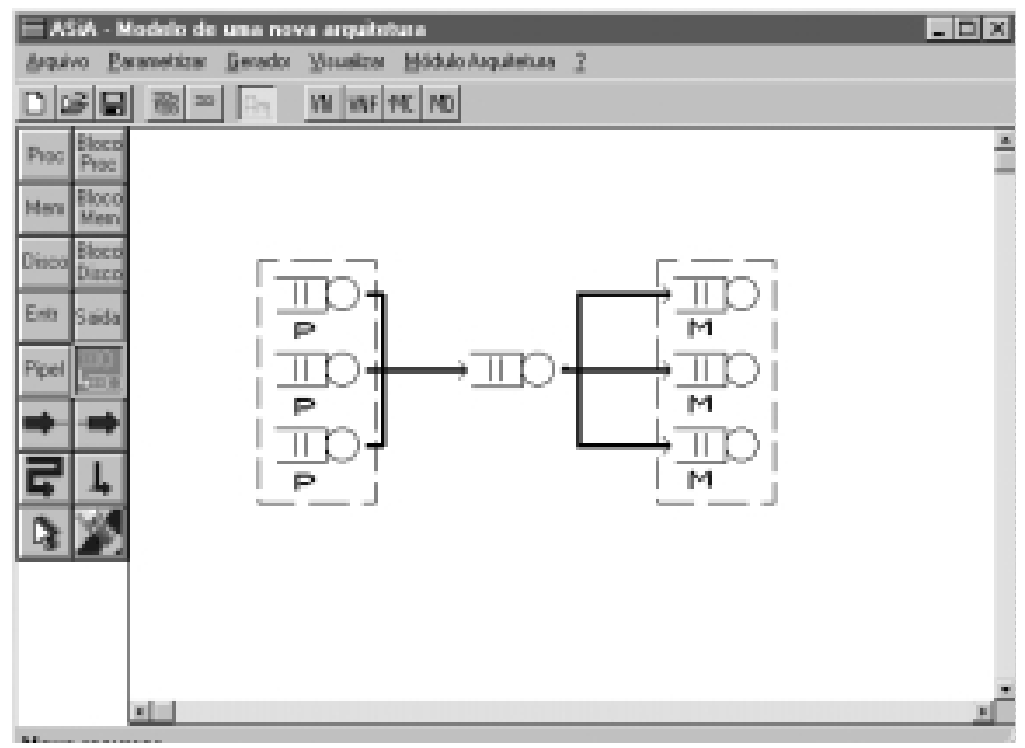

Figura 6.16. Resultado da seleção da opção "Ligar todos com todos"

Parametrizado os recursos, o usuário pode alterar qualquer parâmetro com um duplo pressionamento do mouse sobre o recurso ou selecionando o recurso e a opção Recurso do menu Parametrizar. Para alterar os parâmetros de um bloco que possui mais de 3 recursos (onde é mostrado ao usuário apenas o primeiro e o último), é solicitado ao usuário o número do recurso que será realizada a alteração.

\subsection{ESTUDO DE CASOS}

Será apresentado a seguir dois exemplos: uma alteração realizada no modelo da arquitetura de von Neumann e alterações nos parâmetros da arquitetura de von Neumann com pipeline.

\subsubsection{AlteraÇÃo no MOdelo da ARQuitetura de VON NEUMANN}

A alteração introduzida no modelo da arquitetura de von Neumann (Figura 6.17) consiste basicamente na inserção de mais um processador. Para tanto, necessita-se apagar o processador antigo e inserir um bloco de dois processadores. Ao apagar o processador, as ligações que chegavam e saiam dele também são apagadas. Devido às alterações, toda a parametrização é cancelada.

Ao refazer as ligações do bloco de processadores com os recursos memória e disco, e dos recursos memória e disco com o bloco de processadores, é inserido automaticamente dois recursos auxiliares, os quais evitam um "emaranhado" de ligações.

Com estas alterações, o objetivo foi atingido: acrescentar mais um processador no modelo da arquitetura de von Neumann. O usuário deve então, parametrizar automaticamente o modelo, salvá-lo com um outro nome, para que o modelo original seja mantido, gerar o novo código (visualizá-lo, se desejar) e visualizar o relatório gerado (Figura 6.18). 


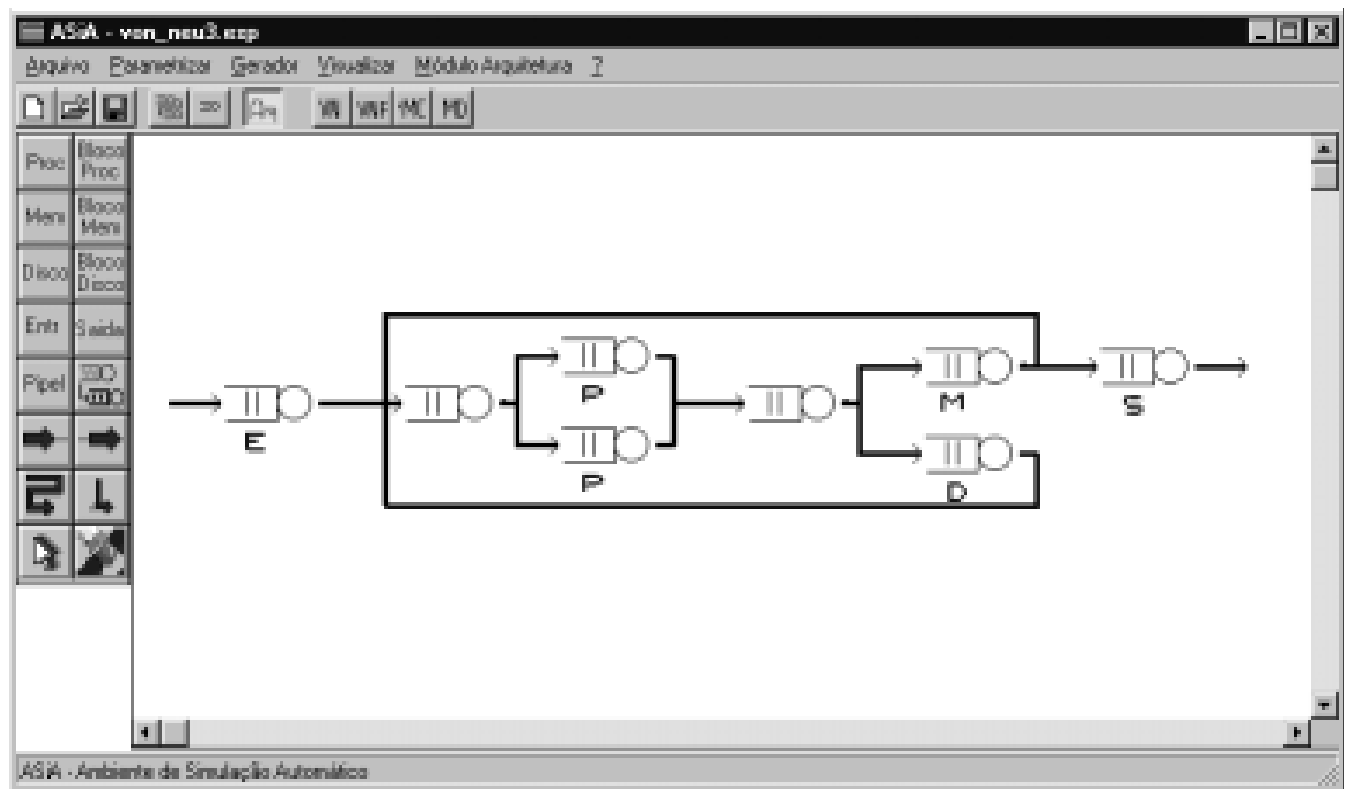

Figura 6.17. Alteração no modelo da arquitetura de von Neumann

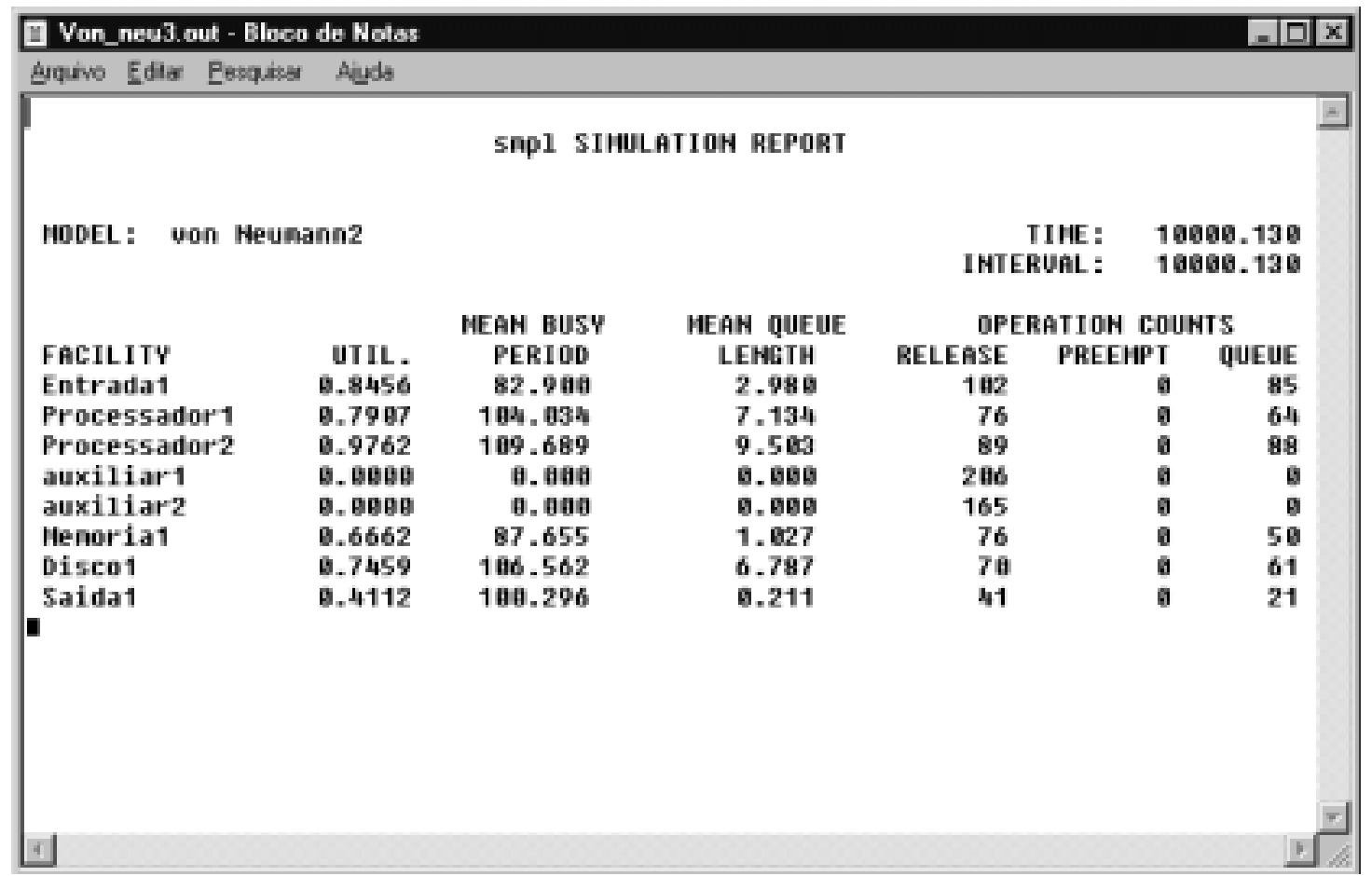

Figura 6.18. Relatório gerado com a alteração da arquitetura de von Neumann

Analisando os relatórios apresentados nas Figuras 6.18 e 6.13, o usuário percebe que, quando o modelo possuía apenas um processador, o tamanho médio da fila no processador era de 23.334. Com a inserção de mais um processador, o tamanho médio das filas nos processadores caiu para 7.135 e 9.503, o que implica em um processamento mais rápido dos dados. 


\subsubsection{ALTERAÇÃo NOS PARÂMETROS DA ARQUITETURA DE VON NEUMANN COM PIPELINE}

O modelo da arquitetura de von Neumann com pipeline pode ser observado na Figura 6.19. Como o pipeline possui cinco estágios, é mostrado ao usuário somente o primeiro e o último estágio, com o número 5 indicando que o pipeline possui cinco estágios.

O relatório que o sistema já tem elaborado para esse modelo pode ser observado na Figura 6.20. Observando o relatório, nota-se que o disco está com um tamanho médio de fila muito maior que os outros recursos, o que pode influir diretamente no desempenho geral da arquitetura. Esse tamanho deve-se principalmente ao valor do tempo médio de serviço do disco, que é de $15 \mathrm{~m}$ seg. Reduzindo-se o valor do tempo médio de serviço para $10 \mathrm{~m}$ seg., obtém-se o relatório observado na Figura 6.21.

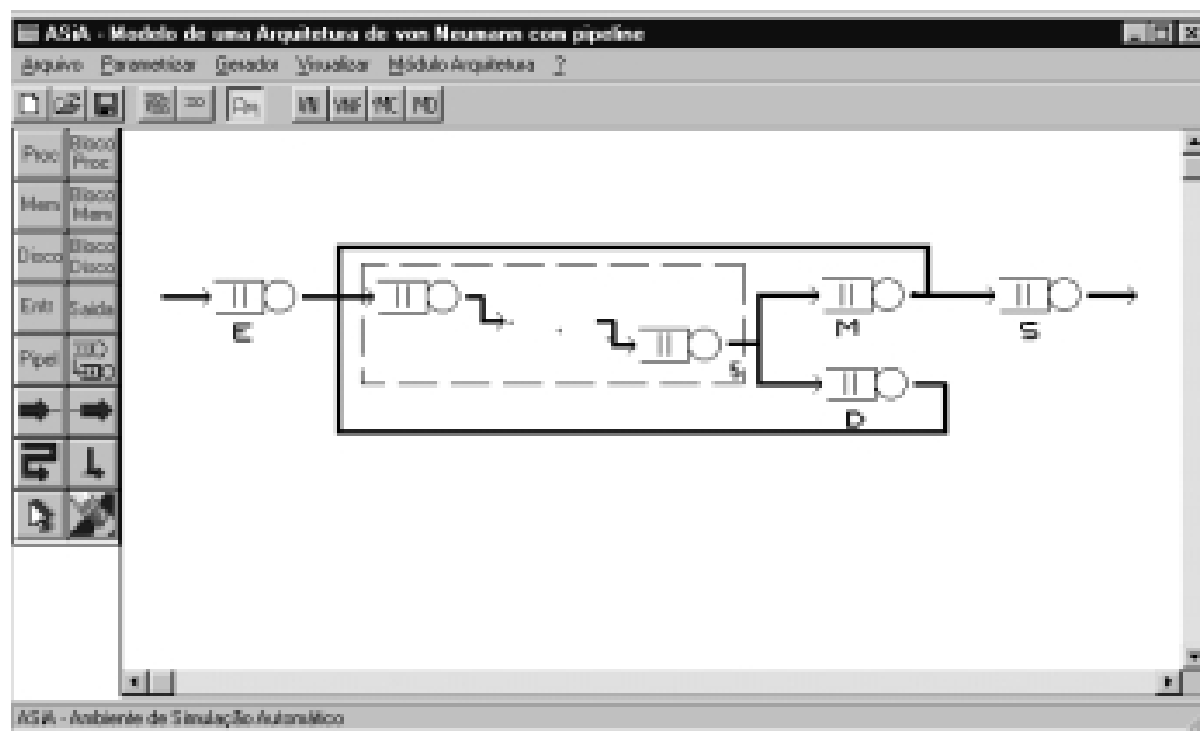

Figura 6.19. Modelo de uma arquitetura de von Neumann com pipeline de instrução

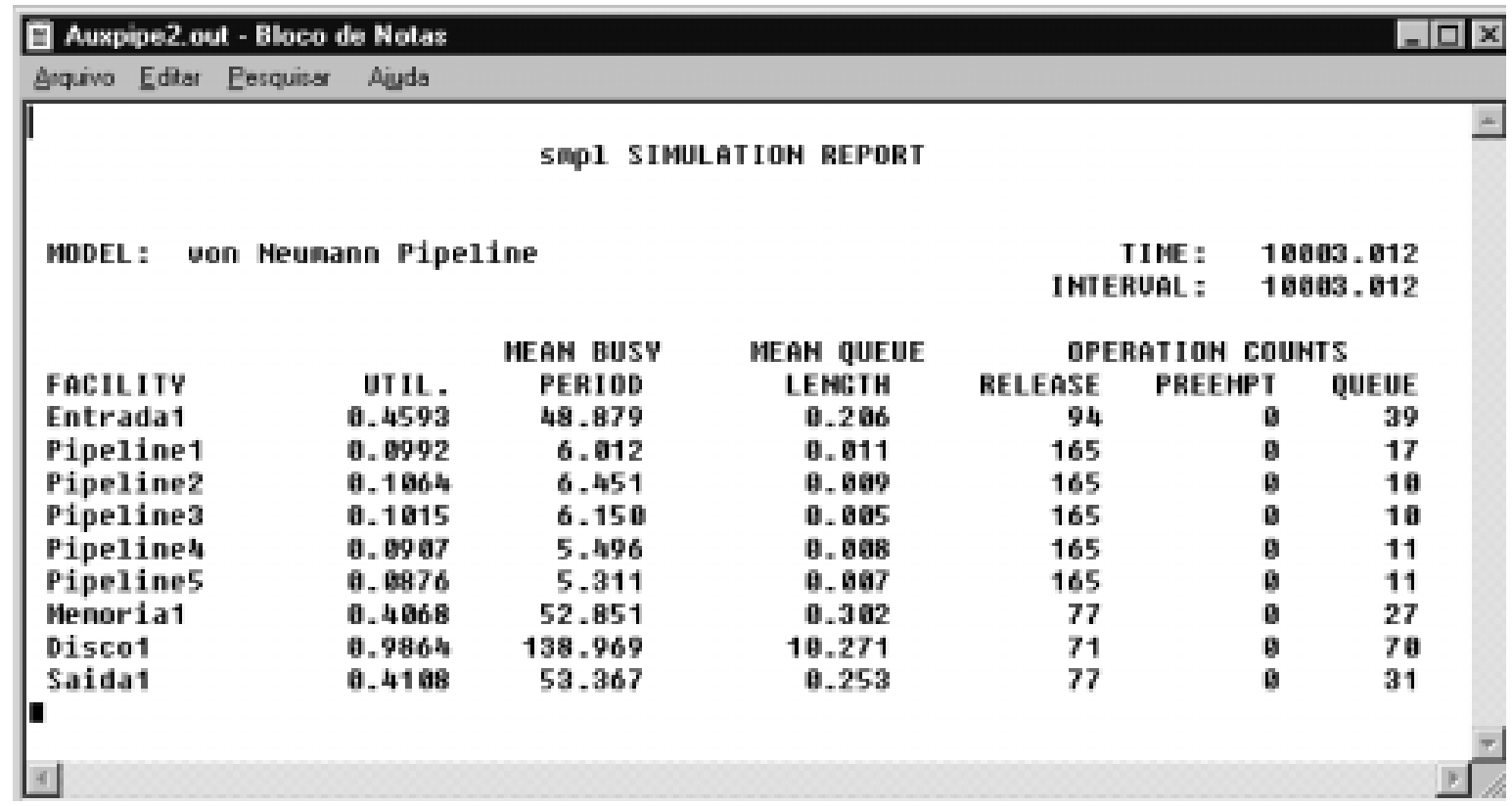

Figura 6.20. Relatório da arquitetura de von Neumann com pipeline 


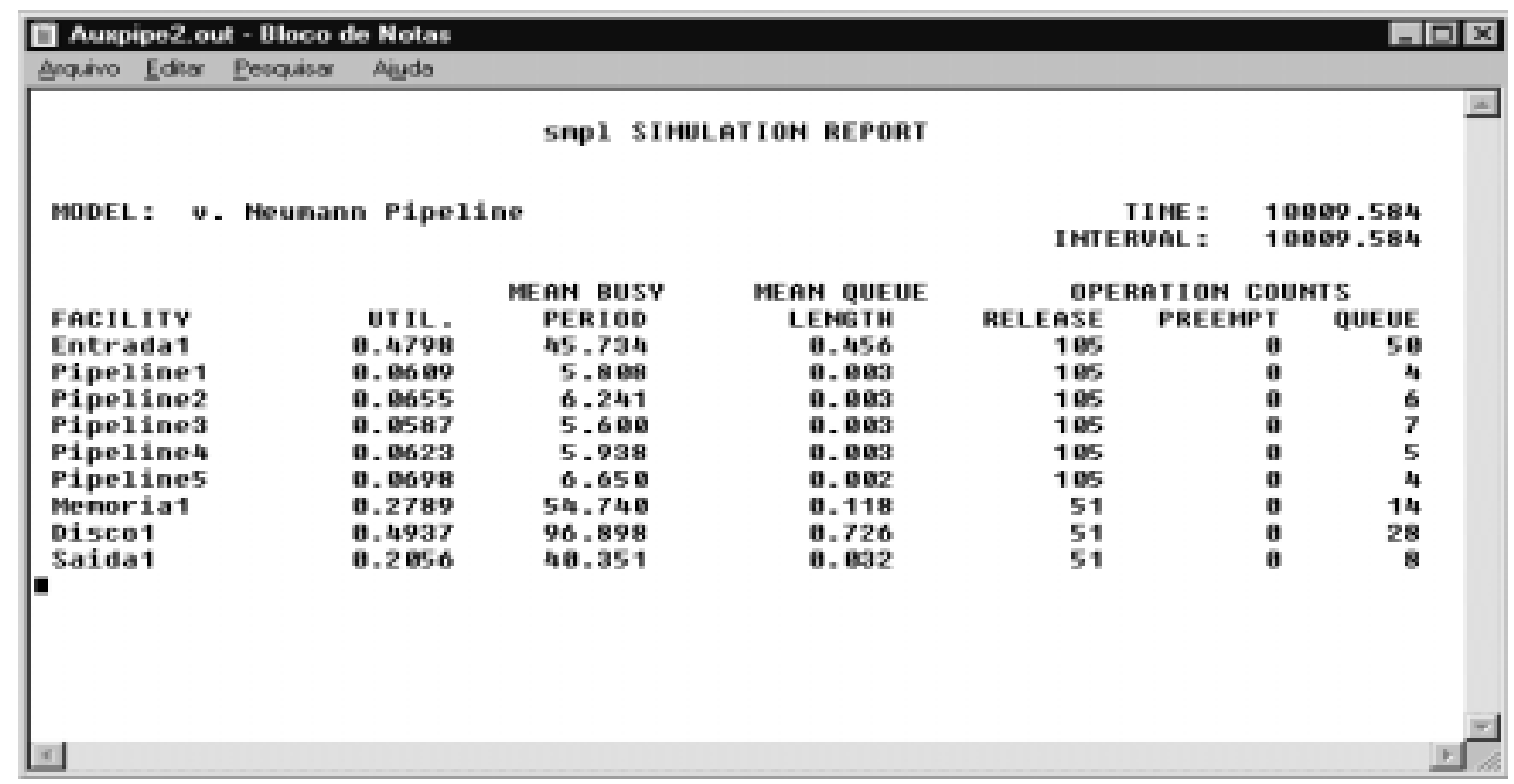

Figura 6.21. Relatório gerado com a alteração da arquitetura de von Neumann com pipeline

Estes dois exemplos ilustram como o usuário pode utilizar o sistema e também que, através da análise dos dados obtidos, pode-se chegar a conclusões importantes no estudo de arquiteturas de computadores.

\subsection{CONSIDERAÇÕES FINAIS}

O Módulo Arquitetura, desenvolvido neste trabalho de mestrado, é uma extensão ao ASiA que permite a simulação de arquiteturas de computadores, possibilitando ao usuário seguir três abordagens:

- utilização de uma arquitetura definida;

- utilização de uma arquitetura definida, alterando-se os parâmetros ou configuração do modelo;

- definição de uma nova arquitetura.

Qualquer que seja a abordagem escolhida, uma série de alterações são introduzidas no ASiA de modo a suportar a simulação de arquiteturas de computadores.

As arquiteturas já definidas no sistema são: arquitetura de von Neumann, arquitetura de von Neumann com pipeline, arquitetura MIMD com memória compartilhada e arquitetura MIMD com memória distribuída. 


\section{Conclusões}

\subsection{ANÁLISE DA BIBLIOGRAFIA}

As arquiteturas de computadores evoluíram muito desde a criação do primeiro computador. Desde o aparecimento dos primeiros computadores, a arquitetura de von Neumann vem sendo largamente utilizada. No entanto, a evolução desta arquitetura não proporcionou a solução das aplicações que necessitam um maior poder computacional a um custo razoável. Neste sentido, surgiram as arquiteturas que exploram um paralelismo em diferentes granulosidades e vem se tornaram a solução para estas aplicações [HWA84, NAV89, ALM94].

As arquiteturas paralelas também evoluíram o suficiente a ponto da classificação de arquiteturas mais conhecida e utilizada (Flynn [FLY72]) não conseguir englobar todas. Duncan [DUN90] propôs então uma classificação só para estas arquiteturas. Esta classificação é mais recente e consegue englobar todas as arquiteturas paralelas.

Com toda essa evolução é necessário alguma forma de avaliar o funcionamento e o desempenho tanto da arquitetura de von Neumann quanto das arquiteturas paralelas. Dentre as diversas técnicas disponíveis para a avaliação de desempenho de sistemas, a simulação, que é uma técnica de modelagem, se adapta muito bem a esta finalidade. Diversos autores destacam a crescente utilização da simulação em diversas áreas devido a sua flexibilidade e baixo custo [SAN90]. Como a simulação é uma técnica de modelagem, é necessário transformar o sistema em um modelo. Um modelo deve refletir com clareza as principais e mais relevantes características do sistema [SOA92, FER92].

A habilidade e a técnica necessária para o desenvolvimento de modelos e simulações somente será obtida com a construção de modelos e a execução de simulações. Um usuário pode aprender muito lendo livros ou conversando com outras pessoas, mas a prática é que trará conhecimento suficientes para decidir o que deve ser modelado ou não em um sistema e saber analisar corretamente os resultados da simulação.

Um projeto de simulação pode ser dividido em três fases: desenvolvimento, testes e análise. A fase de desenvolvimento engloba: descrição do sistema, abstração do sistema e descrição do modelo, coleta de dados, seleção do método de análise e desenvolvimento do programa de simulação; a fase de testes envolve: depuração do programa, verificação (programa x modelo) e validação (modelo x sistema); a fase de análise engloba: análise de saída e análise do problema [MAC87]. 
Uma simulação pode seguir um dos seguintes enfoques: atividade, evento ou processo, que dependerá de como o sistema foi visto pelo modelador. A simulação orientada a evento apresenta uma maior facilidade de implementação mas não oferece um relacionamento claro entre o sistema e o programa de simulação, sendo mais viável para sistemas de pequeno e médio porte. Por outro lado, a simulação orientada a processo possui um claro relacionamento entre o modelo e o programa, sendo mais viável para sistemas de maior porte. Os processos devem ser disparados paralelamente, o que torna o programa mais complexo [SOA92].

Com o crescente uso da simulação foi necessário o desenvolvimento de linguagens ou adaptações de linguagens (através de extensões funcionais) para facilitar a programação. Estas linguagens ou extensões fornecem ao usuário mecanismos para coleta de estatísticas e geração de relatórios além de facilidades para manipulação de estruturas de dados, abstração de dados, etc. Além das linguagens, o usuário pode optar pelo uso de um pacote de simulação específico. Neste caso, porém, o usuário perde a flexibilidade pois não pode utilizar para outros fins senão para aquele em que o pacote foi adquirido [MAC87, SOA92].

Levando-se em consideração que um grande número de usuário inexperientes está surgindo, isto devido principalmente ao barateamento dos computadores, surgiu a necessidade de fornecer a estes ferramentas que facilitem a utilização de simulações.

Os ambientes de simulação automáticos fornecem a geração do programa de simulação através de especificações textuais ou gráficas. Quando a especificação é gráfica utiliza-se a programação visual, a qual vem sendo amplamente explorada. Este tipo de programação interage com o usuário através de ferramentas gráficas tais como editores gráficos e visualizadores. No caso dos ambientes de simulação automáticos, o usuário fornece graficamente o modelo e um gerador de aplicações gera o programa de simulação. O programa é compilado e executado no mesmo ambiente e os resultados são também fornecidos graficamente, o que facilita a análise do sistema. Uma análise estatística dos resultados da simulação podem também ser efetuados por estes ambientes [SPO94, SPO94a].

A revisão bibliográfica revelou a existência de um número considerável de ferramentas para simulação [RAC90, OZD91, FUN91, SWA95]. Swain, em [SWA95] discute 54 sistemas de simulação, com custos variando de dezenas a milhares de dólares. A grande maioria desses sistemas são dedicados a uma aplicação bem definida não apresentando a flexibilidade desejada. Por exemplo, TUTSIM (modelagem de sistemas não lineares), RISK (análise RISK), Best Network (simulação de redes de computadores), FACTOR/AIM (análise de custo), etc. Alguns dos sistemas revisados oferecem apenas uma linguagem para simulação de sistemas de propósitos gerais, como é o caso do GPSS/PC e SIMNET II.

Para facilitar o desenvolvimento de simulações, o grupo de Sistemas Distribuídos e Programação Concorrente do ICMSC - USP vem desenvolvendo um ambiente para simulação automático (ASiA). O objetivo do ASiA é facilitar a implementação de uma simulação através da definição do modelo utilizando uma interface gráfica e da utilização de um gerador de aplicações que gera o programa de simulação. 


\subsection{CONCLUSÕES FINAIS}

O ASiA, em especial, vem se revelando uma ferramenta de grande potencial que pode ser utilizada extensivamente como apoio ao ensino e, ao mesmo tempo, como ferramenta fundamental para a análise de desempenho de sistemas computacionais reais. A concepção modular do ASiA torna bastante fácil a inclusão de novos módulos voltados para aplicações específicas, facilitando a sua expansão para cobrir novos tópicos, o que permitirá a sua utilização tanto em diversas disciplinas do Bacharelado em Ciências de Computação, como para o desenvolvimento de pesquisas que utilizam simulações. Dessa forma, pode-se ter em um único ambiente, ferramentas básicas para simulação de sistemas de diversas áreas, como por exemplo arquiteturas de computadores (considerado nesta dissertação), redes de computadores [OGA97a], etc.

As alterações efetuadas no ASiA para obter-se um ambiente mais adequado para a inclusão de novos módulos, tornou o ASiA um sistema amigável e disponibilizou para o usuário um grande número de ferramentas. Algumas das melhorias incluídas no ASiA são:

- possibilidade do usuário visualizar o código gerado e o relatório dentro do mesmo ambiente;

- alterações nas caixas de diálogo de modo a não permitir que o usuário forneça dados desnecessários;

- inclusão de uma barra de acesso rápido;

- inclusão de um ícone que permite mover recursos;

- alterações no menu que tornaram transparente para o usuário todas as operações com relação aos arquivos gerados pelo sistema.

O Módulo Arquitetura, desenvolvido neste trabalho, disponibiliza para o usuário uma série de ferramentas que auxiliam na simulação de arquiteturas de computadores. Através do Módulo Arquitetura pode-se definir diversas arquiteturas e simulá-las, sem que para isso o usuário necessite ter profundos conhecimentos de simulação, de análise estatística, modelos utilizando redes de filas, etc. A definição das arquiteturas é feita através de blocos básicos que representam os elementos de uma arquitetura: processador, memória, disco e dispositivos de entrada/saída.

Quatro arquiteturas básicas já estão definidas no Módulo Arquitetura: arquitetura de von Neumann, arquitetura de von Neumann com pipeline, arquitetura MIMD com memória compartilhada e arquitetura MIMD com memória distribuída. A partir destas arquiteturas básicas o usuário pode avaliar diferentes modelos, bastando para tanto alterar parâmetros ou a especificação gráfica. Através da execução dos novos modelos pode-se avaliar a influência das características consideradas.

Alguns exemplos foram abordados nesta dissertação para exemplificar a utilização do Módulo Arquitetura para simulação de arquiteturas de computadores. No primeiro exemplo, a influência da existência de dois processadores em uma arquitetura de von Neumann é analisada. 
Através desse exemplo, observa-se que quando o modelo possuía apenas um processador, o tamanho médio da fila era de 23,334. Com a inserção de mais um processador, o tamanho médio das filas caiu para 7,135 e 9,503. Pode-se observar ainda que, como o processamento é mais rápido, a fila no disco torna-se maior.

No segundo exemplo, em uma arquitetura de von Neumann com pipeline foi alterado o tempo de acesso ao disco. Analisando-se os resultados obtidos verifica-se que quando o tempo de acesso ao disco passa de $15 \mathrm{~m}$ seg. para $10 \mathrm{~m}$ seg., o tamanho médio da fila passa de 10,271 para 0,726 .

Estes exemplos ilustram como o usuário pode utilizar o Módulo Arquitetura e também que através da análise dos dados obtidos, pode chegar a conclusões importantes no estudo de arquiteturas de computadores.

A adoção de simulação como uma ferramenta de apoio ao ensino tem se mostrado um eficiente instrumento para o aprendizado, uma vez que através de simulações podem-se explorar mais rapidamente situações bastante diversificadas. Isto traz a oportunidade do estudante ser submetido a uma bateria de exemplos e situações (algumas geradas através da simples modificação de parâmetros do sistema em estudo) que dificilmente seriam viáveis através de outras técnicas.

Particularmente para o caso de arquitetura de computadores, a simulação permite uma experimentação com um número elevado de arquiteturas, o que certamente não é possível sem um instrumental apropriado. A experimentação prática com arquiteturas reais (isto é, utilizandose um processador de fato) não fica descartada, mas o uso de simulação tem-se mostrado muito mais atrativo e eficiente.

\subsection{CONTRIBUIÇÕES}

As principais contribuições deste trabalho são:

- Preparação do ambiente (ASiA) para a inserção da extensão para simulação de arquiteturas de computadores e de futuras extensões. Nesta preparação inclui-se a integração de dois módulos do ASiA (Editor Gráfico e Gerador de Aplicações), migração do código para 32 bits, utilizando o compilador Borland C++ 5.01 e o ambiente Windows95, alteração de menus, caixas de diálogo e modo de parametrização e possibilidade de visualização do código gerado e do relatório;

- Implementação da extensão para simulação de arquiteturas de computadores, sendo que o usuário pode seguir três abordagens: utilização de uma arquitetura já definida, utilização de uma arquitetura já definida, alterando os parâmetros ou desenvolvimento de um modelo de uma nova arquitetura. As arquiteturas já definidas são: arquitetura de von Neumann, arquitetura de von Neumann com pipeline, arquitetura MIMD com memória compartilhada e arquitetura MIMD com memória distribuída;

- Ferramenta para auxiliar o aprendizado de arquiteturas de computadores. 


\subsection{TRABALHOS FUTUROS}

Como sugestões a trabalhos futuros, os seguintes pontos podem ser abordados:

- Inserção de uma extensão para simulação de redes de computadores (trabalho de mestrado em desenvolvimento);

- Inserir uma verificação mais rigorosa na especificação gráfica das arquiteturas, como por exemplo, não permitir a ligação entre um recurso entrada com um saída;

- Inserção de posse simultânea dos recursos. A posse simultânea ocorre quando um cliente requer um serviço, além de um outro serviço adicional. Porém, quando se representa um modelo através de redes de filas convencionais, essa posse simultânea de recursos não pode ser especificada. Uma possível representação é utilizar os símbolos da ferramenta RESQ (RESearch Queueing Package) empregada na modelagem e simulação discreta orientada a processos, denominada Estrutura de Redes de Filas Estendidas [SOA92];

- Incluir mais recursos básicos para a definição de um modelo de uma arquitetura, tais como barramento, unidades funcionais, etc;

- Incluir prioridades e preempção na parametrização dos recursos;

- Definir opções para os dispositivos de E/S, tais como: monitor, teclado, fita, floppy disk, etc.

- Manutenção da parametrização em casos de alteração da especificação gráfica;

- Permitir que o próprio usuário defina novos recursos básicos. 
[ALM94] ALMASI, G. S., GOTTLIEB, A., Highly Parallel Computing, 2a ed., The Benjamin Cummings, 1994.

[BAN96] BANKS, J. “Output Analysis Capabilities of Simulation Software”, Simulation, pp. 23-30, Janeiro, 1996.

[BAS93] BASSI, S., "Entre na pista com o número 1 em velocidade", Exame Informática, pp. 66-67, Agosto, 1993.

[BOR96] BORLAND C++ 5.01, Help on line, 1996.

[CCT94] Center for Computing Technologies (CCT), "ASSERTS - A Software Simulation Environment for Real Time Systems", State University of New York at Binghamton, Página HTML: http://watson2.cs.binghamton.edu/cctwww/ projects/asserts.html.

[DAV89] DAVIES, R., O'KEEF, R., Simulation Modeling with-Pascal, Prentice Hall International Ltda, London, 1989.

[DUN90] DUNCAN, R., “A survey of parallel computer architectures”, IEEE Computer, pp. 516, Fevereiro, 1990.

[EDW92] EDWARDS, G., SANKAR, R., "Modeling and simulation of networks using CSIM", Simulation, v. 58, n. 2, pp. 131-136, Fevereiro, 1992.

[FEI93] FEIBUS, M.; STALER, M., "Pentium Power", PC Magazine, pp. 108-144, Abril, 1993.

[FER92] FERNANDES, M.M., "Modelagem Analítica de desempenho de sistemas microprocessadores: aplicação ao multiprocessador CPER”, Dissertação de Mestrado, UFSCar, Dezembro, 1992.

[FIS95] FISHWICK, P., Simulation Model Design \& Execution: Building Digital Worlds, Prentice Hall International Ltda, 1995.

[FLY72] FLYNN, M. J., "Some computer organizations and their effectiveness", IEEE Transactions on Computers, vol. C-21, pp. 948-960, 1972.

[FUN91] FUNKA-LEA, C. A., et al., Interactive Visual Modeling for Performance, IEEE Software, v. 8, n. 5, pp. 58-68, Setembro, 1991.

[HEN90] HENNESSY, J.L., PATTERSON, D., Computer Architecture: A Quantitative Approach, Morgan Kaufmann Publishers Inc., 1990.

[HWA84] HWANG, K., Briggs, F. A., Computer Architecture and Parallel Processing, McGraw-Hill, 1984. 
[INT97] INTEL Corp. Página HTML: http://www.intel.com/portugues/intel/product/index.htm Setembro, 1997.

[KEL94] KELLER, R. M., "A Brief Introduction to SIGMA: An Intelligent Visual Programming Environment for Scientific Modeling", Página HTML: http://icwww.arc.nasa.gov/ic/projects/sigmai.

[KIR91] KIRNER, C., "Arquiteturas de sistemas avançados de computação", Anais da Jornada EPUSP/IEEE em Sistemas de Computação de Alto Desempenho, pp. 307-353, 1991.

[KOB78] KOBAYASHI, H., Modeling and Analysis - An Introduction to System Performance Evaluation, Addison-Wesley Publishing Company, 1978.

[MAC75] MACDOUGALL, M.H., "System Level Simulation em Digital System Design Automation: Languages, Simulation \& Data Base”, Cap 1, Computer Science Press Inc., $1-115,1975$.

[MAC87] MACDOUGALL, M.H., Simulating Computer Systems Techniques and Tools, The MIT Press, 1987.

[MAC92] MACHADO, F. B., MAIA, L. P., Introdução à Arquitetura de Sistemas Operacionais. Ed. LTC, Rio de Janeiro, 1992.

[MAR80] MARYANSKY, F.J., Digital Computer Simulation. Haydess Book Company Inc, 1980.

[MEL85] MELAMED, B.; MORRIS, R. J. T., "Visual Simulation: The Performance Analysis Workstation”, IEEE Computer, v. 18(8), pp. 87-94, Agosto, 1985.

[MEU92] MEURANT, G., "Os Computadores Paralelos e o Futuro da Computação Científica", I Escola de Computação Científica de Alto Desempenho, LNCC, Agosto, 1992.

[MOR95] MORSELLI, J.C.M.J., "Simulação Distribuída em uma rede de transputter utilizando o método CMB”, Dissertação de Mestrado, ICMSC - USP, Dezembro, 1995.

[NAI95] NAIK, V. K., "Performance of NAS Parallel Benchmark LU on IBM SP Systems", IBM Research Report, RC 20046, 1995.

[NAV89] NAVAUX, P. O. A., "Introdução ao processamento paralelo", RBC- Revista Brasileira de Computação, vol. 5, n. 2, pp. 31-43, 1989.

[OGA96] OGAWA, C. L., Aprimoramento e expansão do Ambiente de Simulação Automático, ASiA, Relatório FAPESP, Setembro, 1996

[OGA97] OGAWA, C. L., Aprimoramento e expansão do Ambiente de Simulação Automático, ASiA, Relatório FAPESP, Março, 1997 
[OGA97a] OGAWA, C. L., Extensão do Ambiente de Simulação Automático (ASiA) para simulação de redes de computadores, Plano de Pesquisa de Mestrado, ICMSC-USP, 1997.

[OLI96] OLIVEIRA, L. L., Um Módulo de Análise de Resultados para o ASiA, Minidissertação (Qualificação), ICMSC - USP, Maio, 1996.

[OZD91] OZDEN, M. H., "Graphical programming of simulation models in an object-oriented environment”, Simulation, pp. 104-116, Fevereiro, 1991.

[PED96] PEDROSO, W. Jr., Módulo Visual: Uma Interface Gráfica para o Ambiente de Simulação Automático (ASiA), Dissertação de Mestrado, ICMSC-USP, Abril, 1996

[PEG91] PEGDEN, C.D. et al, Introduction to Simulation using SIMAN, MacGraw-Hill International Editions, 1991.

[PET96] PETZOLD, C., Programming Windows95: The Definitive Developer's Guide to the Windows95 API, Microsoft Press, 1996.

[PRI96] PRIOLI, M. C., Integração dos Módulos e Expansão do Gerador de Aplicações do Ambiente de Simulação Automático ASiA, Relatório FAPESP, Setembro, 1996.

[QUI87] QUINN, M.J., Designing Efficient Algorithms for Parallel Computers, McGraw Hill, 1987.

[RAC90] RACZYNSKI, S., Graphical Description and a Program Generator for Queuing Models, Simulation, v. 55, n. 3. Pp 147-152, Setembro, 1990.

[RAN94] RANGEL, R., "Uma pequena história dos processadores”, BYTE, pp. 78-82, Maio, 1994.

[ROB83] ROBERTS, N.; ANDERSEN, D.F.; DEAL, R.M.; GARET, M.S.; SHAFFER, W.A., Introduction to Computer Simulation: The System Dynamics Approach, Addison-Wesley Publishing Company, 1983.

[SAN90] SANTANA, M.J., "An Advanced Filestore Architecture for a Multiple Lan Distributed Computing System”, PHD Thesis, University of Southampton, Janeiro, 1990.

[SAN90a] SANTANA, R.H.C., "Performance Evaluation of Lan-Based File Severs", PHD Thesis, University of Southampton, Janeiro, 1990.

[SAN94] SANTANA, R.H.C., SANTANA, M. J., ORLANDI, R.C.G.S., SPOLON, R. CALÔNEGO, N., "Técnicas para avaliação de desempenho de sistemas computacionais”, Notas Didáticas, São Carlos, ICMSC-USP, 1994.

[SAN96] SANTANA, R. H. C. “Ambiente de Simulação Automático para modelamento e análise de Sistemas Distribuídos", Relatório Parcial do Projeto de Pesquisa CNPq, Fevereiro, 1996. 
[SAR84] SARGENT, R.G., "A Tutorial on Verification and Validation of Simulation Models”, Procedings of the 1984 Winter Simulation Conference, pp. 115-121, 1984.

[SAY85] SAYDAM, T. "Process Oriented Languages", Simuleter, vol 16(2), Abril, 1985.

[SHA88] SHARMA, R. and ROSE, L.I., "Modular Design for Simulation”, Sofware Practice and Expeience, vol 18(10), 1988.

[SHA92] SHANMUGAN, K.S.; FROST, U.S.; LARUE, W.A., "A Block-Oriented Network Simulator", Simulation, v.58(2), p.83-94, Fevereiro, 1992.

[SOA92] SOARES, L.F.G. Modelagem e Simulação Discreta de Sistemas, Editora Campus Ltda, 1992.

[SOU92] SOUZA, R.C.G. "Desenvolvimento de uma extensão funcional em C para a construção de um ambiente de simulação orientado a processo", Relatório de Iniciação Científica, ICMSC-USP, 1992.

[SPO92] SPOLON, R. "Extensão Funcional de Módula-2 para Simulação de Sistemas Discretos”, Relatório de Iniciação Científica, ICMSC-USP, 1992.

[SPO94] SPOLON, R. "Um editor grático para um ambiente de simulação automático", Dissertação de Mestrado, ICMSC-USP, Agosto, 1994.

[SPO94a] SPOLON, R. "Um gerador de aplicação para um Ambiente de Simulação Automático”, Dissertação de Mestrado, ICMSC-USP, Agosto, 1994.

[SPO94b] SPOLON, Roberta; SPOLON, Renata; SANTANA, M.J.; SANTANA, R.H.C.; "Desenvolvimento de um gerador de aplicação para simulação de sistemas discretos", Notas do ICMSC-USP, Julho, 1994.

[SWA95] SWAIN, J.J., "Simulation on Survey: Tools for process understanding and improvement”, OR/MS Today, Agosto, 1995.

[SYS95] SYSTEM MODELING CORPORATION, ARENA Help on line, 1995.

[TAN84] TANENBAUM, A.S., Structured Computer Organization, Prentice-Hall Inc, 1984.

[TAN94] TANIR, O.; SEVINC, S., "Defining Requirements for a Standard Simulation Environment”, IEEE Computer, pp 28-34, Fevereiro, 1984.

[THO93] THOMPSON, T., "POWERPC Performs for Less”, BYTE, pp. 56-74, Agosto, 1993.

[THO94] THOMPSON, T., "POWERPC to the Desktop”, BYTE, pp. 44-72, Abril, 1994.

[TUR93] TURCOTTE, L.H., A survey of software environments for exploiting networked computing resources, Engineering Research Center for Computational Field Simulation, Mississippi State, 1993.

[WEI90] WEICKER, R. P., “An Overview of Common Benchmarks”, IEEE Computer, pp. 6575, Dezembro, 1990. 
